Las especies de Hypericum con hojas menudas, densas o imbricadas o aciculares constituyen los más importantes frútices de los auténticos páramos, destacando sus brillantes flores amarillas. En ciertos lugares de humedad adecuada los Hypericum (o chites) son abundantes dominando el estrato ya solos ya en combinación con los frailejones, relegando el graminetum (o pajonal) a escasa participación. Una de las especies de chite más difundidas es Hypericum laricifolium que se encuentra en los páramos desde Venezuela hasta el Perú y en Colombia caracteriza asociaciones (p. ej. Espeletietum hartwegianae hypericetosum Observ. pág. 110).

Otros géneros muy representativos de los fruticetos de páramo son Vaccinium, Gaultheria, Pernettya y varios de Compuestas. La cantidad de arbustitos en el páramo disminuye con la altitud llegando un punto (unos 4500 m.) en que desaparecen completamente. De mi experiencia los arbustitos que suben a máxima altitud son los del género Loricaria, compuestas con las hojas dispuestas en forma semejante a las Thuja (véase Cuatr. 1954 págs. 150-152). Los arbustitos de páramo tienen hojas coriá ceas rígidas y pequeñas, predominando las de tipo leptofilo y nanofilo, siendo escasas las microfilas.

Importantes plantas de los páramos son también numerosas fanerógamas de aspecto herbáceo, pero que son criptofrútices, de Bomarea, Bartsia, Gentiana, Halenia, Geranium, Lupinus, Draba, Lucilia, Lysipomia, Erigeron, Aster, Senecio, Werneria, Castilleja, Ranunculus, Sisyrinchium, las pteridófitas Lycopodium y Jamesonia, etc. etc. Las matas de Lupinus alopecuroides son espectaculares por sus inflorescencias lanosas, columnares, de $1 \mathrm{~m}$. de altura. Las diminutas rosetas de Plantago rigida forman densas y duras almohadillas. Distichia tolimensis es una peculiarísima juncácea que forma alfombras compactas, muy duras, de un espesor de 15 a $20 \mathrm{cms}$. sobre suelos muy húmedos, anegados o en la misma superficie de pantanos formando una estera flotante sobre la cual se puede caminar sin peligro de romperse ni de hundirse. Estas alfombras de Distichia están formadas por las ramas dicótomas de la planta cubiertas de hojas dísticas y aplanadas lateralmente, todas dispuestas paralelamente y densísimamente apretadas unas con otras. Las ramas de Distichia crecen constantemente por el ápice y mueren en su base cayendo las partes muertas al fondo del pantano donde se desintegran y forman turba; presentan un proceso biológico igual a la de los Sphagnum. Otras plantas que forman almohadillas son especies de Azorella y de Paepalanthus. También los Sphagnum forman comunidades entremezcladas con las otras en los páramos, contribuyendo a sus turberas. La flora de los páramos es sumamente rica y hace falta mucho estudio para conocerla totalmente, no obstante existe ya bastante literatura sobre la misma y se puede decir que se sabe más de ella que de las selvas climácicas. Por ello no me extiendo más sobre este tema. Quiero indicar no obstante que es en el páramo en donde hallamos grupos procedentes de migraciones boreales o australes, como p. e. las especies de Gentiana, Draba, Cerastium, Erigeron, Ranunculus, Plantago, Lupinus. Pero esto no quita que, como se dijo, la flora básica de todos los Andes es de origen americano habiéndose diferenciado las estirpes de abajo hacia arriba. Incluso la típica caulirró. sula de las Espeletias paramunas tiene sus ancestrales en las formas arbóreas ramosas que se hallan en el bosque andino. Planchas XIV-XXII.

\section{EL SUPERPARAMO}

Más arriba de $4500 \mathrm{~m}$. alt. cesan absolutamente las Espeletia y empieza una estrecha zona que llega hasta el nivel de la nieve, en donde la vegetación es dispersa y disociada, en un suelo pobre sobre cascos, arenas y grava. Esta vegetación cuya flora es distinta de la del páramo propiamente dicho y cuya "sociabilidad" es también diversa, forma otro subpiso llamado "superpáramo"; corresponde a la "Tierra gélida" de Pittier (1. s. 22). Según mis observaciones el superpáramo está probablemente sometido a diarias nevadas nocturnas excepto en estaciones secas. Hace años describí este tipo de vegetación a base de una sinecia estudiada en el Tolima con el título de consocietas de Culcitium. (Cuatr. Observ.: 119, cuadro 26).

Las especies más características de esta comunidad son los de la sección Culcitium del género Senecio, cubiertos de densa capa de lana blanca, como el Senecio canescens, $S$. cocuyanus y $S$. santanderensis. Otras especies características son las plantas de arenal y cascajar como Cerastium caespitosum, C. floccosum, Draba pachythyrsa, Senecio adglacialis, $S$. supremus, $S$. gelidus, etc., así como las gramíneas Agrostis nigritella, Poa orthophylla, $P$. trachyphylla y Bromus oliganthus y la juncácea Luzula racemosa. Plancha XXIII.

En esta zona de superpáramo se encuentran muchos endemismos localizados y la razón es que se trata de un piso interrumpido constantemente desde un extremo al otro de los Andes; el superpáramo ocupa solo casquetes aislados unos de otros como islas. Esta flora es bien expresiva del concepto del Dr. Murillo sobre "Colombia archipiélago biológico".

En mi trabajo varias veces citado (Observaciones págs. 101) se hallarán detalles sobre la composición y estructura de algunas comunidades vegetales de páramo, así como tabulaciones relativas a la presencia y porcentaje de biotipos. Pero deseo insertar aquí las conclusiones que del análisis de mis datos pude sacar como definidoras de la vegetación paramuna. Estas se basan en el análisis de cinco asociaciones que en conjunto agrupé en un complejo de asociación llamado Espeletion. Sus características son las siguientes:

1.-Elevada expansión, sociabilidad y densidad del caulirrosuletum (Espeletia div. sp.).

2.-Elevada proporción de especies del criptofruticetum, casi el $50 \%$ de la vegetación total.

3.-Proporción pequeña del pereniherbetum, presente solo en formas cespitosas y pulvinadas.

4.-Perennigraminetum de tipo fasciculado y de hoja arrollada (xerofítico), con máxima expansión y densidad; de tipo fasciculado y hoja plana (tropófito) solo en una facies local muy reducida de altitud.

5.-Gran desarrollo numérico y social del muscinetum y liquenetum. Facies turbosas.

6.-Fruticetum relativamente rico en especies, pero solo con densidad manifiesta en un tipo. En los demás discontinuo y afisionómico, y presenta:

a) Predominio de formas leptófilas (superior al 50\%), a las que siguen las nanófilas en gran proporción, con muy pocas micrófilas.

b) Exclusivismo de las formas esclerofilas, con proporción elevada de formas de hojas de bordes revueltos y densamente lanosas por una cara. Formas aciculifolias frecuentes y sociales (facies). 


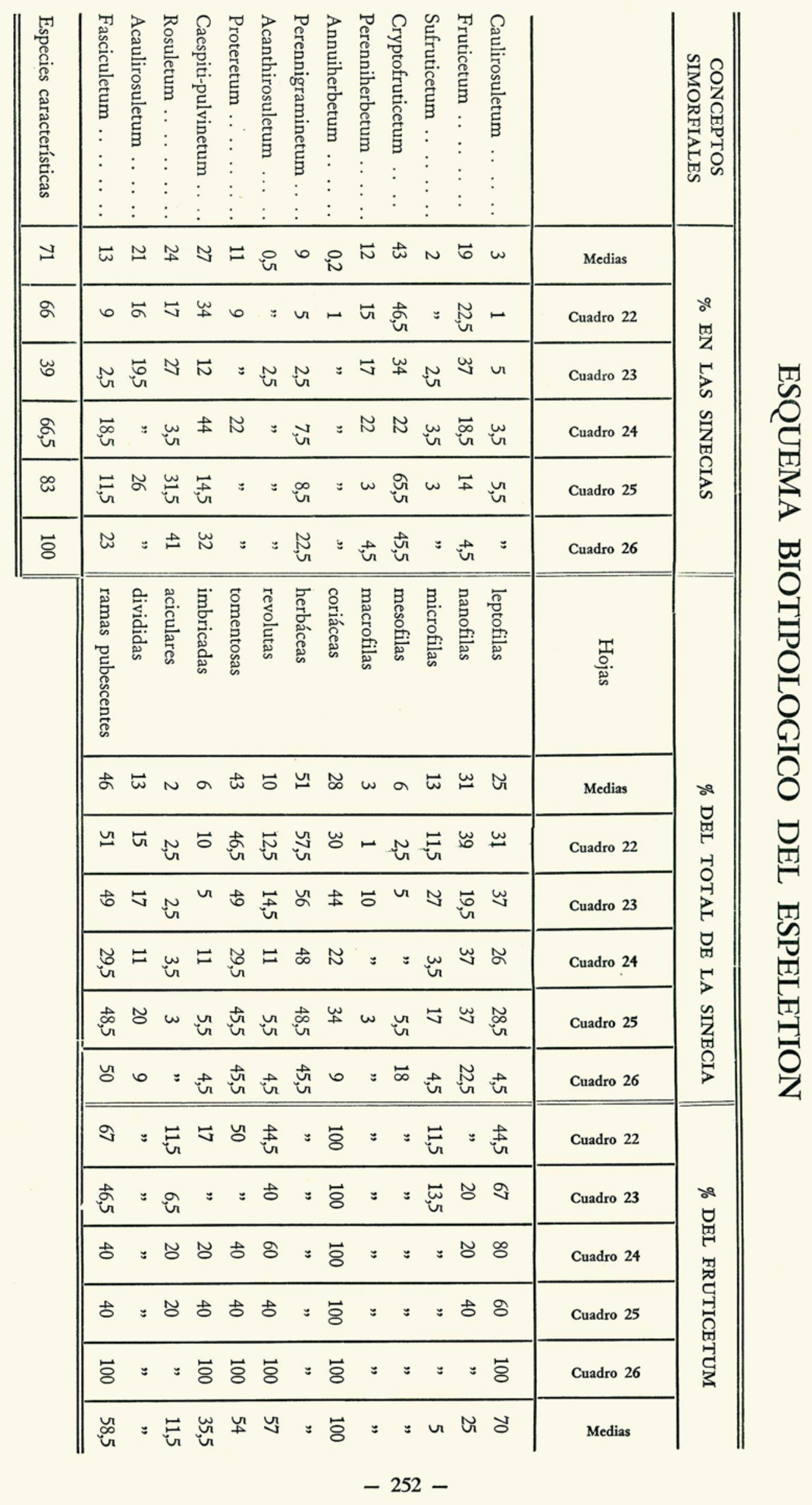


7.--Proporción bastante elevada de formas de hojas o vainas empizarradas.

8.-Proporción elevada de formas arrosetadas.

9.-Proporción elevada de formas cespiti-pulvinadas.

10.-Anuiherbetum nulo o reducidísimo.

11.-Proporción elevada de especies características (exclusivas o electivas); casi su totalidad.

Los páramos están hoy día mucho más extendidos de lo que fueron en otro tiempo y alcanzan un nivel mucho más bajo del que les corresponde en la vegetación climácica. La destrucción de los bosques andinos, especialmente en sus límites altitudinales para proveer de pastos y formar campos de cultivo, depredación continuada por la acción del fuego, es la causa de que la vegetación paramuna se haya difundido a zonas más bajas desertizadas, originando subpáramos y páramos "secundarios".

\section{LA SABANA}

Las sabanas son llanuras cubiertas de una vegetación baja de gramíneas, arbustitos y a veces árboles esparcidos. Ocupan regiones bajas, cálidas, con estación seca más o menos larga, cómo ocurre en los llanos orientales al N. del río Guaviare y E. de la Cordillera, en la costa atlántica al este del río Sinú, en parte del bajo Magdalena y en algunos enclaves del interior, p. ej. en Tolima y Huila.

En los Llanos orientales la sabana cubre miles de kilómetros cuadrados en Colombia y Venezuela. La mayor parte de estos Llanos está caracterizada por pajonales o pastos subxerófitos, con frútices abundantes, sin árboles o con ellos esparcidos; se pueden distinguir en ellos muchas asociaciones relacionadas generalmente a factores edáficos. Son especies típicas y características de las sabanas varios árboles de escasa altura, perennifolios, algunos de hoja muy gruesa, otros con corteza suberosa:

Bowdichia virgilioides (Leguminosae) (alcornoque)

Byrsonima crassifolia (Malpighiaceae) (chaparromantecón)

Curatella americana (Dilleniaceae) (chaparro)

Palicourea rigida (Rubiaceae) (chaparro bobo)

y el bototo, Cochlospermum vitifolium de grandes

flores amarillas y hoja caediza en el verano.

Las gramíneas típicas y más frecuentemente dominantes en las asociaciones de las sabanas son
Andropogon bicornis
Eragrostis maypurensis
Andropogon leucostachyus
Andropogon cirrhatus
Axonopus chrysoblepharis
Paspalum millegrana, etc. Paspalum pectinatum
Aristida capillacea
Panicum rudgei
Aristida tincta
Ctenium planifolium, etc.

Entre los arbustos y subarbustos más comunes se hallan principalmente Melastomatáceas, Leguminosas, Labiadas, Esterculiáceas, Malváceas, etc., como p. ej.

\footnotetext{
Hyptis brachyata

Hyptis dilatata

Sida glomerata
}

\author{
Waltheria glomerata \\ Pavonia speciosa \\ Grimaldia llanorum \\ Mimosa pudica \\ Clitoria rubiginosa \\ Miconia rufescens \\ Miconia macrothyrsa \\ Miconia acinodendron \\ Tibouchina bipenicillata
}

a las cuales acompañan muchas otras especies.

Como ejemplo indicamos que en Apiai, no lejos de Villavicencio, anotamos densas formaciones de Andropogon bicornis, entrelazadas con otras más o menos abiertas de Tibouchina bipenicillata, Miconia rufescens y Grimaldia llanorum, que forman consocies o asocies locales extensas. Presentes en la asociación variando el grado de densidad o de dispersión, se encontraron los siguientes frútices:
Mimosa indivisa
Borreria capitata
Hyptis dilatata
Waltheria glomerata
Miconia stenostachya
Miconia albicans
Miconia acinodendron
Miconia scorpioides
Miconia minutiflora
Miconia mollicula
Miconia ulei
Miconia amplexens
Clidemia neglecta
Clidemia tiliaefolia
Siparuna chiridota
Pavonia fruticosa
Bauhinia bicuspidata
Xylopia aromatica
Vismia angusta

y las siguientes gramíneas:

Eragrostis maypurensis

Panicum versicolor

Paspalum leucostachyus

Eriochloa distachia

Panicum rudgei

Paspalum conjugatum

Según el predominio de unas u otras especies varía la fisonomía local del paisaje, por lo que en ciertos lugares prevalecen formaciones arbustivas con gramíneas dispersas y en otros las gramíneas son densas con arbustos y hierbas esparcidas. Es frecuente encontrar densos pajonales de hasta 1 a 2 metros de altura como los que forman Paspalum millegrana y algunos Andropogon. También Axonopus cirrhatus da lugar a formaciones densas. Lo mismo ocurre con los arbustos o subarbustos predominando en matorrales sabaneros las antes mencionadas Miconia rufescens, $M$. albicans, M. stenostachya, Sida glomerata, Hyptis brachyata, H. dilatata, H. colombiana.

Como se ha dicho, el factor edáfico es muy importante, en función en parte de la permeabilidad del terreno la cual ocasiona una rápida desecación en época seca y un lavado del suelo en la época de las lluvias. Por esto en gran parte las sinecias están localmente determinadas por la topografía y calidad del suelo. En lugares bajos más o menos pantanosos o constantemente imbibidos en 
época seca se halla una flora distinta de la de las sabanas elevadas y está constituída por elementos higrófilos como son:

Polygala higrophila
Fimbristylis complanata
Rynchospora kunthii
Blechnum serrulatum
Siphanthera alsinoides
Acisanthera limnobios
Naiadothrix myriophylloides
Caperonia angustifolia
Syngonanthus caulescens
Syngonanthus gracilis
Syngonanthus huberi
Eriocaulon humboldtii
Limnosipanea sp.
Coutoubea spicata
Chelonanthus uliginosus
Cipura paludosa
Cypella linearis
Utricularia hispida, etc.

En cambio en lugares altos bien drenados y despejados se desarrollan consocietas de gramíneas más bajas y densas o de ciperáceas arrosetadas como las tan típicas de Oncostylis paradoxa y Bulbostylis lanata (cabeza de negro), que encontramos extensamente en La Serranía.

Los Llanos de sabana están con frecuencia interrumpidos o cruzados por manchas alargadas de "mata de monte" llamadas también selvas de galería, las cuales siguen los cursos de los ríos y riachuelos o de las aguas freáticas en la época seca. La vegetación de estas "matas" es semejante en estructura a la de la selva higrófila ya tratada; depende de la extensión de la misma, la riqueza de su composición y el volumen de la masa arbórea. Es evidente que generalmente hay una intromisión en ella de elementos de sabana, así como hacia la sabana avanzan constantemente los constituyentes genuinos de estas "matas" (selva). La constante tendencia a expansionarse que demuestran las "matas" es una de las pruebas del origen antropógena de las formaciones de sabana, las cuales son-mantenidas en virtud de los incendios periódicos y de la constante depredación por el pastoreo.

La naturaleza selvática de estas "matas" salta a la vista cuando encontramos en ellas las mismas especies de la selva amazónica indicando que no son más que una extensión de las mismas. Por ejemplo en pleno Llano hallamos Palicourea condensata, Bauhinia tarapotensis, Siparuna guianensis, Guatteria metensis, Hirtella elongata, Palicourea punicea, Myrica sylvatica, Tococa guianensis, Jacaranda obtusifolia, Capironia decorticans, Pterocarpus ulei, Brownea vaupesana, Rourea glabra, Hieronyma laxiflora, Senegalia glomerata, Forsteronia benthamiana, Casearia javitensis, Duguetia odora, Couroupita peruviana, Chrysochlamys ulei, Allophylus amazonicus, etc. así como el gigante de las hierbas, el terriago, Phenakospermum guianense, el cual acompaña las "matas" en estas islas remanentes de selva a través de los Llanos. Lo mismo ocurre con el moriche, la palma Mauritia minor, que es tan fiel a los cursos de agua en las abiertas sabanas como lo es en el interior de la selva del Vaupés; en ambos ambientes constituye formaciones lineales por causa hidro-edáfica. Si en los Llanos persiste el moriche aun donde todo el resto de la selva ha sido anulada, es por su resistencia al fuego; por esta razón destacan con trecuencia morichales aislados en medio de amplia sabana limpia de matorrales. La existencia en la región de los Llanos de una época seca no es causa exclusiva del tipo de vegetación de sabana. La sequía periódica facilita la acción aniquiladora de las quemas, las cuales se repiten anualmente. Donde el período seco sea corto y la precipitación anual exceda de $1200 \mathrm{~mm}$. se hace difícil sostener la sabana. Planchas XXIV y XXV.

La vegetación de la sabana que es típica en los Llanos orientales también se encuentra en el interior del país en partes bajas de las grandes hoyas (Magdalena, Cauca, Zulia...) en donde forman enclaves subseriales. Con frecuencia estas sabanas están más afectadas por el hombre dada la vecindad de los cultivos y un más intenso pastoreo. Pero la sabana está siempre tipificada por un grupo de elementos. Como ejemplo cito el siguiente tomado bastante arriba del Magdalena, en los llanos más al sur de Neiva, con las siguientes especies esparcidas:
Bursera tomentosa
Byrsonima crassifolia
Curatella americana
Rondeletia pubescens. .
Malpighia glabra
Randia aculeata
Rapanea guyanensis
Casearia nitida
Neltuma juliflora
Machaonia acuminata
Croton glabellus
Muntingia calabura
Calliandra tolimensis
Clusia parvicapsula
Ficus elliptica
Ficus prinoides
Guazuma ulmifolia, etc.

Aquí se nota la existencia de elementos extraños a las sabanas típicas procedentes del bosque climácico cercano o de las comunidades xerófilas de las lomas áridas contiguas. En realidad aún está por hacer el estudio de las diversas asociaciones de sabana y de sus relaciones con la selva y con las sinecias de los desertizados áridos, que se mencionan en el capítulo siguiente.

\section{LA SABANA CASMOFITA}

Un tipo especial de vegetación que se menciona como de "sabana" es la que se halla en lo alto de los cerros y mesetas, aisladas entre las selvas de las Guayanas, como son los cerros Roraima, Duida, Kaietur, Tafelberg, Auyan-tepuí, Ptari-tepuí, Chimanta-tepuí, Sipapo, etc. los cuales en recientes años han sido motivo de activas exploraciones que han proporcionado muchos descubrimientos. Estos cerros, formados o cubiertos por rocas de arenisca, se consideran las reliquias de un escudo de rocas cristalinas que se extendía continuo en el cretáceo descansando sobre granitos paleozoicos. La naturaleza química de estos cerros y su estructura física, muy permeable, que hace que el agua se filtre y escurra en ellos rápidamente, constituye un factor ecológico que imprime carácter a su vegetación. La flora de estos cerros es un matorral de tipo xeromorfo, predominando arbustos y árboles pequeños con hojas coriáceas, plantas arrosetadas de hojas firmes, con frecuencia espinoso-dentadas, de las Bromeliáceas, matas del tipo de caulirrósula pertenecientes a las Compuestas-Mutisieas y a Rubiáceas y las bizarras Vellozia. 
Este tipo de vegetación, que adquiere extensísimo desarrollo en los países vecinos tiene, aunque más pobremente, alguna representación en Colombia, en donde por vez primera en 1939 el autor exploró una estación de este tipo cerca de San José del Guaviare encontrando Navia acaulis, Vellozia lithophila, Senefelderiopsis chiribiquitensis, Mandevilla nerioides, Acanthella conferta, Aneimia bumifolia, Syngonanthus humboldtii, Puya floccosa, Aranella fimbriata, Siphanthera capitata, Cassytha filiformis, Pitcairnia turbinella. Quien después ha explorado y estudiado más esta flora ha sido R. Evans Schultes, que ha visitado varios de los cerros y mesas de difícil acceso situados a modo de islas en medio de la inmensa selva del Vaupés-Caquetá-Meta. Schultes ha llamado especialmente la atención sobre este tipo de vegetación semejante a la de los cerros de la Guayana, habiendo explorado entre otros puntos los cerros Campana, Chiribiquete, Monachi, Isibucuri, etc. También la Sierra Macarena comprende en parte este tipo de flora, así como ciertos puntos situados en las faldas que originan los raudales, p. ej. Yuruparí. Según Schultes son típicos de estas formaciones los arbolitos o arbustos de Senefelderopsis chiribiquitensis, la siringa enana Hevea nitida v. toxicodendroides, especies de Clusia, Ternstroemia, Miconia pradoxa, Bombax coriaceum, las bromeliáceas del género Navia, abundantes, varias orquídeas, Poepalanthus, etc. Todas ellas con su diversa estructura xeromorfa dan carácter a la flora de estos terrenos rocosoarenosos, y muy especialmente se lo dan las Vellozia cuando presentes. Ojalá se active la exploración de los enclaves colombianos de esta flora.

\section{FORMACIONES XEROFITICAS Y SUBXEROFITICAS}

La costa del Caribe al N. de Colombia, desde el río Sinú hasta toda la península Goajira forma una zona en gran parte seca, resultado de la acción de los alisios. Aquí se deja sentir en la vegetación el efecto del clima del tercer tipo, caracterizado por un período muy seco que puede durar hasta seis meses, durante los cuales las lluvias son escasas y pueden ser hasta nulas. La precipitación varía localmente siendo mayor donde se levantan serranías capaces de detener los vientos; también varía según los años, pero siempre octubre y noviembre son los meses húmedos, los más lluviosos, y enero y febrero son absolutamente secos. La vegetación que se desarrolla de este modo es de tipo xerofítico: árboles pequeños y arbustos achaparrados, de hojas persistentes, coriáceas y rígidas con gruesa cutícula o que las pierden en verano (tropofitia), matas espinosas, plantas crasas, adquiriendo gran desarrollo, rosuletos de hojas rígidas y punzantes, sarmientos espinosos, y pequeños sufrútices y gramíneas que se secan en verano. Cavanillesia platanifolia (macondo), bombacácea de tronco bombacho, es forma biológica típica de este medio. Características de las formaciones son arbolitos espinosos de mimosáceas, más o menos densos o esparcidos, generalmente caducifolios, los perennifolios de las caparidáceas y teofrastáceas (Jacquinia) y los cardones, es decir las cactáceas columnares que pueden alcanzar gran tamaño y densidad. También árboles resinosos de las burseráceas, como el almácigo, la bija y la caraña y los guayacanes de las zigofiláceas son típicos de estas formaciones xerófitas. Según las condiciones de sequía local varía la concentración y distribución de especies en la formación, que puede ser bos- que bastante denso con predominio de arbolitos, bosque claro o muy abierto, intrincado espinar o convertirse en completo erial. En ciertos lugares los cardones (Lemaireocerus, Acanthocereus...) son esparcidos o raros, en otros predominan formando bosque. En todo caso el aspecto del paisaje durante la época seca (verano) es de gran aridez. Esta vegetación ha sido descrita del departamento del Atlántico por Dugand (1938, 1944, 1947) quien ha dado además un cuadro analítico de la composición de una de las más importantes asociaciones de la región (1941). La comunidad estudiada por Dugand es de tipo tropofítico (es decir predominantemente caducifolia) y se trata de un complejo que denomina Cappari-piptadenion, en el cual la especie más abundante es el árbol espinoso caducifolio Piptadenia flava; va mezclado con otros numerosos árboles, de los que enumera 34 especies. Las especies más conspicuas son:

Piptadenia flava

Neltuma juliflora

Poponax tortuosa

Chloroleucon mangense

Coccoloba ramosissima

y las caparidaceas perennifolias

Capparis odoratissima

Capparis flexuosa

Capparis verrucosa

Stuebelia nemorosa

y la teofrastácea Jacquinia aurantiaca.

Además las suculentas:

Lemaireocereus griseus

Acanthocereus colombianus

Epiphyllum sp.

Pereskia colombiana

Pedilanthus tithymaloides

Dicliptera assurgens

Ruellia albicaulis

Tillandsia aloifolia

Phoradendron venezuelense,

el crassicauletum armado de Bromelia pinguin, muy difundido y que forma grandes gregies; las brevicaducifolias Libidibia coriacea, Neltuma juliflora y Zizyphus angolito; otro árbol de los mayores con grueso tronco espinoso, Bombacopsis quinata (ceiba) y la palma Copernicia sanctamartae que se establece en formaciones en terrenos anegadizos.

Ahora bien, los bosques de selva no están muy lejos de esta estrecha región, ellos asoman por las serranías del oeste o suroeste y por las faldas de la Sierra de Santa Marta; donde condiciones locales de irrigación, protección topográfica, etc., lo favorecen, la selva se adelanta y sus formas subhigrófilas hacen contacto con las comunidades subxerófitas, de tal modo que en los límites de la zona y en enclaves se pueden encontrar todas las transiciones entre el tipo desértico de vegetación, el espinar, el bosque tropófilo y el subhigrófilo.

Asociaciones subxerófitas y aun xerófitas y otras intermedias se hallan también en la región de Zulia y entre las Cordilleras donde las condiciones locales son semejantes, por ejemplo en la hoya del Chicamocha, en la del Dagua, en Río Sucio sobre Dabeiba, en el Magdalena, etc. Plancha XXVI.

Sorprendentemente, en el valle interior del Chicamocha, entre 1700 y $2200 \mathrm{~m}$., en las abruptas y secas ver- 
tientes y en la misma hondonada se halla una vegetación semejante constituída por los siguientes más visibles y típicos elementos:
Pithecelobium dulce
Poponax tortuosá
Fagara culantrillo
Cercidium praecox (yabo)
Neltuma juliflora (cují)
Ficus soatensis (uvo)
Thevetia peruviana
Dodonaea viscosa (ayuelo)

entremezcladas con las siguientes cactáceas, algunas formando candelabro de considerable altura:

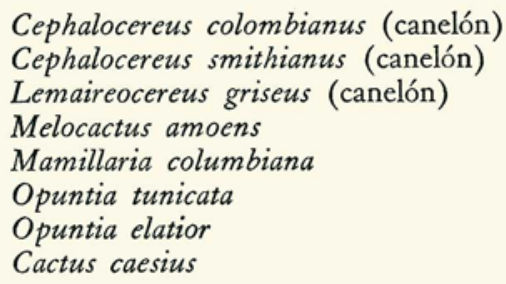

Cephalocereus colombianus (canelón)

Cephalocereus smithianus (canelón)

Lemaireocereus griseus (canelón)

Melocactus amoens

Mamillaria columbiana

Opuntia tunicata

Opuntia elatior

Cactus caesius

generalmente hay una cobertura baja de pequeños frútices o sufrútices y gramíneas, siendo las especies más abundantes:

Croton meridensis y Cordia curasavica a las que
siguen
Lantana rugulosa
Malvastrum spicatum
Evolvulus argyreus
Alternanthera pungens
Jatropha gossypifolia
Eragrostis tephrosanthos
Tricholena repens
Pappophorum pappiferum

Los arbolitos que dominan en algunas de estas secas lomas son los tropófilos Cercidium praecox (yabo) y $\mathrm{Nel}$ tuma juliflora (cují) que con su copa aparasolada y de fino follaje dan notable carácter al paisaje.

En muchas lomas de estas regiones desertizadas, cuando el drenaje es grande o debido a causas que aun no se conocen, quizás quemas muy continuadas, solo prospera el pajonal. Así se forman las llamadas por algunos autores estepas, si bien este tipo de formación es bien distinto de las verdaderas estepas. Las gramíneas del género Andropogon son muy frecuentes en estas formaciones en haces, especialmente $A$. condensatus. También se presenta Aristida, habiendo observado extensas formaciones de Aristida laxa en lomas desertizadas de la hoya del río Bugalagrande a unos $2250 \mathrm{~m}$. alt. En lugar más bajo y cálido (Ibagué) las hay muy altas y densas de Hyparrhenium bracteatum (Observ. p. 85) que se repi. ten frecuentemente. En cerros del Valle del Cauca (1000-1200 m. alt.), sometidos a constantes quemas, se hallan formaciones de Andropogon condensatus en haces, acompañadas de otras especies como Sporobolus indicus, Paspalum paniculatum y de dicotiledóneas, p. ej. Croton ferrugineus, Hyptis colombiana, H. pectinata, Senecio semidentatus, Baccharis trinervis, Buchea prismatica, etc.

\section{LOS MANGLARES}

Son asociaciones arbóreas o arbustivas perennifolias de carácter anfibio, halófilas que prosperan en las costas tropicales, ofreciendo generalmente un efecto espectacu- lar. Las plantas de los manglares están estructuradas para resistir fuertes oleajes y para la vida en agua salobre pues están sometidas a las periódicas inundaciones provocadas por la marea. Es adecuada adaptación morfológica de las plantas de manglar un sistema de raíces aéreas formado por estribos, fúlcreos o zancos, cables (con geotropismo positivo) y raíces terrífugas (geotropismo negativo) en forma de codo o de bujía. Este complicado sistema radical fija las plantas al suelo que es de tipo flojo y lodoso, ayudando a su estabilidad y sirve también para absorber durante la bajamar el aire que no puede tomar del suelo inundado. El suelo de los manglares es limoso, carece de oxígeno y contiene gran concentración de substancias disueltas, lo cual dificulta la absorción por las raíces. Los manglares ocupan lugares de la costa generalmente junto a los estuarios de los ríos; las aguas cargadas de detritus y materia orgánica depositan sus acarreos entre el sistema radical del manglar; con ello el suelo se enriquece y se eleva progresivamente. Cuando el terreno alcanza el nivel de la pleamar, es ya firme y es invadido por una vegetación no halófila que sustituye el manglar por la selva tropical. Así el manglar avanzando hacia el mar y retirándose del interior va ganando nuevo terreno para la tierra firme.

En Colombia los manglares ocupan casi toda la costa del litoral Pacífico y la occidental del Atlántico en donde forman una faja, en lugares de gran anchura, atravesada por una compleja red de canales o esteros. Los manglares colombianos son de los más extensos del mundo, pues alcanzan completo estado de madurez, formando una densa selva de gran volumen y altura. El manglar corresponde al complejo de asociación llamado Rhizophoretalia, el cual en Colombia está integrado por comunidades de especies de Rhizophora (Rhizophoraceae), Pelliceria (Theaceae), Avicennia (Avicenniaceae), Laguncularia y Conocarpus (Combretaceae). En la costa atlántica es Rhizophora mangle, pero en la del Pacífico es Rhizophora brevistyla la especie que constituye la masa más importante e imponente del manglar. En la costa del Pacífico Rhizophoretum brevistylae cubre enormes extensiones ofreciendo el espectáculo de la gran selva; aquí alcanzan los tallos una altura de hasta 40 metros y de 1 metro de diámetro; además están sostenidos por un sistema de corpulentas raíces-estribos, arqueadas, que levantan la base del tallo a una altura de hasta $10 \mathrm{~m}$. sobre el nivel del lodo. Plancha XXVII.

Recorriendo los esteros que cruzan el manglar y que comunican la desembocadura de un río con la de otro, se encuentran las diversas comunidades de manglar. Cada especie aparece en asociaciones exclusivas que se distribuyen de afuera hacia adentro según la solidez del terreno, la salinidad y la distancia que les separa del océano. Una de las sucesiones de comunidades más frecuentes es la siguiente:

1.--de Rhizophora brevistyla (mangle rojo), muy desarrolladas en el frente marino.

2.--de Avicennia nitida (iguanero), asociación de árboles de mediana altura, le sigue en terreno más elevado.

3.- de Laguncularia racemosa (comedero) arbustiva o arborea de menos altura; forma una tercera faja.

En ciertos lugares hay una aparente inversión de la sucesión, pues por haberse acumulado depósitos aluviales entre las raíces del manglar (Rhizophora), luego este ha sido invadido exteriormente por comedero o iguanero. 
No lejos de formaciones de Laguncularia en playas limosas se encuentran formaciones herbáceas de Sessuvium portulacaceum, lo cual indica un estado avanzado en la consolidación del terreno. En el frente marítimo, está siempre en primer lugar, en rompeolas, el mangle rojo. Pelliceria rhizophorae (piñuelo) es un arbolito de forma de ciprés, de unos 10 a 15 m., se encuentra cerca de Rhizophora y en donde el terreno es duro, rocoso y no demasiado hondo. Los piñuelos pueden formar comunidades pero no se internan. Rhizophora y Pelliceria son sucedidas por Avicennia (iguanero) al internarnos y esta lo es por Laguncularia (comedero). En terreno aun más elevado se encuentra la asociación de Conocarpus. Para Colombia una de las plantas de mayor interés científico del manglar es el piñuelo, porque es un árbol de una familia muy diversa de las de los restantes mangles y constituye un género endémico con una sola especie. Pelliceria rhizophorae es exclusiva de la Costa del Pacífico.

Otras especies secundarias se hallan en el manglar y tienen interés, porque en realidad esta formación es pobre en especies. Dos de ellas son un arbolito Ardisia granatensis y un arbusto, Pavonia rhizophorae, que se encuentran asociados al comedero y al iguanero; son especies limitadas a estas formaciones de la Costa del Pacífico. Otras especies secundarias son la Rizoforácea Cassipourea killipii, la Melastomatácea Conostegia polyantha y la Rubiácea Rustia occidentalis, frecuentes en la zona de transición. Una nota ornamental del manglar es el gran helecho Acrostichum aureum (chigua macho), que es frecuente en los terrenos más elevados bajo Rhizophora. Además tienen interés ciertas epífitas que son algunas bromeliáceas y orquídeas y dos compuestas: Tuberostylis rhizophorae y $T$. axillaris, ambas de la importante lista de endemismos de esta formación.

\section{FORMACIONES DE PLAYAS Y MARGENES}

Las formaciones de playas representan las primeras fases de la vegetación sobre un suelo primario nuevo formado por recientes depósitos aluviales. Las plantas que primero aparecen sobre estos suelos son heliófilas de pocas exigencias y capaces de aprovechar la escasa cantidad de nutrimento de un suelo pobre. Las especies más generalmente representadas en estas formaciones de playa son gramíneas; suelen tener tallos rastreros y estolones que se extienden y enraizan fácilmente, contribuyendo con ello a fijar el terreno y prepararlo para la invasión de otras plantas. En las grandes playas y bancos aluviales de los ríos de los Llanos orientales se encuentran con frecuencia asociaciones pioneras de gramíneas monoespecíficas o dominadas por una sola especie. En el río Meta (p. ej. en Vuelta Mala) he observado largos tallos o cañitas estoloníferas extendidas sobre playas nuevas, formando malla que fija los arenales; con gran frecuencia estas son de Hymenachne amplexicaulis y de Paspalum millegrana. Estas especies forman luego grandes haces erguidos de pajonal. También se hallan en esta fase primaria de las playas otras gramíneas más esparcidas como son

$$
\begin{aligned}
& \text { Eriochloa punctata } \\
& \text { Leptochloa virgata } \\
& \text { Panicum elephantipes } \\
& \text { Eragrostis acutiflora } \\
& \text { Echinocloa crus-pavonis }
\end{aligned}
$$

la ciperacea Cyperus ligularis y los grandes haces o gregies de Imperata contracta. Esta es una de las de más efecto fisionómico en las playas nuevas y en vías de fijación, pero otra dominante de la primera fase es Paspalum millegrana que da lugar a grandes y densas formaciones. No obstante, a medida que la playa se afirma, gana terreno y se establece el pajonal de Hymenachne amplexicaulis (gramalote, cañizo) formando comunidad cerrada de cañitas de 1 a 2 metros de alto, a través de la cual es difícil abrirse paso y que puede extenderse en muchos kilómetros de superficie. Otra fase en la fijación que sucede a las anteriores y donde el suelo es menos pobre es la de la caña brava, Gynerium sagittatum, y también la de la compuesta Tessaria integrifolia. Esta última, llamada "sauce" constituye formaciones de arbustos o arbolitos uniformes de $2-4 \mathrm{~m}$. altura en playas o bordes interiores de las playas firmes. Una vez asentadas estas comunidades se asocian progresivamente nuevas especies que van ganando terreno y mejorando el suelo, favoreciendo la entrada de una más compleja vegetación. Entre estas especies invasoras se pueden citar Mimosa pigra (mata de espino), Sesbania exasperata, Funastrum clausum, etc. Plancha XXVIII.

La caña brava desempeña un papel importante en la fijación de los terrenos primarios en una etapa siguiente a la del graminetum o pajonal inicial. Diversas dicotiledóneas, arbustos o árboles son también características de etapas priseriales y entre ellos se encuentran los guarumos o yarumos (Cecropia). Es evidente, que tanto en los bancos de los ríos orientales como en los del centro (Magdalena) y occidentales, los yarumos caracterizan formaciones marginales riparias, en las que esquematizando consideramos que constituyen una tercera etapa en la invasión de las playas por la vegetación. La primera etapa es la inicial, la de varias gramíneas fijadoras, ramosas o fasciculadas, una segunda etapa es la de caña brava o de ciertos arbustos o pequeños arbolitos ("sauce", "chíparos") o de grandes Escitamineas (Calathea, $\mathrm{He}$ liconia, Costus: 'hoja blanca', bijao, platanillo, cañagria); a todo esto suceden las formaciones de Cecropia. Estas forman comunidades monoespecíficas uniformes que cubren extensos bancos formando fajas marginales de más o menos anchura a lo largo de los ríos, separando la playa de la selva. Plancha XXX. En el Meta, he observado tal sucesión, es decir de fuera adentro:

1.-pajonal de gramínea (p. ej. Hymenachne amplexicaulis).

2.- - cañar de Gynerium sagittatum.

3.--guarumal de Cecropia sp.

También puede presentarse:

1.--pajonal.

2.-formación de Tessaria.

3.--formación de Cecropia sp.

En el río Sucumbíos (Putumayo) en la playa de Singüé anoté semejante sucesión:

1.-pajonal (Paspalum virgatum y Oryza latifolia y Hymenachne amplexicaulis y Panicum zizanioides).

2. cañar de Gynerium sagittatum.

3.- guarumal de Cecropia pacis.

También en el Putumayo el pajonal de orilla o de playa es con frecuencia una formación extensa de $H y$ menachne amplexicaulis o de $H$. donacifolia. La etapa segunda puede también consistir en formación de esci. 
tamíneas, p. ej. Calathea comosa, etc. o bien puede ser un matorral formado por Tessaria o por leguminosas (p. ej. Zygia, Inga, Mimosa...). También se presenta el caso en que a la formación de caña brava suceden otras de matorral (Tessaria, leguminosas, etc.), resultando como una serie de cuatro etapas; de este tipo indiqué unas en el río Magdalena (Observ. 28-31), en las cuales, al cañar de Gynerium sagittatum sigue una formación de Salix humboldtiana, y a esta la de Cecropia. Esta serie completa (el ejemplo de la fig. 3, loc. cit. es un margen cortado en el que falta la playa baja) sería como sigue:

1.- graminetum con Hymenachne.

2.- cañar de Gynerium.

3.--arbusculetum de Salix.

4.- guarumal (Cecropia sp.).

En otra publicación anterior (Vistazo, 309-310, pl. 5 y 6) he resumido cómo tiene lugar la invasión de las playas nuevas del río Calima en la Costa del Pacífico. También allí es frecuente el pajonal de Hymenachne ample. xicaulis presentándose con cierta importancia el de $\mathrm{Pa}$ nicum grande. Además, otras especies pueden ser las primeras dominantes de playas (p. ej. Panicum laxum) y también se señala con frecuencia una sucesión desde la orilla hacia el interior formada por: 1, graminetum p. ej. Panicum laxum; 2, Gynerium sagittatum; $3, \mathrm{Ce}$ cropia.

Cuando las orillas se inundan con frecuencia puede presentarse también una vegetación especial de gramíneas más higrófilas, p. ej. algunas del género Ischaemum, que constituyen densas formaciones de alto pajonal más o menos tiempo inundado en los márgenes de ríos.

A veces aparecen dicotelidóneas arbustivas como primera fase, de vegetación exclusiva en un terreno nuevo, lo cual se puede explicar por depósitos de limo que puede haber en el subsuelo. Un ejemplo de este caso es el de arbolitos de Calliandra angustifolia (chípero) en el $\mathrm{Pu}$ tumayo y Sucumbios; son arbolitos bajos achaparrados, de copa aplanada, que aparecen solitarios, esparcidos, en los islotes de cascajo y arena exentos de cualquier otro tipo de planta. Precisamente entre las Mimosáceas se encuentran especies que buscan las orillas de los ríos aún en tierra templada, p. ej. desde 0 a $1400 \mathrm{~m}$. alt. he observado en tales estaciones Calliandra pittieri, $C$. angustifolia, Albizzia carbonaria, Inga spp., Zygia spp., etc.; también suben por los ríos Tessaria integrifolia, Heliocarpus popayanensis y con más tolerancia Salix humboldtiana que alcanza a más de $2600 \mathrm{~m}$. alt. Igualmente forman grupos riparios las guaduas. Ya por el nivel ciel piso andino, además del sauce (Salix humboldtiana), se encuentran en formaciones de importancia Alnus jorullensis v. ferruginea, Eugenia sp., Vallea stipularis, $M y$ rica spp., etc.

En las playas marítimas (Costa del Pacífico) las gramíneas reptantes fijadoras más importantes en formación son Cenchrus pauciflorus y Homolepis aturensis, siendo también reptantes típicas de estos arenales, Phyla nodiflora, Pectis arenaria, Ipomoea pes-caprae, I. stolonifera, Canavalia maritima, Stenotaphrum secundatum. Los primeros arbustos que se encuentran al fijarse la playa son Mimosa pudica, M. pigra, Psidium guayabo, Ditremexa occidentalis, Hibiscus tiliaceus, Chrysobalanus icaco, Anona glabra. Este último es un arbolito que abunda en ciertas zonas más al interior dando sabrosos frutos (guanabanillo). Planchas XXIX y XXX.

\section{LOS PRADOS}

Las áreas deforestadas de las montañas que en algunas regiones son extensas están frecuentemente cubiertas con prados. Esto ocurre cuando la precipitación es suficientemente uniforme y no hay un período anual bastante seco para favorecer las quemas continuadas. En este último caso se originan sabanas o lomas de aspecto estepario. Cuando la humedad es bastante sostenida, en tierra caliente se suelen desarrollar prados o praderas de gramíneas introducidas que se han propagado y difundido profusamente; estas son el yaraguá, Melinis minutiflora y el pasto micay, Axonopus compressus y $A$. scoparius. Estos pastos ocupan extensiones en clima cálido y templado cálido. También se han difundido en tierra caliente formando praderas, el pará (Panicum purpurascens) y el guineo o yerba guinea (Panicum maxi mum). Otros pastos abundantes en tierras deforestadas cálidas y húmedas son los de Paspalum bijugatum, $\mathrm{Pa}$ nicum polygonatum, Paspalum decumbens, Panicum zizanioides y Panicum hylaeicum.

Subsiguientes a la destrucción y quema de los bosques subandinos, se siembran o esparcen semillas de algunos pastos, y se difunden también espontáneamente procedentes de los campos vecinos, especies de Paspalum, Axonopus, Panicum, Trifolium y Dactylis glomerata. Cerca de Tacueyó en la Cordillera Central encontré una formación de prado constituída por las siguientes especies dominando la primera:
Paspalum macrophyllum
Digitaria sanguinalis
Kyllinga odorata
Setaria geniculata
Polypogon elongatus
Trisetum deyeuxioides
Cyperus niger
Bohmeria aspera
Manettia coccocypseloides
Cuphea racemosa
Pilea microphylla
Scutellaria trianea
Chaptalia nutans
Borreria laevis
Equisetum bogotense
Spilanthes americana
Trifolium repens
Oxalis martiana
Ranunculus vaginalis

En el Valle del Cauca, cerca de La Margarita, 2100-

$2200 \mathrm{~m}$. alt., la composición de la pradera es como sigue:

Panicum olivaceum

Oplismenus burmannii

Holcus lanatus

Setaria geniculata

Calamagrostis viridiflavescens

Polypogon elongatus

Sporobolus poiretii

Pseudochinolaena polystachya

Zeugites mexicana

Salvia scutellarioides

Rumex obtusifolius v. agrestis

Trifolium repens

Jaegeria hirta

Spilanthes americana

Stemmatella urticifolia

Cyperus hermaphroditus 
Bidens pilosa v. minor

Borreria ocymoides

Borreria laevis

Verbena litoralis

Erechtites valerianifolia

Castilleja arvensis

Cissus rhombifolia

Piper glanduliferum

Peperomia pennellii

Bomarea patinoi

En cuanto a los prados que se forman en las montañas del piso andino por supresión del monte, sirve de ejemplo el siguiente, anotado en la loma de Barragán, Cordillera Central, en extensa formación prácticamente uniforme entre 2660 y $2800 \mathrm{~m}$. alt. Son dominantes las cinco primeras especies (asocies), las restantes abundan, aunque más esparcidas:

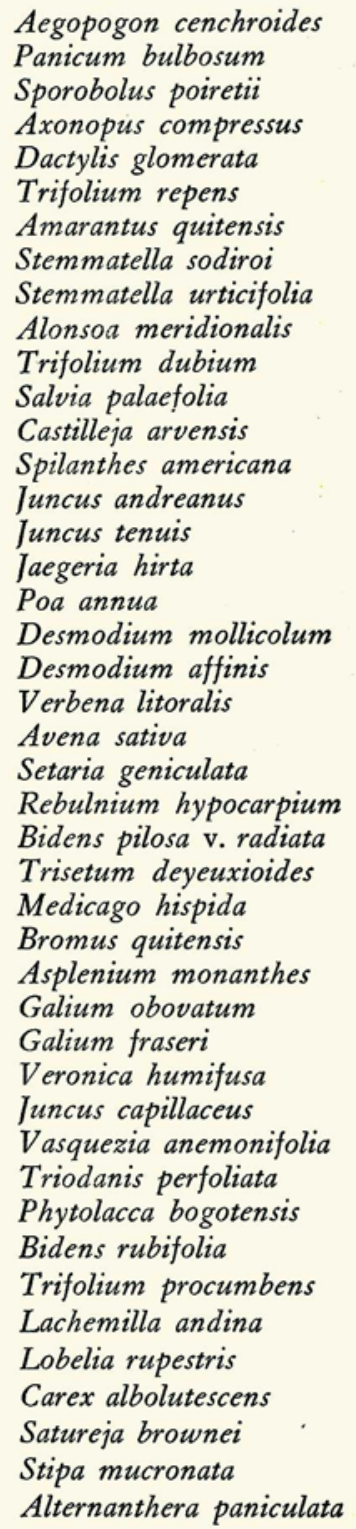

En estaciones muy locales más húmedas se concentran:

Hydrocotyle sp.

Spilanthes

Trifolium repens

\section{Stemmatella \\ Jaegeria \\ Lachemilla}

Es indudable que la riqueza en especies de la formación y su diverso origen es clara expresión del carácter subserial o secundario de estos pastos.

Es interesante la composición de uno de estos prados de la sabana de Bogotá, en lugar cercano a Sibaté, en terreno poco inclinado que fue abandonado de cultivo dos años antes; el aspecto es de prado graminoide bastante denso con dominio completo de Anthoxanthum odoratum de unos $60 \mathrm{~cm}$. de alto; las demás especies esparcidas:

Anthoxanthum odoratum
Eragrostis soratensis
Paspalum trianae
Stipa mucronata
Bromus coloratus
Eragrostis pastoensis
Dactylis glomerata
Holcus lanatus
Brassica campestris
Rhaphanus sativus
Stevia elongata
Stevia rhombifolia
Chrysanthemum leucanthum
Apium leptophyllum
Daucus montanus
Bidens triplinervia v. hirtella
Bidens pilosa v. minor
Oenothera multicaulis v. tarquensis
Sisyrinchium sp.
Anthericum sp.
Gnaphalium sp.
Gnaphalium spicatum
Silene gallica
Ranunculus pilosus
Lachemilla aphanoides
Lithospermum mediale
Cologania ovalifolia
Oxalis corniculata
Siegesbeckia sp.
Erigeron uliginosum
Sonchus oleraceus
Veronica sp.

En realidad, a la altitud entre 2500 y $3000 \mathrm{~m}$. los prados suelen estar dominados por las gramíneas introducidas Dactylis glomerata (pasto azul), Holcus lanatus, Anthoxanthum odoratum y Agrostis palustris, como he comprobado también en antiguas praderas de la sabana en los terrenos que son ahora la Ciudad Universitaria. A mayores altitudes generalmente van tomando preponderancia especies de las asociaciones del Lachemillion especialmente Lachemilla orbiculata y Lachemilla aphanoides. Estas especies dominan desde los 2600 a 3600 m. alt. extensos prados de tipo cespitoso en suelos bastante húmedos o irrigados. Para citar solo un ejemplo doy la composición de uno de estos prados formado por denso césped de Lachemilla en el cual las restantes especies están esparcidas. Es un Lachemilletum orbiculatum Trifoliosum situado en la Quebrada de San Cristóbal sobre Las Delicias (Bogotá) a $2950 \mathrm{~m}$. alt. (Plancha XXXI) :

Lachemilla orbiculata

Lachemilla aphanoides 


\author{
Trifolium repens \\ Trifolium filiforme \\ Hypochaeris sessiliflora \\ Aster marginatus \\ Gnaphalium spicatum \\ Rumex acetosella \\ Carex bonplandii v. humilior \\ Altensteinia rostrata
}

En mi trabajo mencionado (Observ.: 88-99) se trataron diversas asociaciones de prados de este tipo, relativos al Lachemillion (= Alchemillion) y a ellos se remite al lector.

\section{VEGETACION ACUATICA}

Es poco lo que se conoce hoy día de la vegetación acuática, y parte de las observaciones hechas no pueden actualizarse por estar pendiente la identificación de muchas colecciones.

Como vegetación acuática de tierra caliente en aguas tranquilas se pueden referir las formaciones flotantes de Eichornia erassipes (lirio de pantano) de flores azules que dominan grandes extensiones cubriendo la superficie de ciénagas y de aguas lentas, como p. ej. ocurre en el Valle del Cauca y en el bajo Magdalena. En forma semejante se encuentra Pistia stratiotes de flores blancas ya sola ya acompañando la anterior o con otras especies esporádicas. También las Pteridofitas Salvinia natans y Marsilia sp. cubren la superficie de lagunas o pantanos; en Puerto Carreño entre peñascos graníticos, encontré una de estas asociaciones (Salvinia y Marsilia) en una laguna cuya temperatura era de $50^{\circ} \mathrm{C}$. Planchas XXXIIXXXIV.

En las lagunas de tierra fría no faltan tampoco las hydropteridales, habiendo observado en muchos pozos o lagunitas subparameras (2000-3000 m. alt.) que tenían gran parte de la superficie o toda ella cubierta por una continua capa flotante de color verde o más comunmente rojizo, de Azolla filiculoides.
La región amazónica del sur de Colombia alcanza a desarrollar la extraordinaria Victoria regia cuyas hojas flotantes en forma de plato alcanzan más de $1 \mathrm{~m}$. de diámetro y cuyas grandes flores rosadas emergen a la superficie del agua. Formaciones de esta extraordinaria especie tropical fueron encontradas en un afluente tranquilo cerca de Leticia por R. Evans Schultes.

Frecuentes en tierra caliente son también asociaciones de Nymphaea goudotiana, Limnanthenum humboldtianum, Trapa natans y Cabomba aquatica (p. ej. Valle, $1000 \mathrm{~m}$. alt.). Comunidades monoespecíficas semisumergidas de Araceas spp. y de Carludovica son frecuentes en las zonas cálidas, en caños más o menos sombríos y de agua limpia y tranquila, p. ej. la de Urospatha sagittifolia con espatas blanquecinas y espádice violáceo, de los caños del Vaupés.

Lo mismo en tierra caliente que en tierra fría son frecuentes formaciones palustres de ciperáceas y gramíneas. Pajonales densos e inundados se pueden encontrar en todos los climas. En tierra caliente llaman la atención las formaciones sumergidas (inundadas) de la "cortadera" Lagenocarpus guianensis, de Rynchospora div. sp., así como en tierra fría forma enormes juncales en ciénagas la "totora" Scirpus californicus, Juncus bogotensis (Pl. XXXV) y otras.

Aunque no muy abundantes, existen en Colombia también formaciones acuáticas de aguas torrentosas, especialmente en las cataratas y en los raudales de los ríos orientales. Así p. ej. entre las peñas batidas por la corriente del río Vaupés, en el raudal de Yuruparí, encontré una asociación de Rhyncholacis brassicifolia y Weddellina squamulosa (Podostemonaceae). En la base del Salto de Tequendama junto a la hoya de recepción otra Podostemonácea forma una asociación rupestre de chorrera Marathrum foeniculaceum (donde la anoté en 1938). En el Chocó es frecuente en raudales Tristicha hypnoides. Dugand publicó un interesante estudio sobre la ecología de las Podostemonáceas en general y en Co. lombia (1944). 


\section{BIBLIOGRAFIA}

Barriga Villalba, A. M. - Las heladas en la sabana de Bogotá. Rev. Acad. Col. de C. E. F. y N., 9: 274-279, 1956.

Bates, M. 1948. - Climate and vegetation in the Villavicencio region of eastern Colombia. Geogr. Rev. 38 (4): 555-574.

Caldas, Francisco José. - Memoria sobre la invelación de las plantas que se cultivan en la vecindad del Ecuador. Rev. Ac. Col. C. E. F. Nat. 8: 168-172, 1951.

Chapman, Frank $M$. - The distribution of Bird-life in Colombia. Bull. of Am. Mus. of Nat. Hist. Vol. 36, 729 pages. New York 1917

Chardon, Carlos E. - Viajes y Naturaleza, 379 págs. Editorial Sucre, Caracas 1941.

Chaves, Milcíades. - La Guajira: Una región y una cultura de Colombia. Rev. Colomb. Antrop. 1: 125-152, Bogotá 1953.

Cuatrecasas, José. - Plantae Colombianae Novae. Trab. Mus. Nac. Cienc. Nat., Ser. Bot. 26, 30 págs. y 1 láms. (Lámina 1 representa el Espeletietum en el Tolima). Madrid, 15-IV1933.

Cuatrecasas, José. - Observaciones geobotánicas en Colombia Trab. Mus. Nac. Cienc. Nat., Ser. Bot. 27, 144 págs. 32 láms. Madrid 1934.

Cuatrecasas, José. - Impresiones sobre la vegetación de los Andes en Colombia. Rev. Acad. Cien. 18: 29-41 Zaragoza 1935

Cuatrecasas, José. - Zusammenfassung, en Resumen de mi actuación en Colombia con motivo del II Cent. del nacimiento de Mutis, págs. 149-156. Trabajos del Mus. Nac. de Cienc. Nat. y Jardín Bot., Ser. Bot. 33, 158 págs. y 8 láms. Madrid, julio 1936.

Cuatrecasas, José. - Resumen de unas Observaciones Geobotánicas en Colombia. Revista de la Academia Colombiana de Ciencias E. F. y Nat., 5: 289-294. Bogotá, diciembre 1943.

Cuatrecasas, José. - Vistazo a la Vegetación Natural del bajo Calima. Revista de la Academia Colombiana de Ciencias E. F. y Nat., 7: 306-312, y 6 láminas. Bogotá 1947.

Cuatrecasas, José. - New mural shows plant life of Colombia's High Andes. Bull. of Chicago Nat. Hist. Museum 19 (n. 9): 1-3, 1948.

Cuatrecasas, José. - Rosette Trees, a tropical growth form. Bull. of Chicago Nat. Hist. Museum 20 (n. 10): 6-7, 1949.

Cuatrecasas, José. - Frailejonal, típico cuadro de la vida vegetal en los páramos andinos. Rev. Ac. Col. C. E. F. y Nat. 7: 457-461, Bogotá 1950.

Cuatrecasas, José. - Notas a la Flora de Colombia XII. Rev. Acad. Colomb. C. E. F. Nat. 8: 464-488, Bogotá 1952.

Cuatrecasas, José. - Synopsis der Gattung Loricaria Wedd. Feddes Repertorium 56: 150-172 Tafl. 1, Berlín 1954.

Cuatrecasas, José. - Outline of vegetation types in Colombia. VIIIe Congres International de Botanique. Rapports et Communications, Sect. VII: 77. París 1954.

Cuatrecasas, José. - Distribution of the genus Espeletia. VIII ${ }^{\mathrm{e}}$ Congres International de Botanique, Raports et Communications, Sect. IV: 131, París 1954.

Cuatrecasas, José. - Esquema sumario de la vegetación de la "Provincia Norteandina". Suelos Tropicales 1: $13-30$ con 8 láminas. Medellín, 1956.

Cuatrecasas, José. - A sketch of the vegetation of the NorthAndean province (Summary). Proceedings of the Eight Pacific Science Congress, vol. IV, Botany, págs. 167-173. Quezon City, 1957.

Daniel, $H$. - Aspectos de una Flora 15 págs. Medellín 1939.

Daniel, H. - Una Ascensión al Cerro de "La Vieja". 14 págs. Medellín, 1940.

Daniel, H. - Apuntes sobre la Flora de Antioquia. Medellín, 1942.
Diels, L. - Pflanzengeographie. 3. Augl., Sammlung Goeschen. 159 págs. Berlín \& Leipzig 1921.

Dugand, Armando. - The transition forests of Atlántico, Colombia. TROPICAL WOODS, 40: 1-14. 1934.

Dugand, Armando. - Estudios Geobotánicos Colombianos (Descripción de una sinecia típica en la subxerofitia del Litoral Caribe) Revista de la Academia Colombiana de Ciencias E. F. y Nat., vol. 4: 135-141 y 2 láminas. Bogotá julio 1941.

Dugand, Armando. - Apuntaciones sobre el medio en general y la vegetación en Colombia. Revista trimestral de la Universidad Nacional 1: 307-343. Bogotá, octubre 1944.

Dugand, Armando. - Nuevos conceptos biotipológicos y ecológicos en la Hydrophytia y breve sinopsis de la Flora podostemonácea de Colombia. Revista Academia Colombiana de Ciencias E. F. y Nat., VI: 28-31 Bogotá, diciembre 1944.

Dugand, Armando. - On the vegetation and plant resources of Colombia. In Verdoorn's Plants and Plant Science in Latin America, 289-293. Waltham, 1945.

Dugand, Armando. - Aves del Departamento del Atlántico, Colombia (introducción ecológica geográfica, págs. 497-546). Caldasia, 4: 499-648, 1947.

Fosberg, F. R. - El Páramo de Sumapaz. Colombia. Journ. New York Bot. Gard. 45: 226-234 (1944).

Guhl, Ernesto. - La Costa del Pacífico entre los ríos Dagua y Naya. Bol. Soc. Geogr. Colomb. 7: 100-112. Bogotá, 1948.

Hammen, Thomas van der. - El desarrollo de la Flora Colombiana en los períodos geológicos. Bol. Geológico 2, n. 1: 49-106 pl. 1-7 y 1-21, Bogotá, 1954.

Holdridge, L. R., Little, E. L. Jr. and others. - The forests of western and central Ecuador, Forest Service, United States Department of Agriculture. 134 págs. and 2 maps. Washington, 1947.

Howe, Marshall A. - A little-known Mangrove of Panamá. Journ. New York Bot. Card., vol. XII, págs. 61-72, April 1911.

Jenny, Hans. - Great soil groups in the equatorial regions of Colombia, South América. Soil Science 66: 5-28 (1946).

Knoch, K. - Klimakunde von Südamerika. Berlín, 1930.

Lauer, Wilhelm. - Humide u aride Jahreszeiten in Afrika und Suedamerika u ihre Beziehungen zu den Vegetationsgürteln. Bonner Geogr. Abhand. 9: 15-98. Bonn, 1952.

Little, E. L., Jr. - A collection of tree specimens from western Ecuador. The Caribbean Forester, 9: 215-298 ( $\left.\mathrm{N}^{0} 3\right)$ Puerto Rico, 1948.

Llano, Manuel del. - Planeamiento regional de Colombia con fundamento ecológico. Suelos Ecuatoriales 1: $39-45$ ocho lá minas y un mapa. Medellín 1956.

Merizalde del Carmen, P. Bernardo. - Estudio de la Costa Colombiana del Pacífico, 248 págs. Bogotá, 1921.

Moldenke, H. N. - The known geographic distribution of the member of the Verbenaceae and Avicenniaceae. New York City, 1942.

Murillo, Luis María. - Colombia, un archipiélago biológico. Documentos para un estudio ecológico del país. Rev. Ac. Col. de C. E. F. y N. VIII: 168-220, 1951; VIII: 409-431, 1951; IX: 1-XX, 1956.

Murphy, R. C. - The littoral of Pacific Colombia and Ecuador. The Geographical Review, 29: 1-33 (1939).

Oppenheim, O. - Geología de la Costa Sur del Pacífico de Colombia. Inst. Geogr. Boletín N 1 Bogotá 1949.

Patiño, V. M. y colaboradores. - Presentación del Calima. 162 págs. Cali, 1946. 
Patiño, V. M. - Estación Agro-Forestal del Pacífico de CalimaBuenaventura. Publ. Secret. Agr. y Fom., Cali, 1948.

Pérez, Arbeláez, E. - Plantas útiles de Colombia. Bogotá, 1947; Madrid, 1956.

Pérez, Arbeláez, E. - Hilea Magdalenesa (Prospección Económica del Valle Tropical del Río Magdalena). Contraloría General de la República. Bogotá, 1949.

Ruebel, E. - Pflanzengesellschaften der Erde. Bern-Berlín, 1930.

Salvoza, F. M. - Rhizophora. Natural and Applied Science Bulltin. Univ. of Philippines, vol. 211. Manila, 1936.

Schaufelberger, $P$. - Apuntes geológicos y pedológicos de la zona cafetera de Colombia 296 págs. Manizales, 1944.

Schimper, A. F. und Faber, F. C. von. - Pflanzengeographie auf Physiologischer Grundlage, 3 Aufl., 2 vols. Jena, 1935.

Schmidt, $R$. Dietrich. - Die Niederschlagsverteilung in andinen Kolumbien. Bonner Geogr. Abhand. 9: 99-119. Bonn, 1952.

Schroeder, Rudolf. - Die Verteilung der mittleren Lufttemperatur in Kolumbien. Bonner Geogr. Abhand 9: 120-123. Bonn, 1952.

Schultes, Richard E. - Plantae Colombianae IX, Nova species Senefelderae. Caldasia 3 ( $\left.\mathrm{N}^{9} 12\right)$ : 121-130. 1944.

Schultes, Richard E. - La riqueza de la Flora Colombiana. Rev. Acad. Col. de C. E. F. y N. 8: 230-241; láminas y figuras. 1951.

Schultes, Richard E. - La familia de la Velloziáceas en Colombia. Rev. Ac. Col. de C. E. F. y N. 8: 458-463 y 4 láms. 1952.

Schultze, Arnold. - Flammen in der Sierra Nevada de Santa Marta. Mitteilungen der Geogr. Gasell. in Hamburg 45: 59-226, 1 map and 13 plates. Hamburg 1937.

Schultae, Rohnhof, Arnold. - Plfanzengeographische Beobachtungen aus den Regenwaeldern von Ecuador und den angrenzenden Gebieten von Colombia. Botanische Jahrbuecher; 75, 2: 221-272 Stutgart 1950.
Servicio Geológico Nacional. - Mapa Geológico general de la República de Colombia a escala 1: 2.000 .000 y breve explicación. Comp. Est. Geol. Ofic. en Colombia Tom. VI-Anexo I. Bogotá, 1945.

Smith, Albert C. \& Koch, M. F. - The genus Espeletia: a study in phylogenetic taxonomy. Brittonia 1: 479-530, 2 pl., 1935.

Troll, Carl. - Der asymmetrische Aufbau der Vegetationszonen und Vegetations-stufen auf der Nord und Südhalbkugel. Ber. Geobet. Forch. Rübel Zürich Jahr 1947: 46-83. Zürich, 1948.

Troll, Carl. - Das Pflanzenkleid der Tropen in seiner Abhängkeit von Klima, Boden und Mensch. Deutscher Geographentag Frankfurt 28: 35-66. Frankfurt 1952.

Troll, Carl. - Die Lokalwinde der Tropengebirse u ihr Einfluss auf Niederschag u Vegetation. Bonner Geogr. Abhand. 9: 124-182. Bonn, 1952.

Troll, Willhelm. - Die Mangrovengewaechse in "Vergleichende Morphologie der hoeheren Pflanzen" Vol. I, part 3, BerlínZehlendorf, 1942.

Vareschi, Volkmar. - Sobre las superficies de asimilación de Sociedades Vegetales de Cordilleras tropicales y extratropicales. Boletín Soc. Venez. Cienc. Nat. 14: 121-173. Caracas, 1953.

Vergara y Velasco, F. G. - Nueva Geografía de Colombia. Bogotá, 1901.

Vergara y Velasco, F. J. - Las Regiones Naturales de Colombia, publicado por L. M. Murillo en Archipiélago Biológico, Rev. Acad. Col. de C. E. F. y N., 8: 409-431, 1951.

Verdoorn, F. (editor). - Plants and Plant Science in Latin América. Waltham, 1945.

Vila, Pablo. - Nueva Geografía de Colombia 358 págs. y 1 map. Librería Colombiana, Bogotá, 1945.

Weddell, H. A. - Chloris Andina, 2 vols. París, 1855-1857.

\section{G L O S A R IO}

\section{Acaulirrósula}

Plantas con hojas arrosetadas a ras del suelo.

\section{Aciculifolias}

Plantas con hojas en forma de aguja (aciculares), como los pinos.

Asocietas, asocies

Varias especies que comparten el dominio de una asociación.

\section{Bioma}

Conjunto de todos los seres, vegetales y animales, que forman una comunidad biológica estabilizada.

\section{Biotipo}

Forma biológica, tipo biológico.

\section{Casmófitas}

Plantas que prosperan en las fisuras de las rocas.

\section{Caulifloras}

Plantas que presentan las flores directamente sobre el tallo o ramas gruesas.

\section{Caulirrósula}

Planta de tallo recto y simple terminado por un penacho o roseta de hojas.

\section{Caulirrosuletum}

Formación o agrupación de plantas de tipo caulirrósula.

\section{Climácico}

Que corresponde a la clímax.

Climax

Estado espontáneo de la vegetación natural de una región cuando ha adquirido el máximo desarrollo (mayor masa) posible en las condiciones de su clima con caracteres de estabilidad.

\section{Consocietas, consocies}

Dominancia de una sola especie en una asociación.

Corológico

Relativo a la distribución geográfica de las plantas.

\section{Criptofruticetum}

Formación de plantas criptofrútex. Sinónimo de criptolignetum.

Criptofrútex (cryptofrutex)

Arbustito rastrero cuyos tallos se ocultan entre el suelo y los residuos vegetales acumulados sobre el suelo. 
Disclimácico

Relativo a una condición distinta de la clímax, originada por la destrucción total o parcial de la vegetación espontánea.

Ecología (vegetal)

Estudio de las relaciones o interdependencia de las plantas con el medio

Edáfico

Relativo al suelo.

Epífita

Planta que vive encima de otra planta que le sirve de soporte o casa, sin parasitar o vivir de ella.

Esclerofilas

Plantas de hojas gruesas y coriáceas.

Especiación

Proceso de formación o de diferenciación (derivación) de nuevas especies.

\section{Esquema biotipológico}

Representación esquemática o tabular de la cantidad o del porcentaje de cada uno de los tipos biológicos presentes en una comunidad vegetal. Sinónimo de "espectro biológico".

Formación

Asociación vegetal caracterizada por la forma biológica dominante, p. ej. bosque, matorral.

\section{Formas biológicas}

Categorías en que se clasifican las plantas según su estructura vegetativa independientemente de su posición sistemática, por ejemplo: hierba, bejuco, árbol, caulirrósula, etc. Sinónimo de biotipo y de tipo biológico.

Fúlcreos

Raíces sostén que nacen oblicuas sobre la base del tallo y forman como una armazón cónica. También "zancos" o "sancos".

\section{Halófilas}

Plantas que prosperan en suelos salinos.

Halófobas

Plantas que no pueden prosperar en suelos con sal.

\section{Heliófilas}

Plantas que buscan la luz, amantes de lugares abiertos.

Hidrófilas

Plantas acuáticas o semiacuáticas.

Higrófilas

Plantas adaptadas a la humedad.

\section{Higrofitia}

Sector y tipo de vegetación de países lluviosos con abundantes precipitaciones durante todo el año.

\section{Leptofilas}

Hojas muy pequeñas, de menos de $25 \mathrm{~mm}^{2}$. de superficie (escala de Raunkiaer).

\section{Macrofilas}

Hojas grandes, de superficie entre 18225 y $164025 \mathrm{~mm}^{2}$. (escala de Raunkiaer).
Megafilas

Hojas muy grandes, como las del plátano, por ejemplo.

\section{Megatermas}

Plantas que prosperan a temperatura elevada durante todo el año, con mínima media mensual de $16^{\circ}$.

\section{Mesofilas}

Hojas de tamaño mediano, de superficie entre 2025 y $18225 \mathrm{~mm}^{2}$. (escala de Raunkiaer).

\section{Mesotermas}

Plantas que prosperan a temperaturas con mínima mensual entre $0^{\circ}$ y $16^{\circ}$, tolerando poco temperaturas inferiores.

\section{Microclima}

Factores climáticos que recaen en la limitada estación en que vive la planta.

Microfilas

Hojas pequeñas de superficie entre 225 y $2025 \mathrm{~mm}^{2}$. (escala de Raunkiaer).

\section{Microtermas}

Plantas que viven en países fríos o con largos períodos invernales con heladas y nevadas.

Nanofilas

Hojas pequeñas, de superficie entre 25 y $250 \mathrm{~mm}^{2}$. (escala de Raunkiaer).

\section{Neumatóforo}

Raíces desarrolladas fuera del suelo, con función respiratoria, en forma de bujía, fúlcreo, codo, etc.

Nortandina (área)

El área de la región norte de los Andes que abarca Colombia, Ecuador y la parte andina de Venezuela.

Parásito

Planta que vive de otro, que toma su alimento de otro ser viviente.

\section{Pulvinetum}

Conjunto de plantas del tipo biológico en almohadilla (pulvinulum).

Raíz bujía

Raíz terrífuga, que emerge del suelo con un brote de esparraguera o aparentando una bujía.

Raíz terrífuga

Raíz con geotropismo negativo, que crece para arriba, saliéndose del suelo, como en ciertas especies de los manglares y de lugares pantanosos (p. ej. el iguanero, el naidí, el machare).

\section{Simorfia}

Conjunto de los elementos de una sinecia o de una comunidad vegetal, que presentan la misma forma biológica. Por ejemplo las hierbas de un robledal, que forman la simorfia herbetum.

Sinecia

Conjunto de todas las plantas que viven reunidas formando una agrupación homogénea, definida por la morfología de los componentes. 
Subhigrofitia

Sector y tipo de vegetación de países lluviosos con un corto período seco o muy poco lluvioso.

\section{Subserial}

Estado de la vegetación, alterada, en una etapa alejada de la climácica.

\section{Tropandina (área)}

El área que abarca los Andes tropicales, es decir las regiones andinas comprendidas entre los dos círculos tropicales.

\section{Tropófitas}

Plantas que pierden la hoja en una estación del año desfavorable, que pueden ser por causa de excesivo frío o de excesiva sequedad.

\section{Truncifloras}

Plantas que presentan las flores directamente sobre el tronco.

Xerófitas

Plantas que prosperan en lugares secos.

\section{Xeromorfas}

Plantas de estructura adecuada para prosperar en lugares secos. 


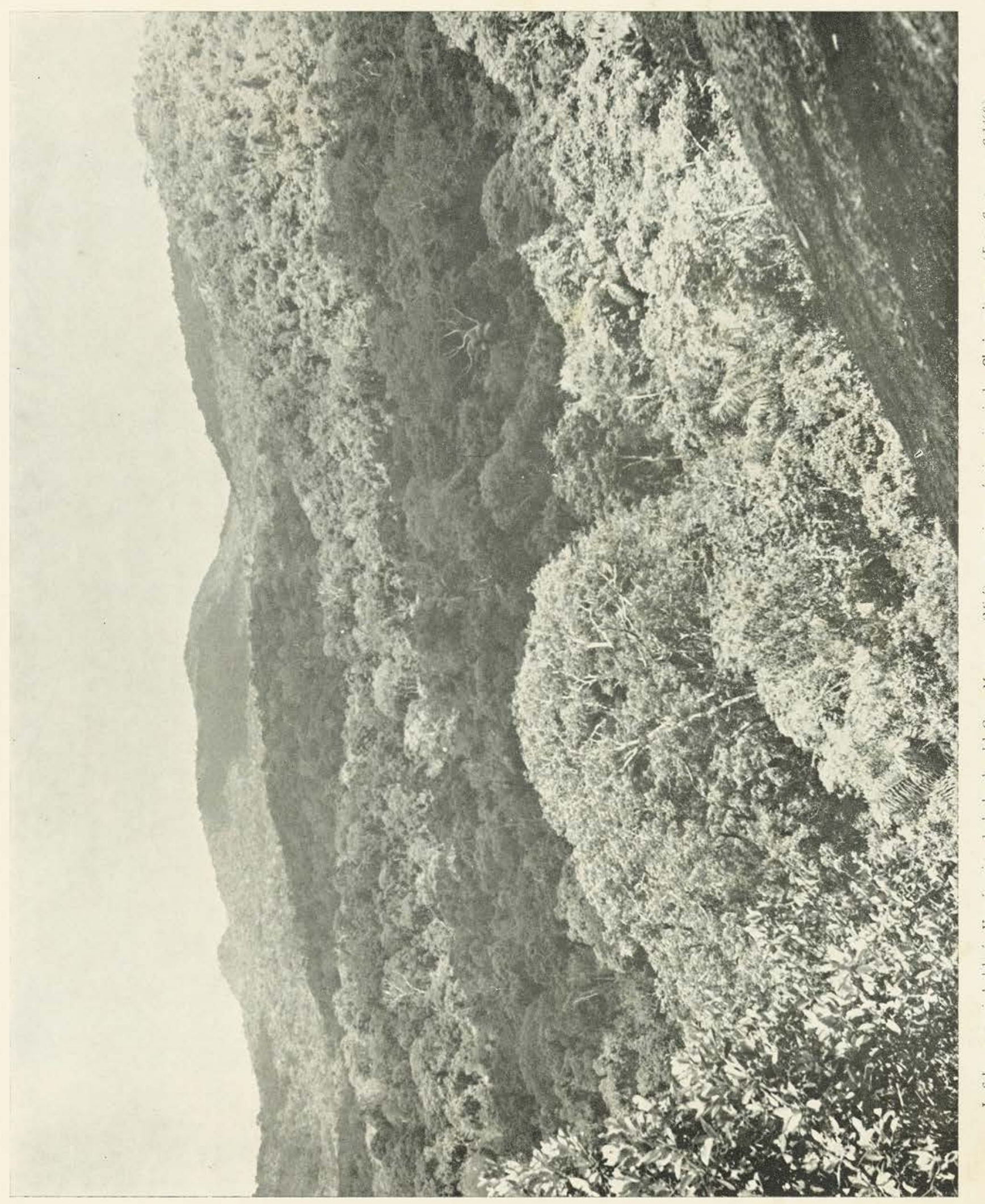




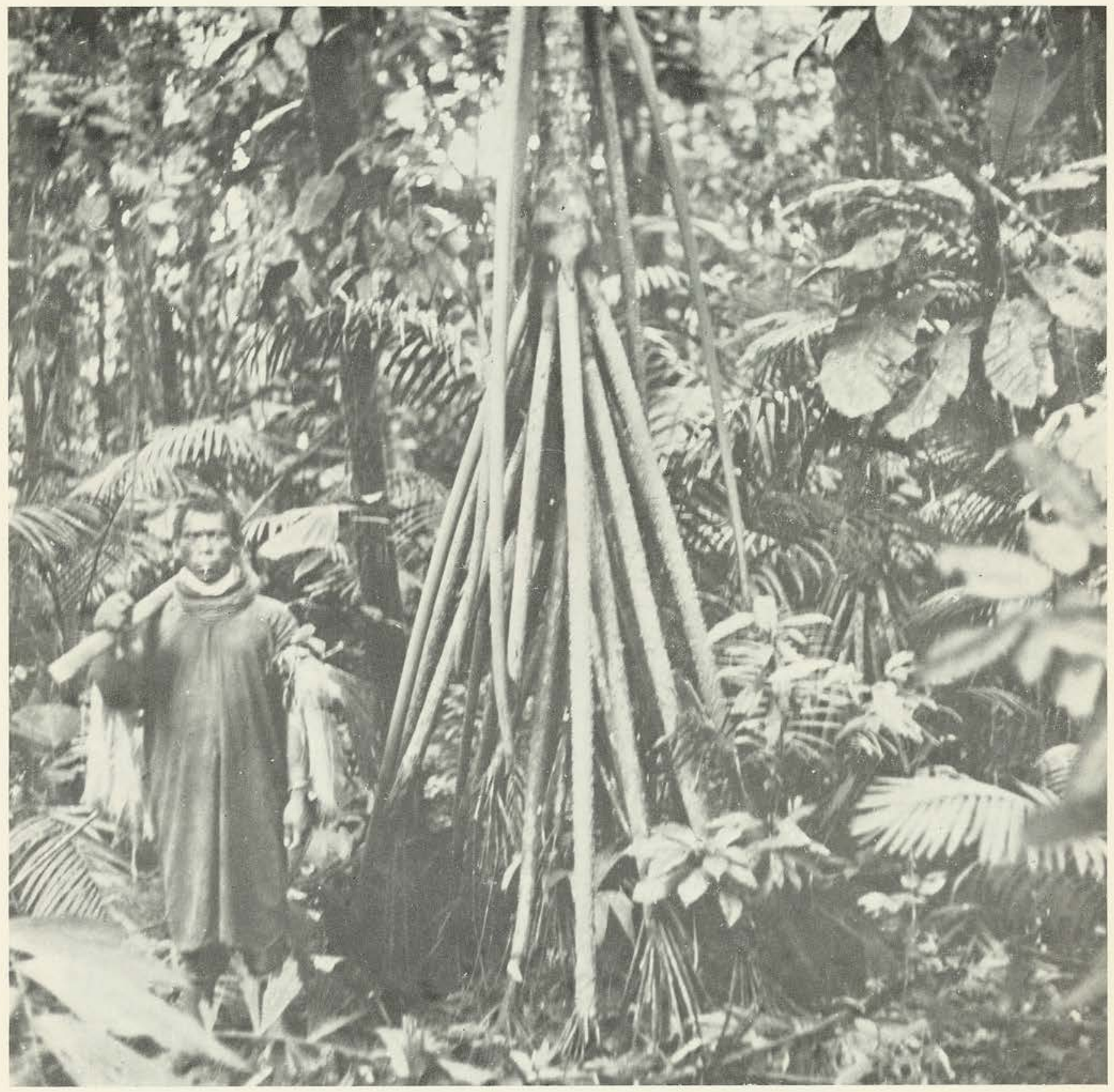

II-Selva neotropical del río Putumayo, con el cono de fúlcreos típico de Socratea elegans. Fimpollo de Gustavia sp. con un penacho de grandes hojas. Un indio Kofán. (Foto Cuatrecasas 1-581). 


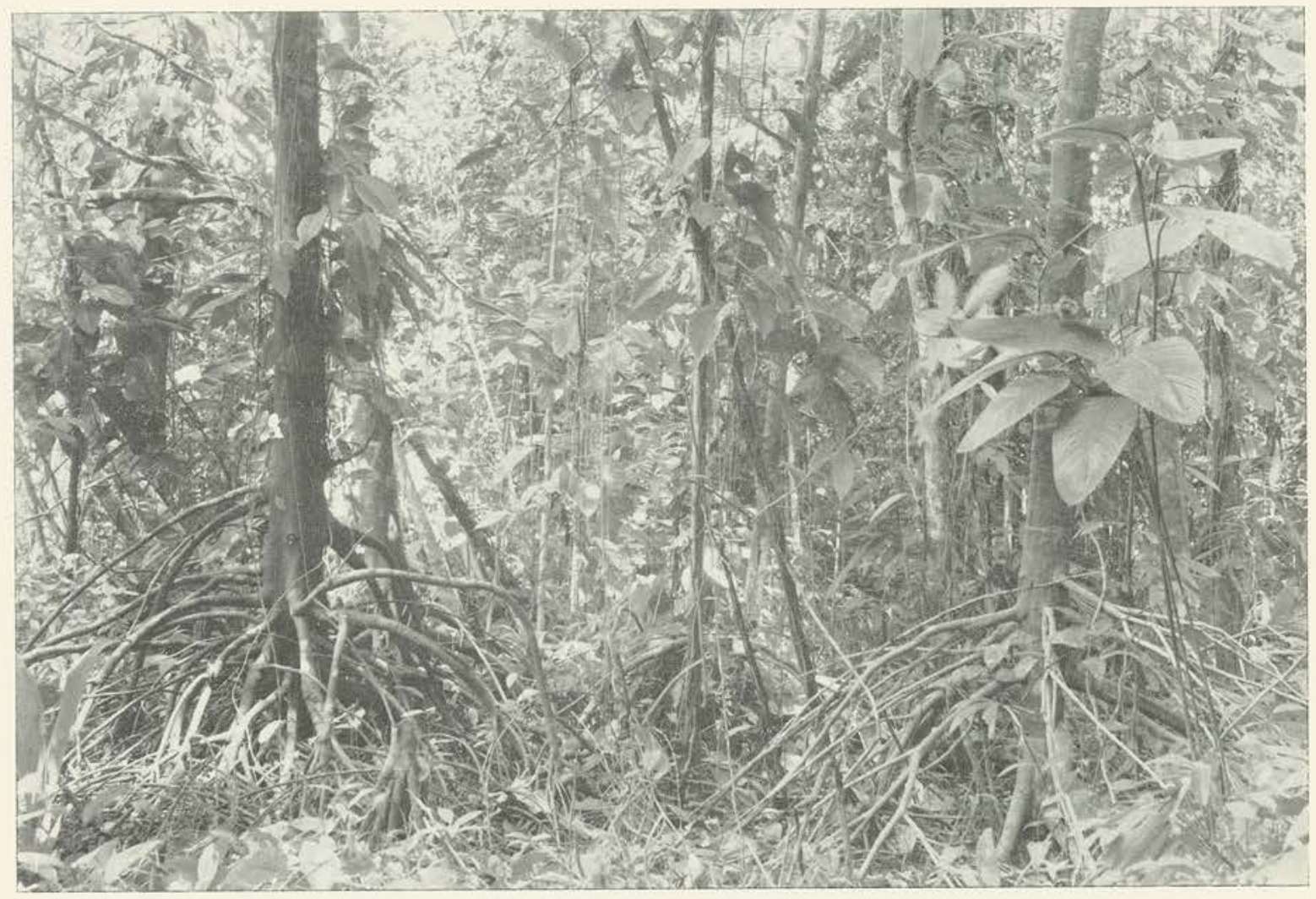

III-1 - Aspecto de una asociación de Tovomita rhizophoroides, exhibiendo sus típicas raíces epigeas, en la selva neotropical pantanosa de la Costa del Pacífico, que sucede en el interior a los manglares. (Foto Cuatrecasas C-2082).

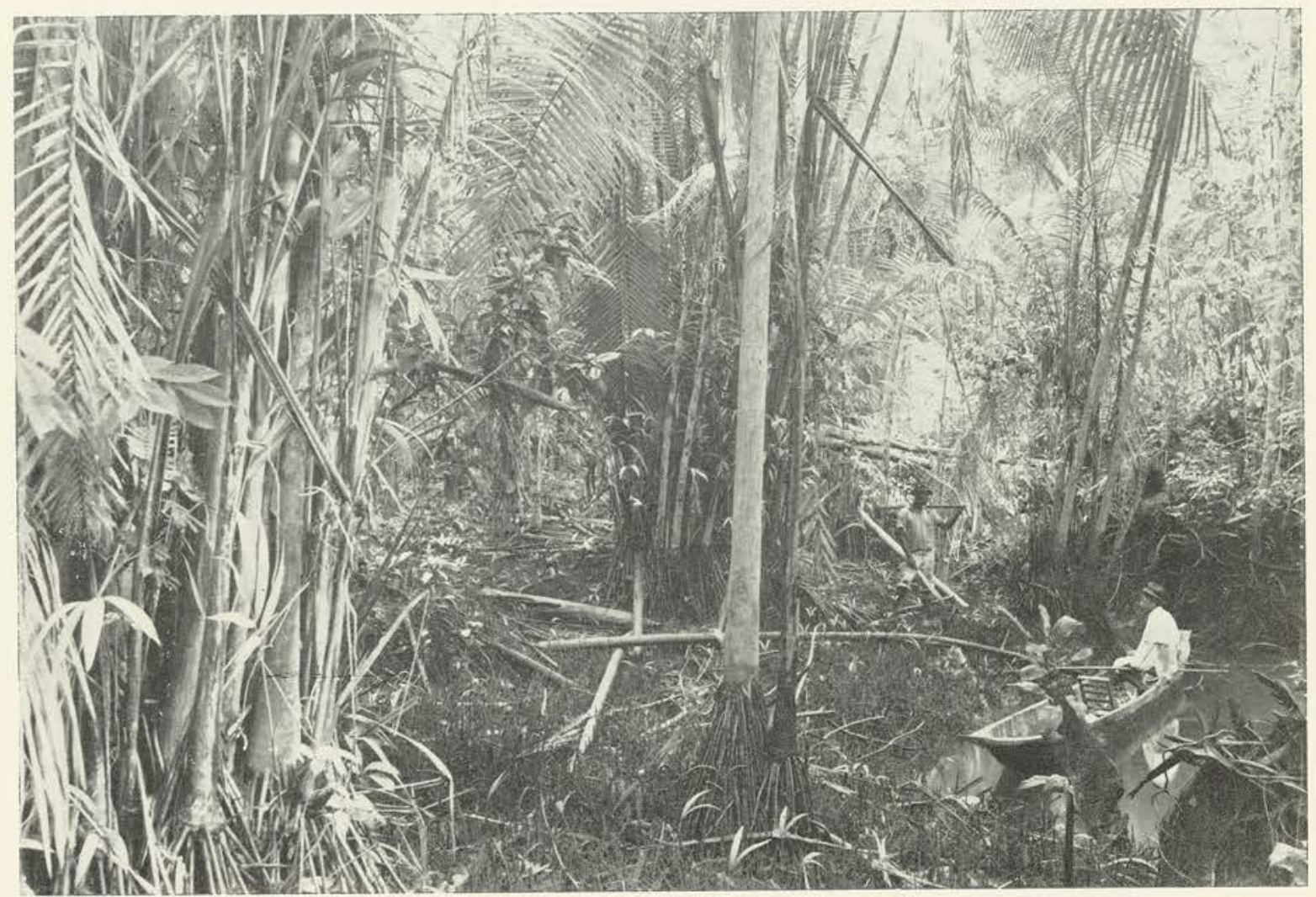

III-2 - Gregies de Euterpe cuatrecasana en la asociación Moretum oleiferae de la Costa del Pacífico, río Yurumanguí. Obsérvense los típicos fúlcreos y las raices terrífugas en bujía. (Foto Ctatrecasas C-2198). 


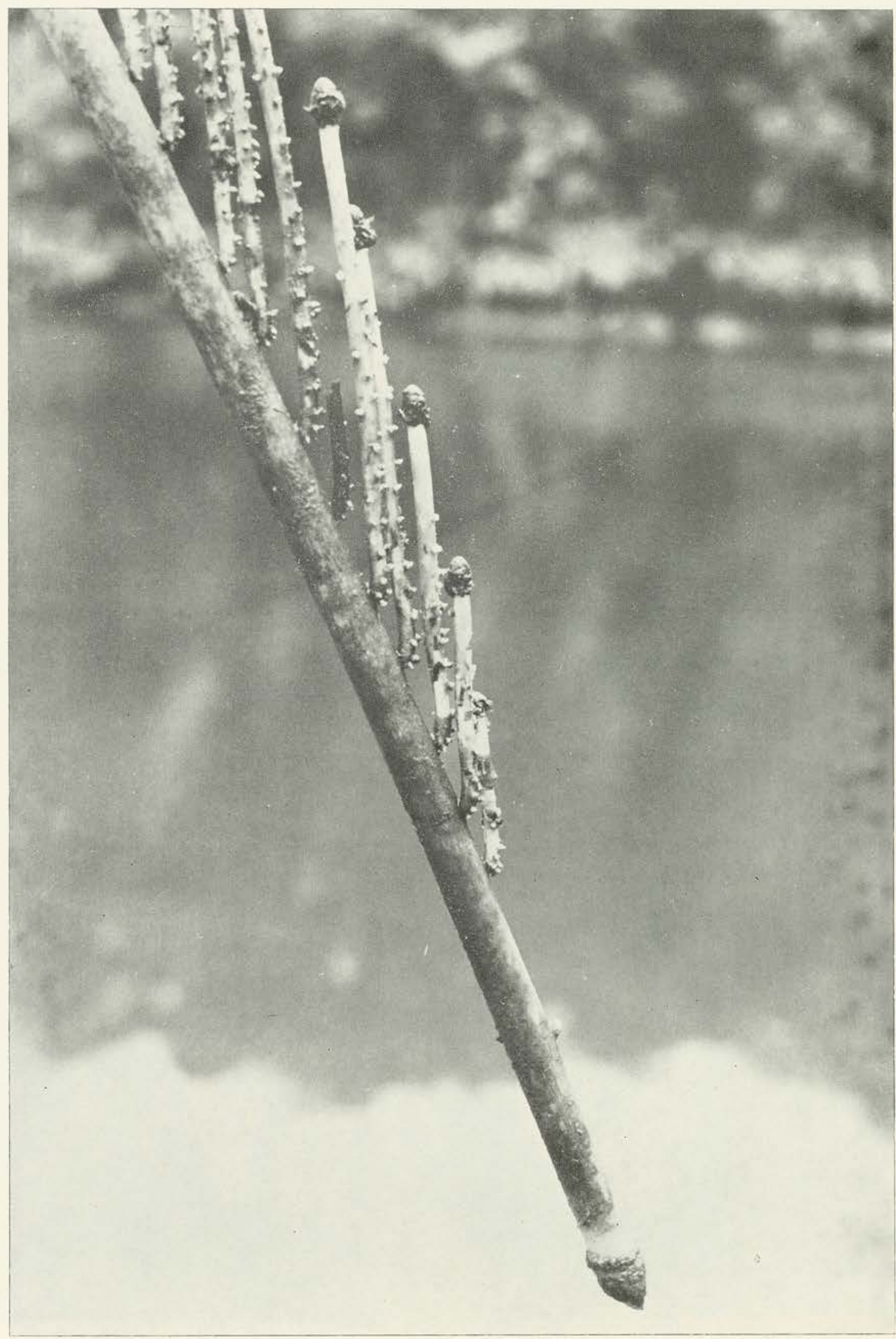

IV-Raíz geotrópico-positiva, inclinada, (normal) de Euterpe cuatrecasana (naidí) mostrando el nacimiento de ramas geotró. pico-negativas (ascendentes), las raíces terrífugas en bujía, también llamadas neumatóforos. (Foto Cuatrecasas C-2205). 


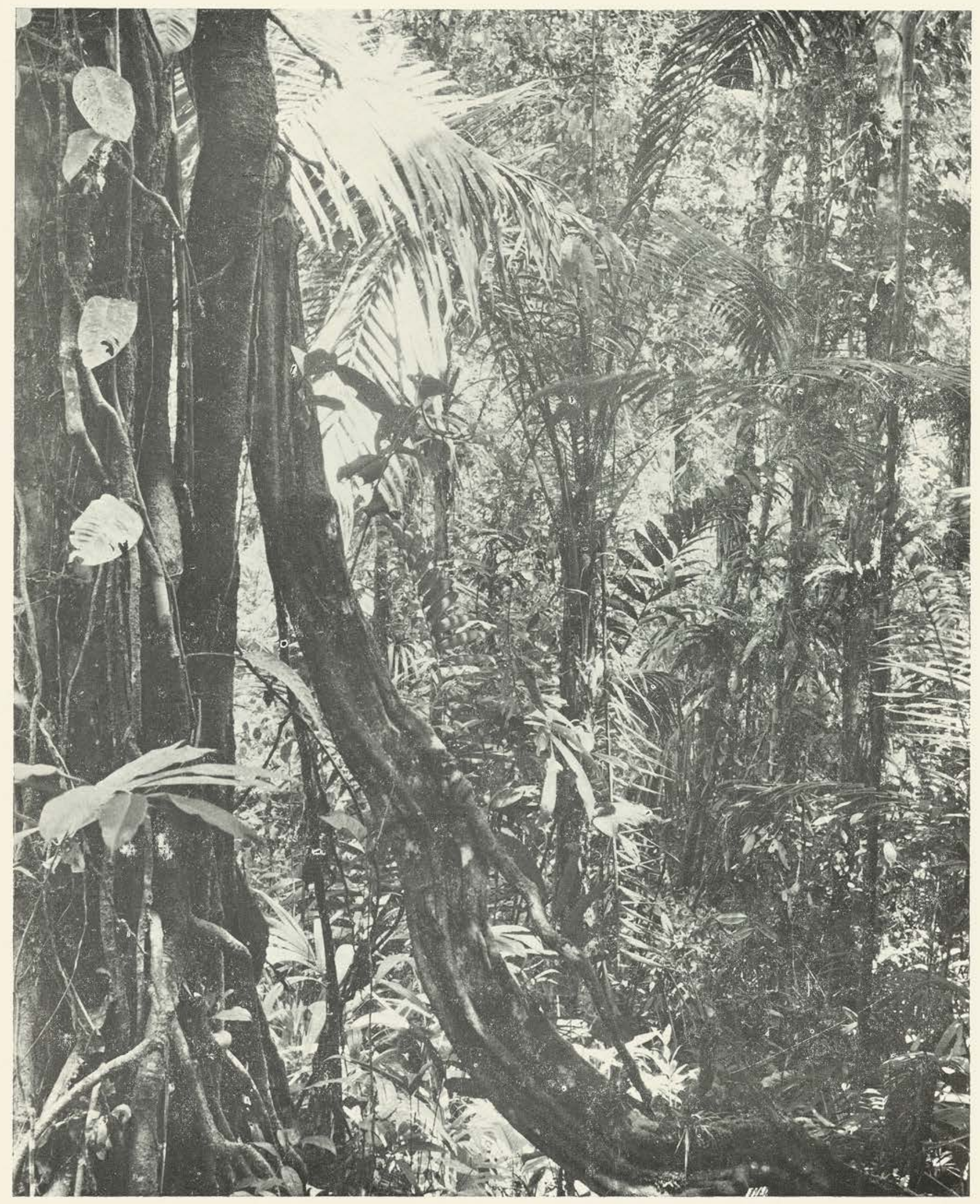

V-Selva neotropical de la Costa del Pacífico, río Yurumanguí. A la izquierda el tronco de un guasco (Eschweilera sp.) y tallos trepadores epífitos de Clusia sp.; palmas jóvenes de Welfia regia y Wettinia quinaria y un gran bejuco, el "rayo" (Abuta colombiana). (Foto Cuatrecasas C-2057). 


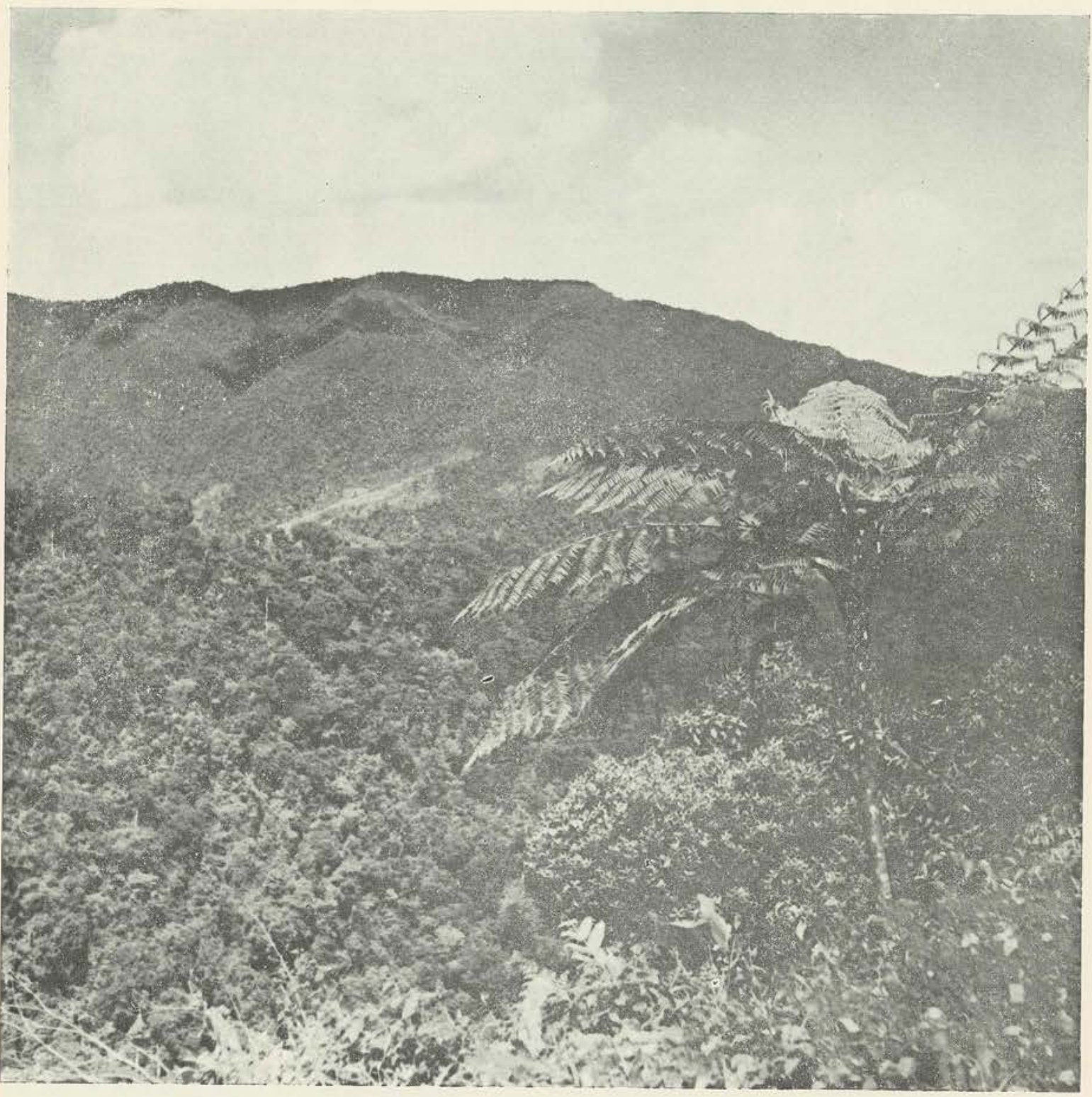

VI-La selva subandina en la Hoya del río Anchicayá-Dígua, a $1.350 \mathrm{~m}$. alt. En primer término un helecho arbóreo de Alsophila sp. (Foto Cuatrecasas 1-1974) 


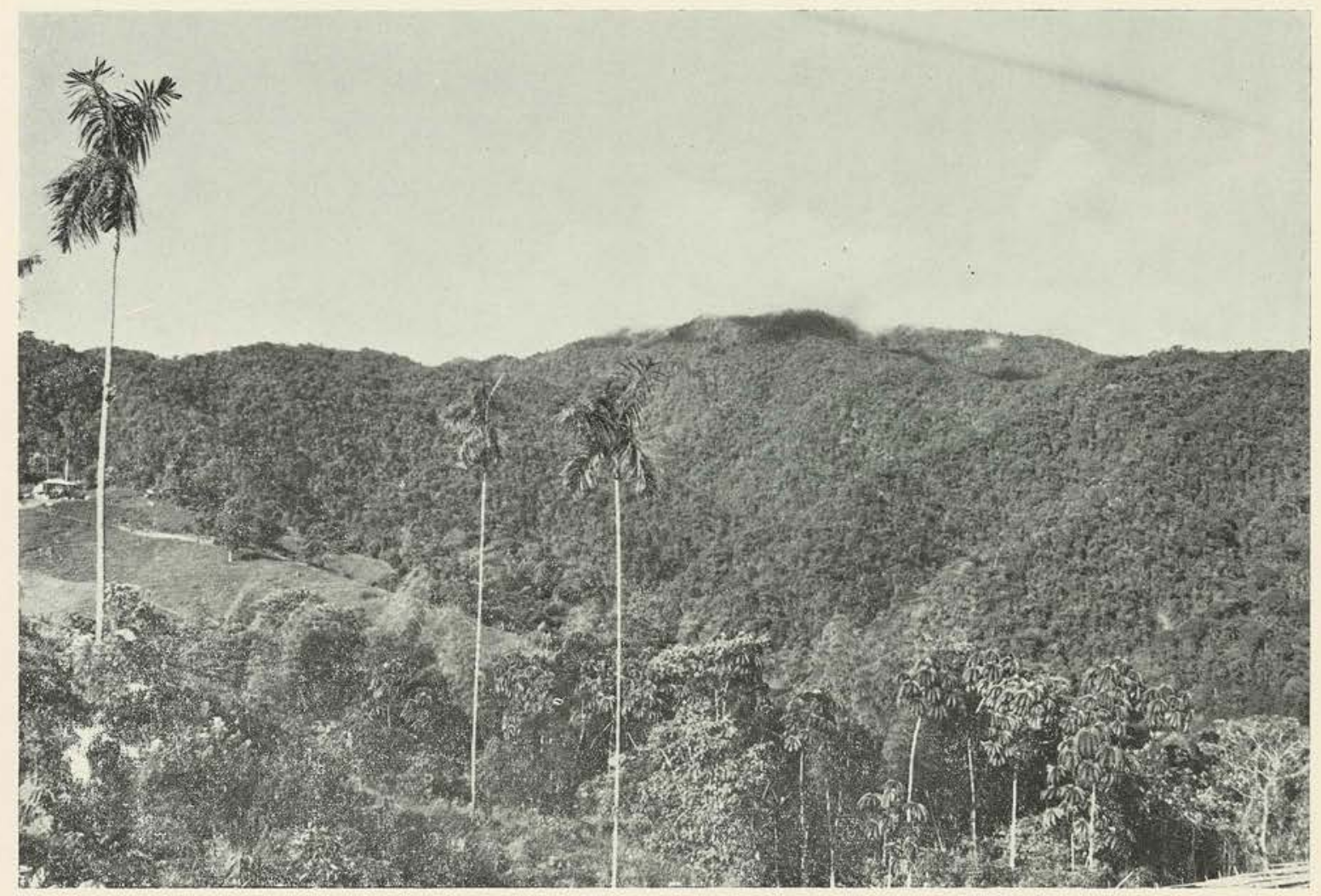

VII-1 - Selva nestropical subandina, en la Cordillera Occidental. En primer término a $\pm 1.100 \mathrm{~m}$. alt. palmas de Catostigma inconstans, Cecropia megastachya (yarumos con grandes hojas palnaadas) y guaduas conspicuas. (Foto Cuatrecasas C-2116).

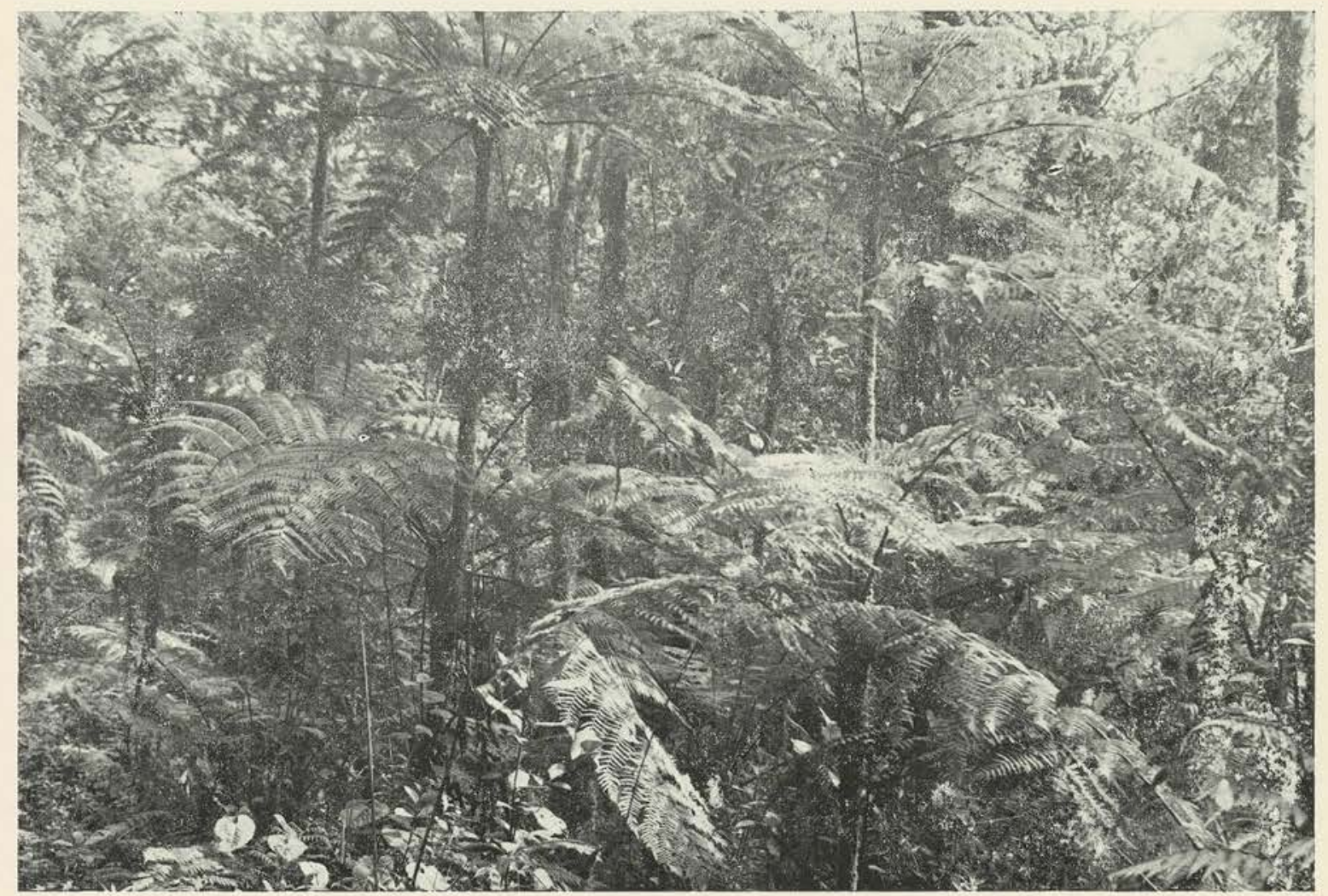

VII-2 - Formación de helechos arbóreos, en el sotobosque de la selva subandina. Cordillera Oriental, región del Sarare, $2.100 \mathrm{~m}$. alt. (Foto Cuatrecasas C-1871). 


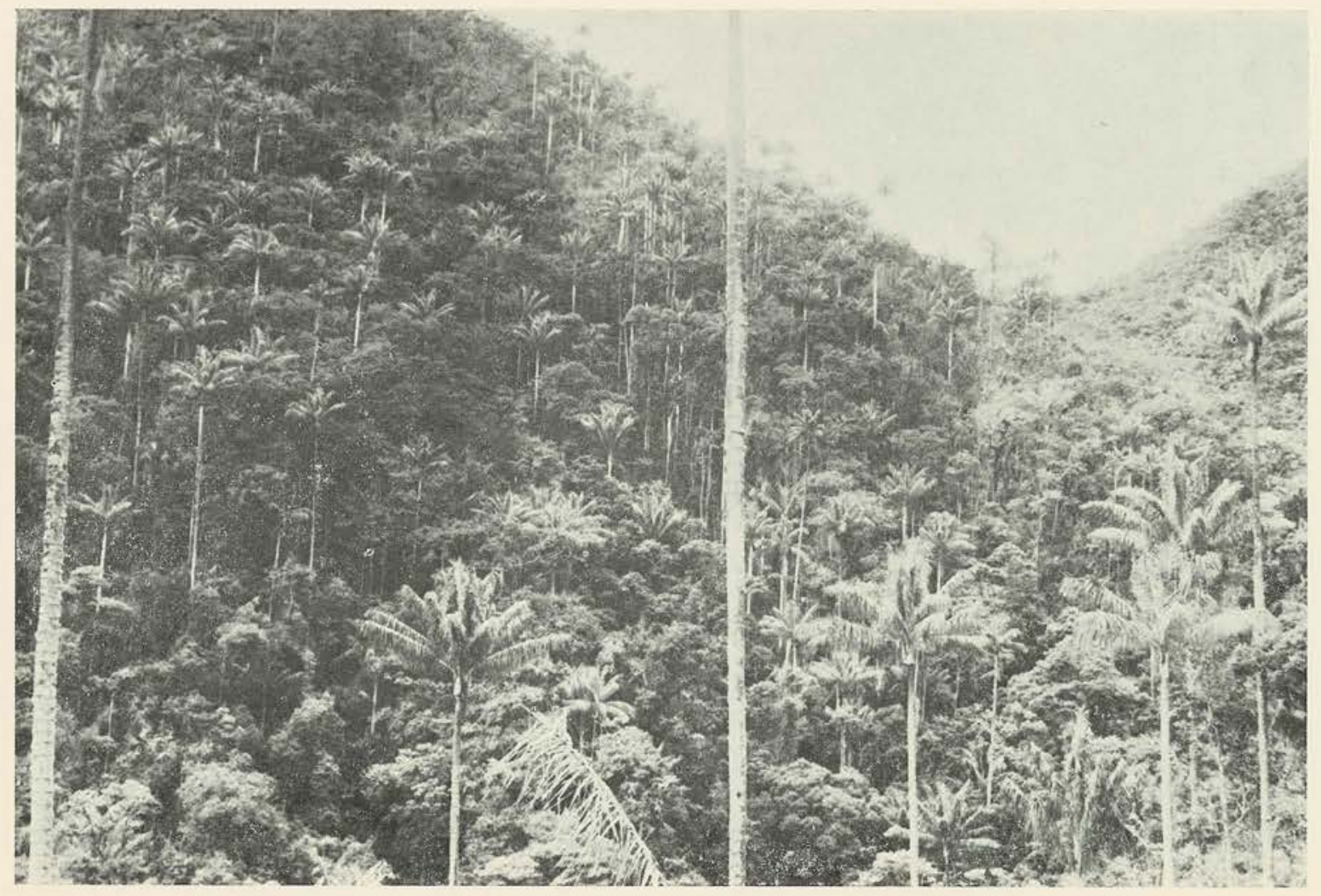

VIII-1 - Cordillera Central, Cauca, Hoya del río Palo, 2.600-2.700 m. alt. Bosque andino densamente salpicado por palmas de Ceroxylon. (Foto Cuatrecasas C-2341).

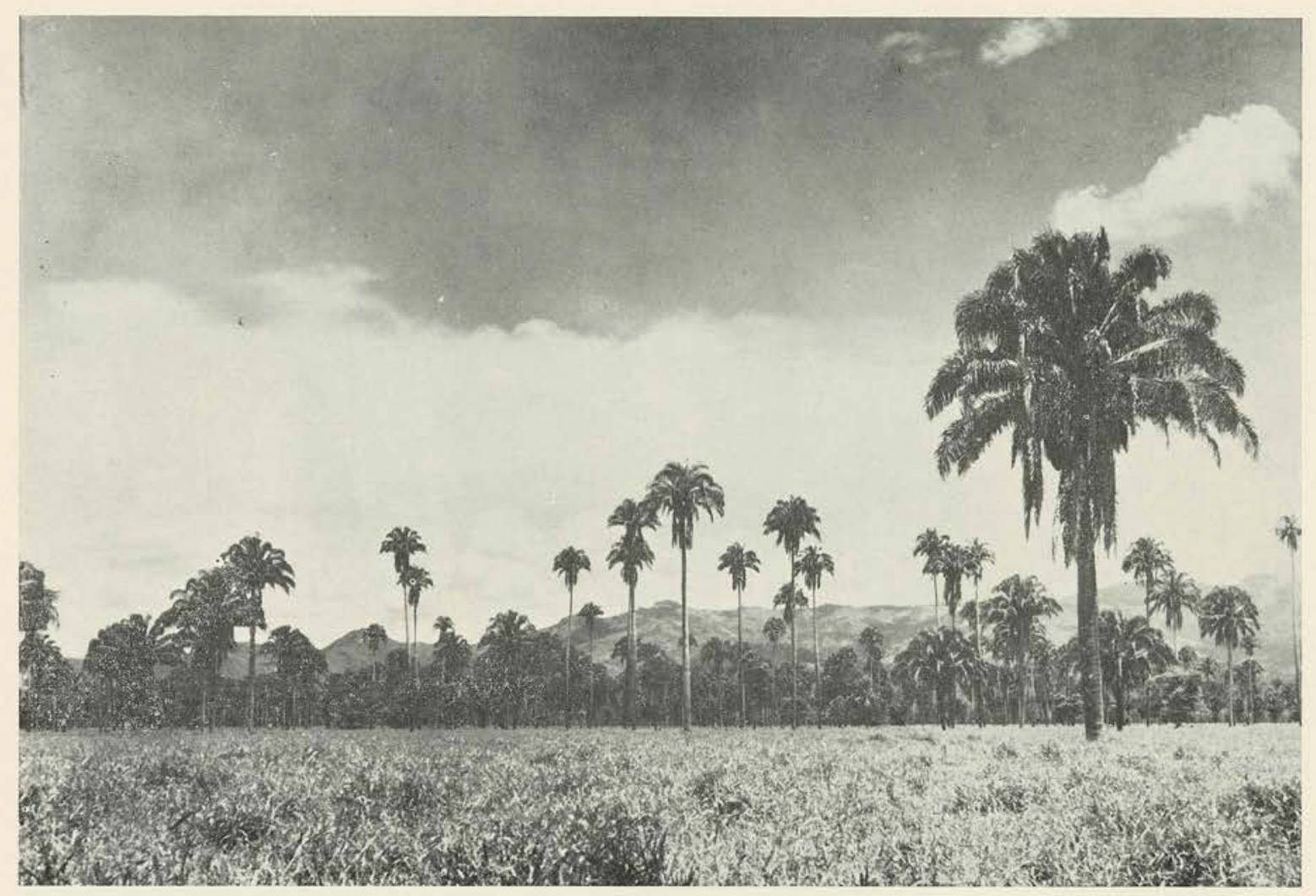

VIII-2 - Valle del Cauca, $1.000 \mathrm{~m}$. alt. "Corosal", formación de Scheelea butyracea (Mutis) Karsten, "palma de puerco" o "coroso de puerco". (Foto Cuatrecasas C-2434). 


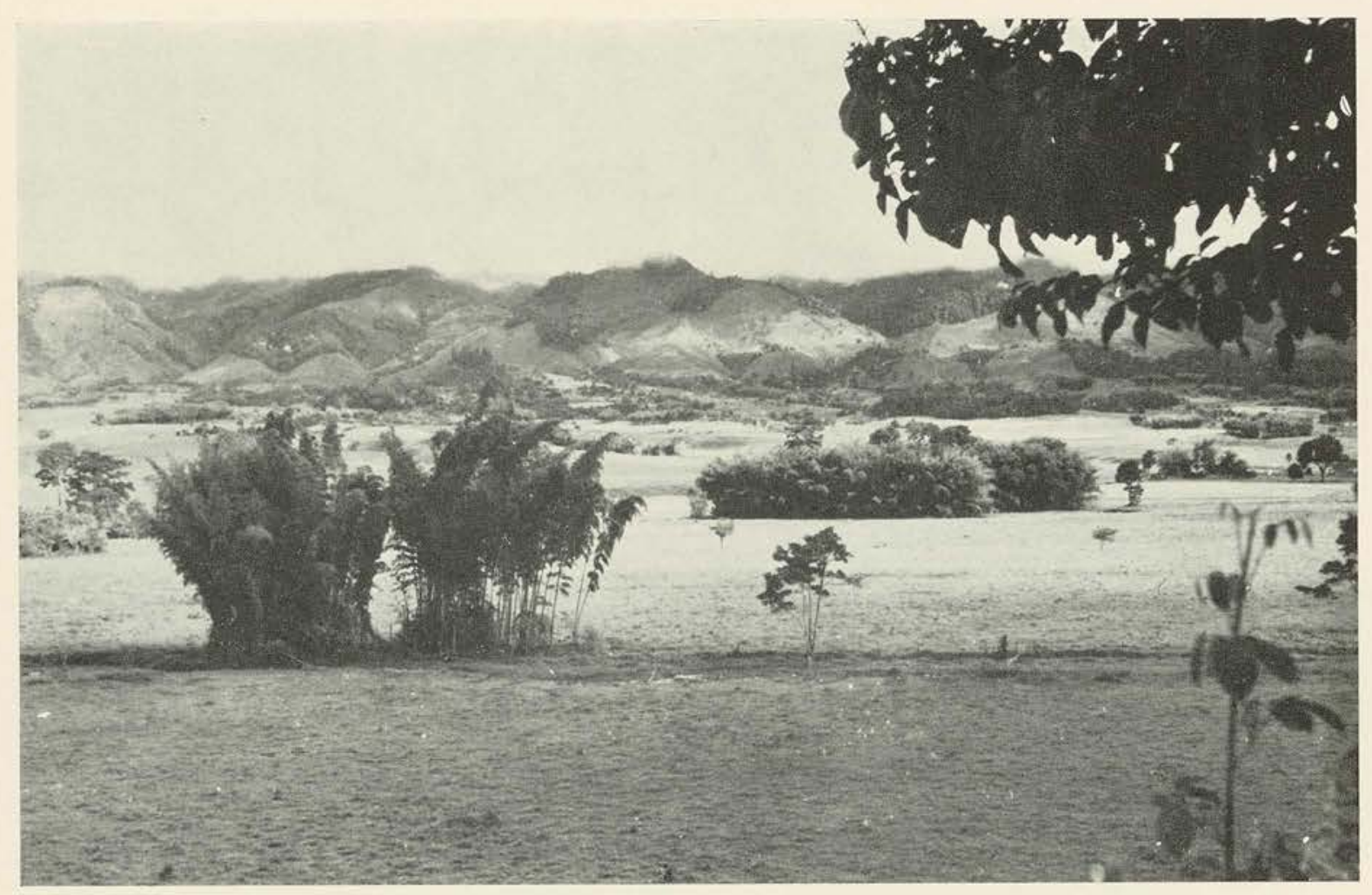

IX-1 - Alto Calima, entre Restrepo y Darién, paisaje de guaduales. (Foto Cuatrecasas 1-1658).

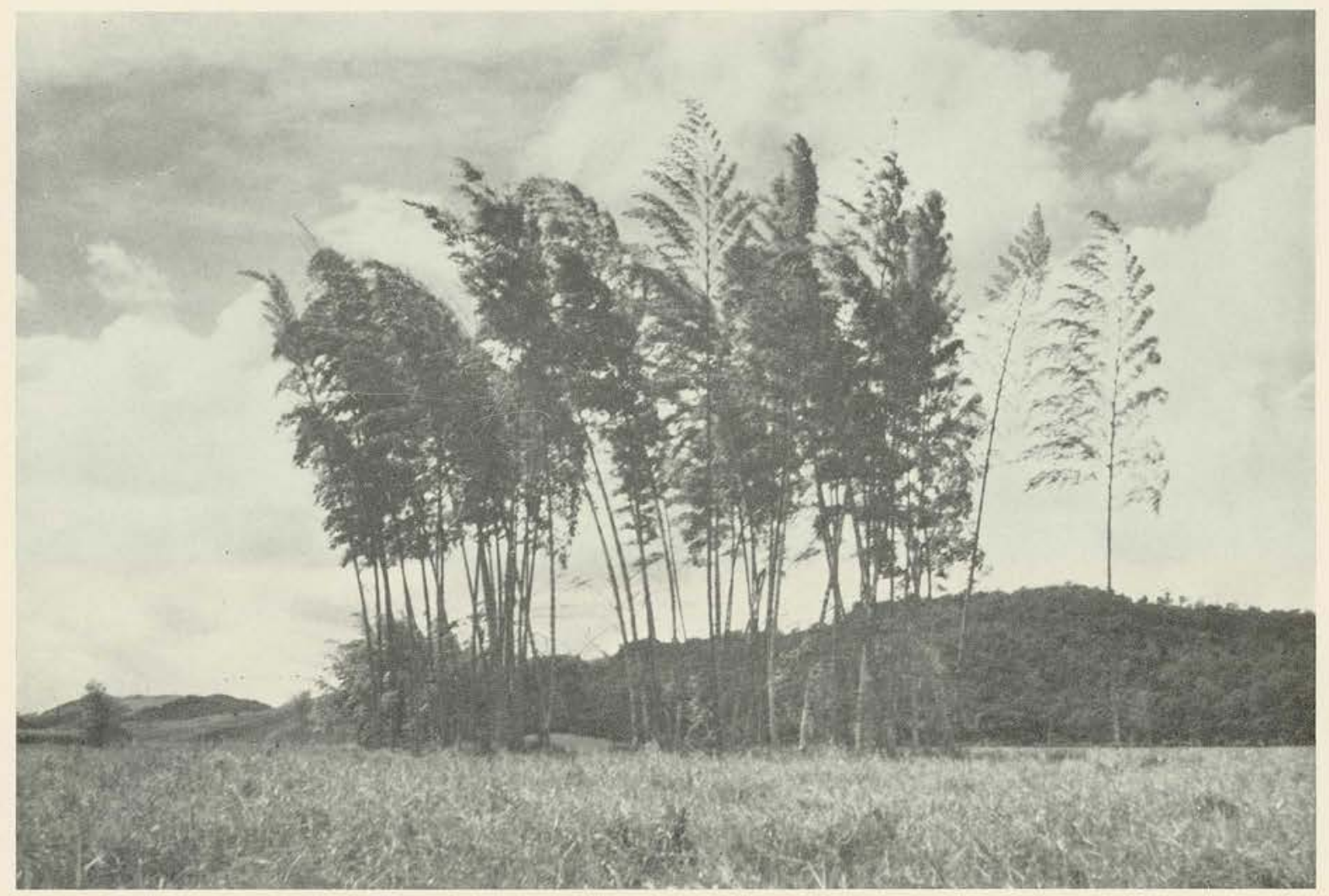

IX-2 - Guadual en el Alto Calima. (Foto Cuatrecasas 1-1666). 


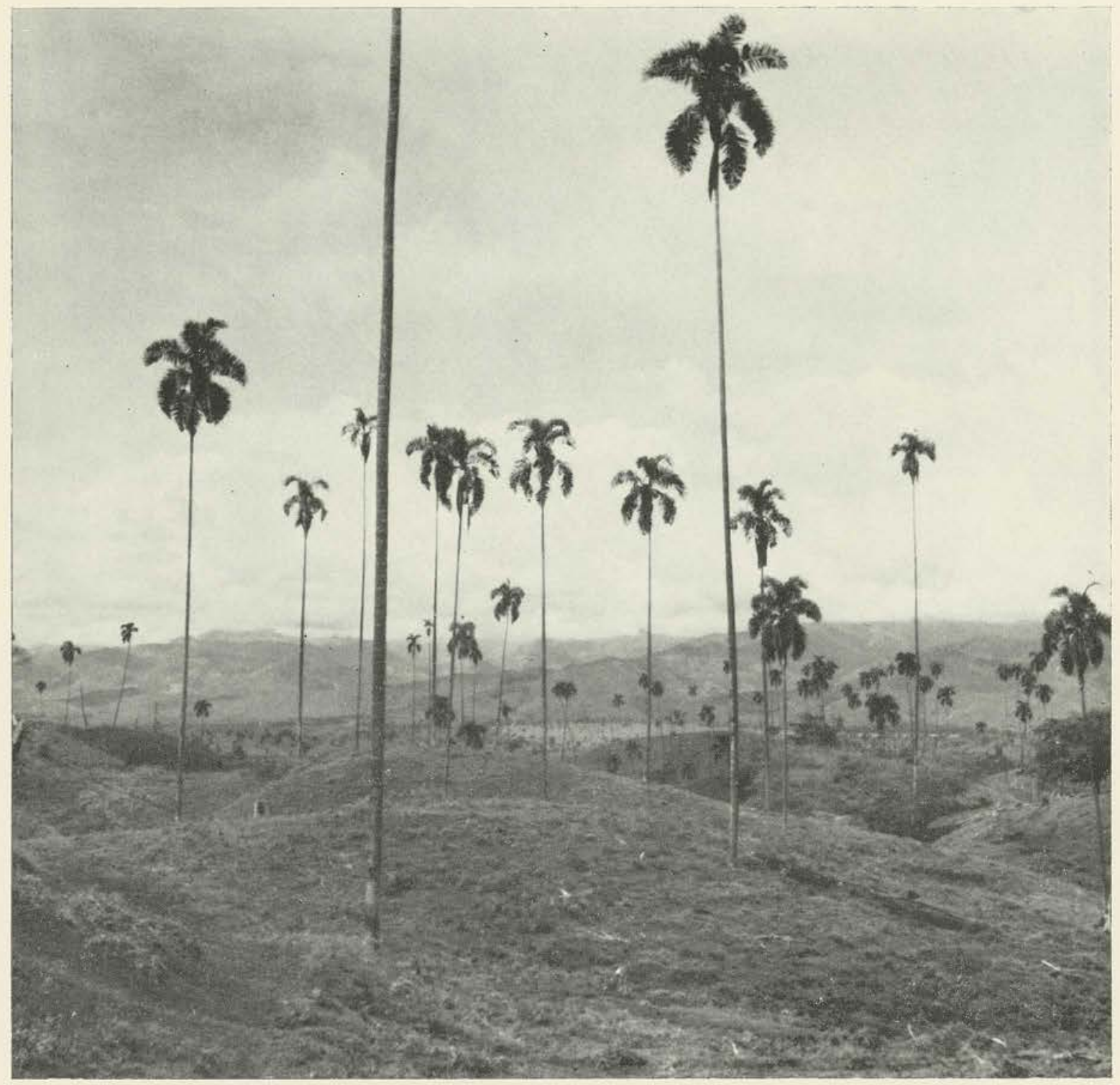

$\mathrm{X}$-Syagrus sancona (HBK) Kartsen, entre Cartago y La Virginia, $\pm 1.200 \mathrm{~m}$. alt. (Foto Cuatrecasas I-1816). 


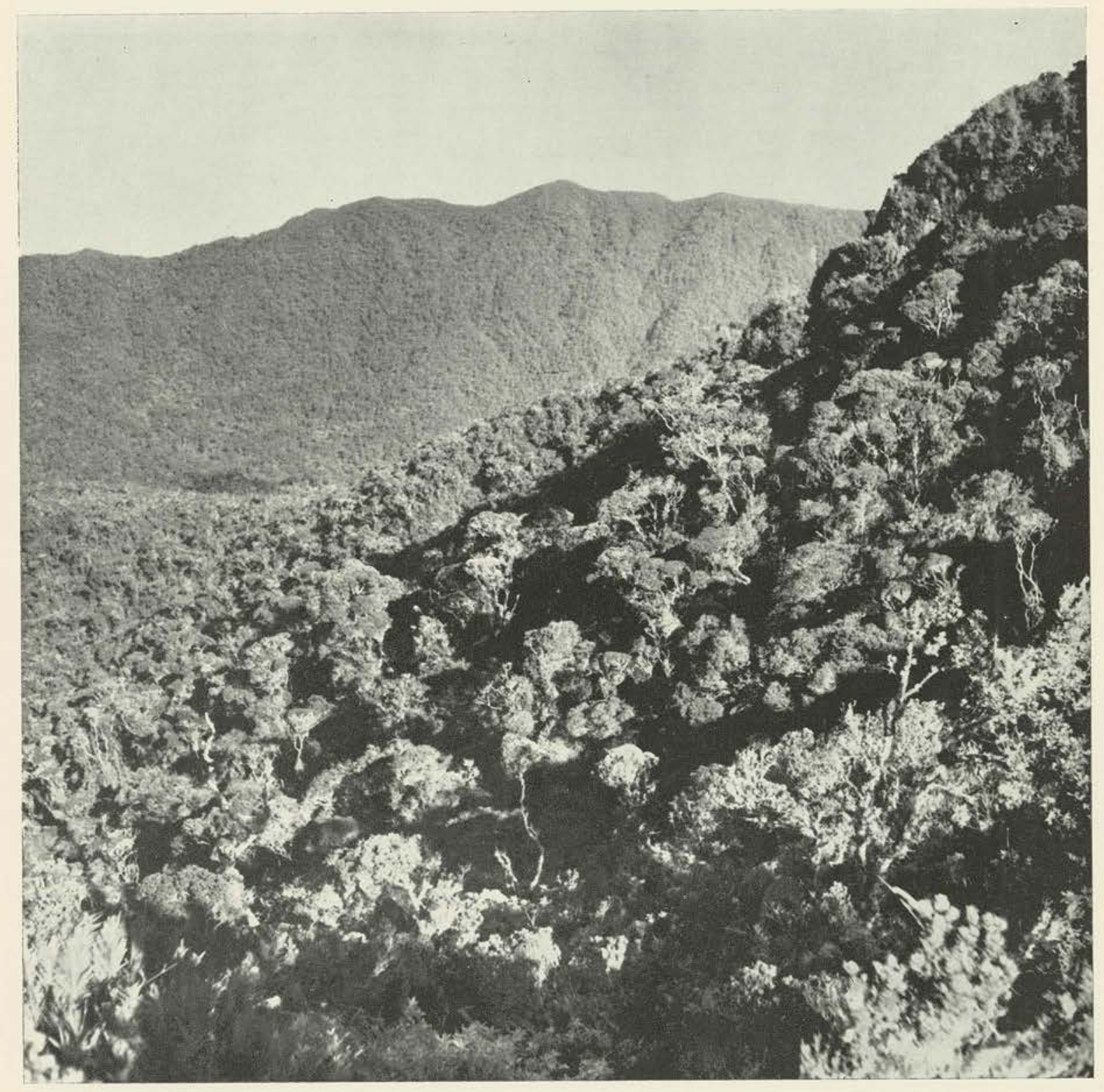

XI-Cordillera Occidental, Los Farallones. La selva andina a $3.500 \mathrm{~m}$. alt. Primer término con abundante Weinmannia engleriana y Miconia orcheotoma. (Foto Cuatrecasas 1-1707). 


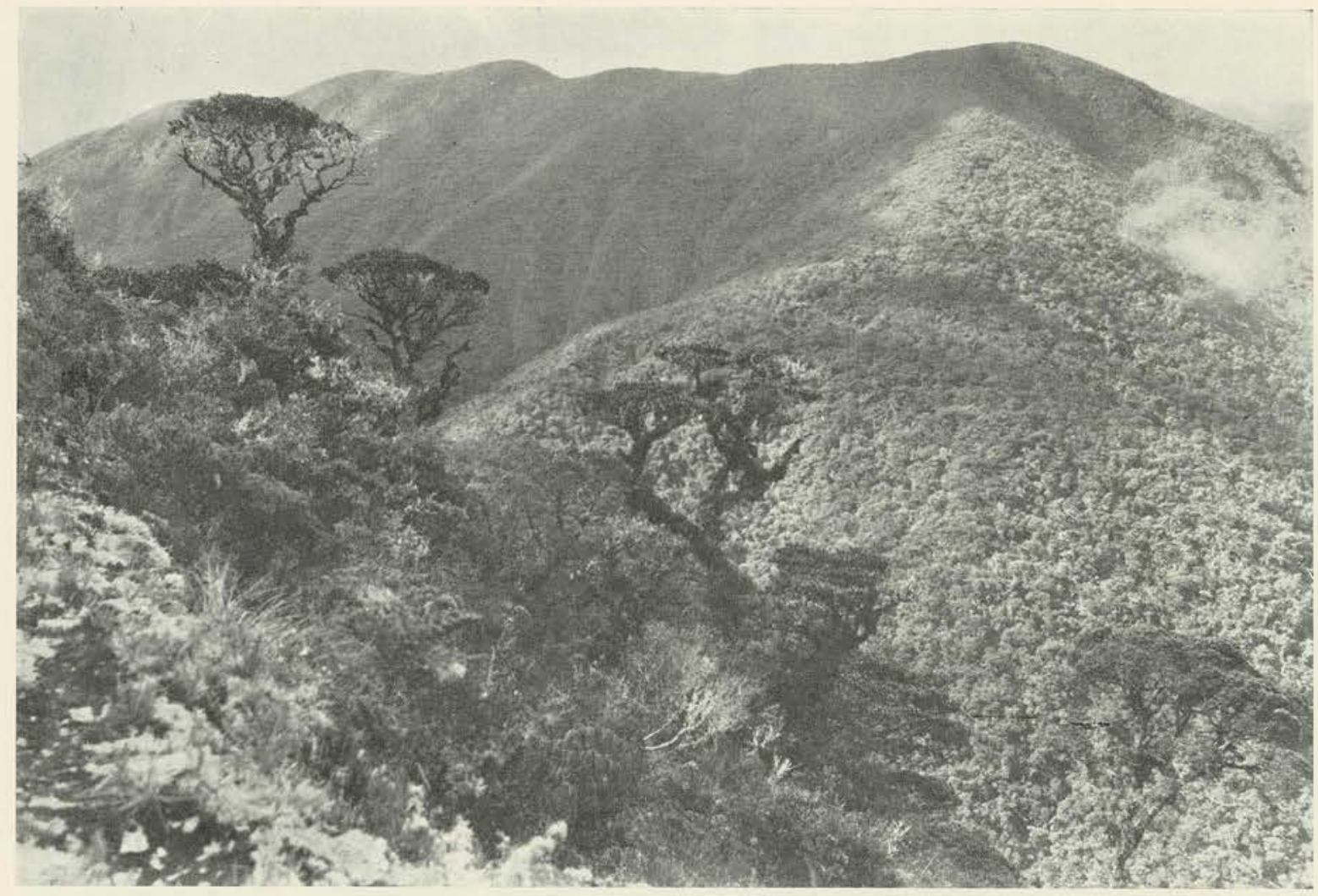

XII-1 - Cordillera Central, Cauca, alta cuenca del río Palo, Selva andina y en lo más alto, páramo. Primer término, bosque de Weinmannia engleriana y Ocotea sp., $3.400-3.450 \mathrm{~m}$, alt. (Foto Cuatrecasas C.2327).

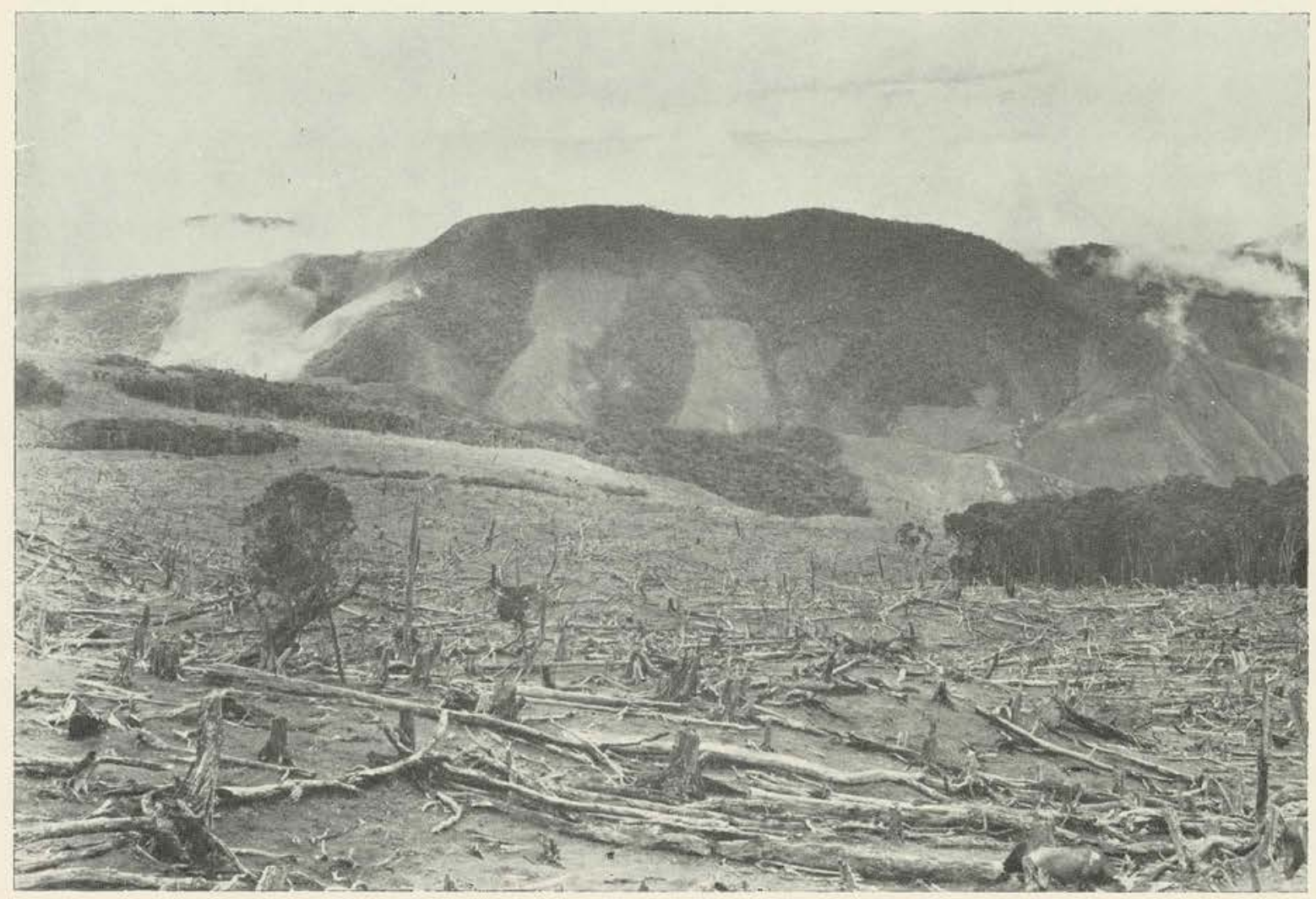

XII-2 - Cordillera Central, Valle, Montañas de Barragán, $\pm 3.250 \mathrm{~m}$. alt. Inmenso proceso de destrucción del bosque clímax predominantemente Weinmannietum y Hesperomeletum, para formar pastos; domina en estes Dactylis glomerata. (Foto Cuatrecasas C-2408). 


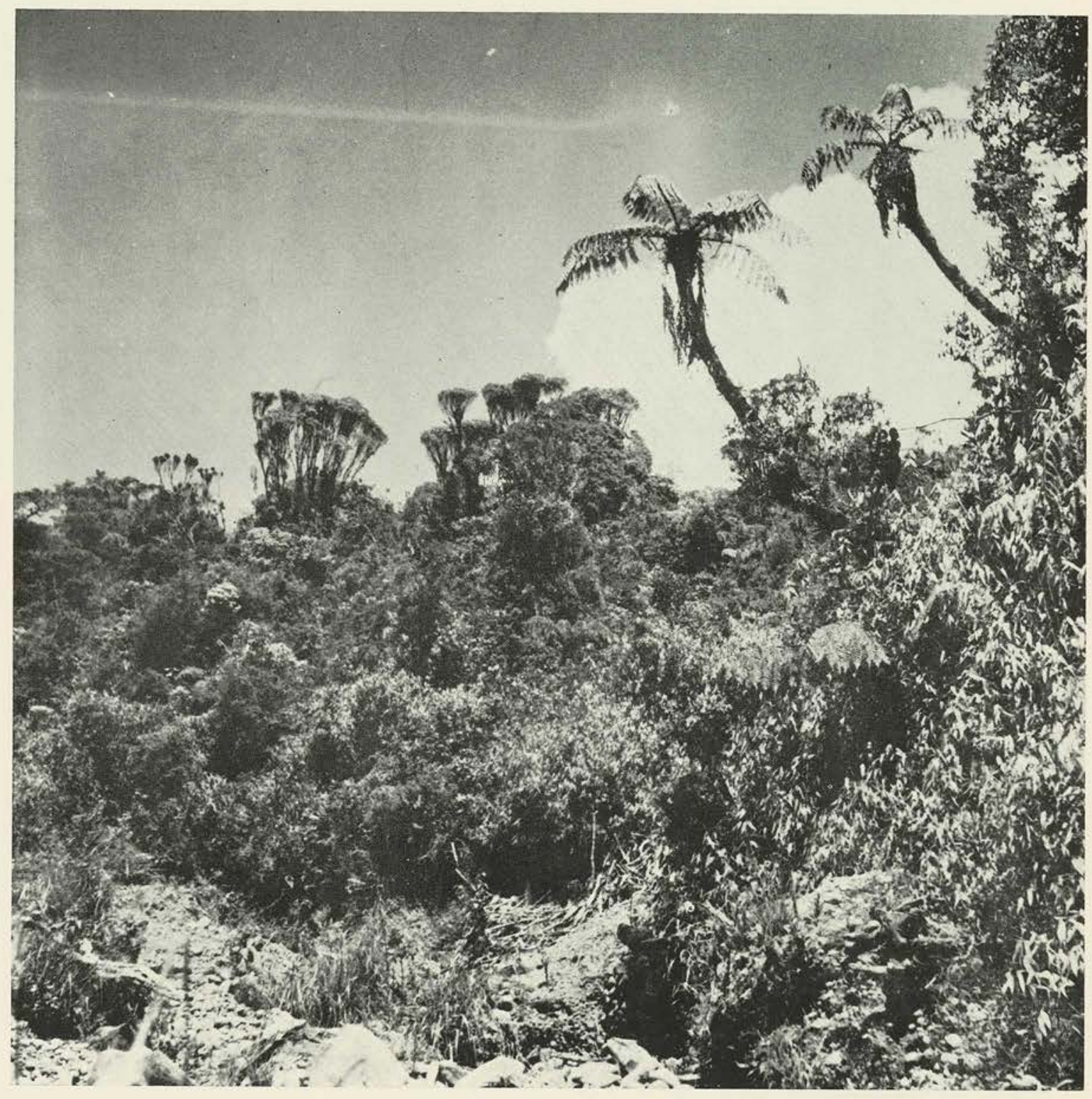

XIII-Cordillera Occidental, Los Farallones, $3.200 \mathrm{~m}$. alt. Bosque de páramo destacando los encenillos escobiformes (Weinmannia penicillata). Escallonia sp., chusques y helechos arbóreos. (Foto Cuatrecasas 1-1695). 

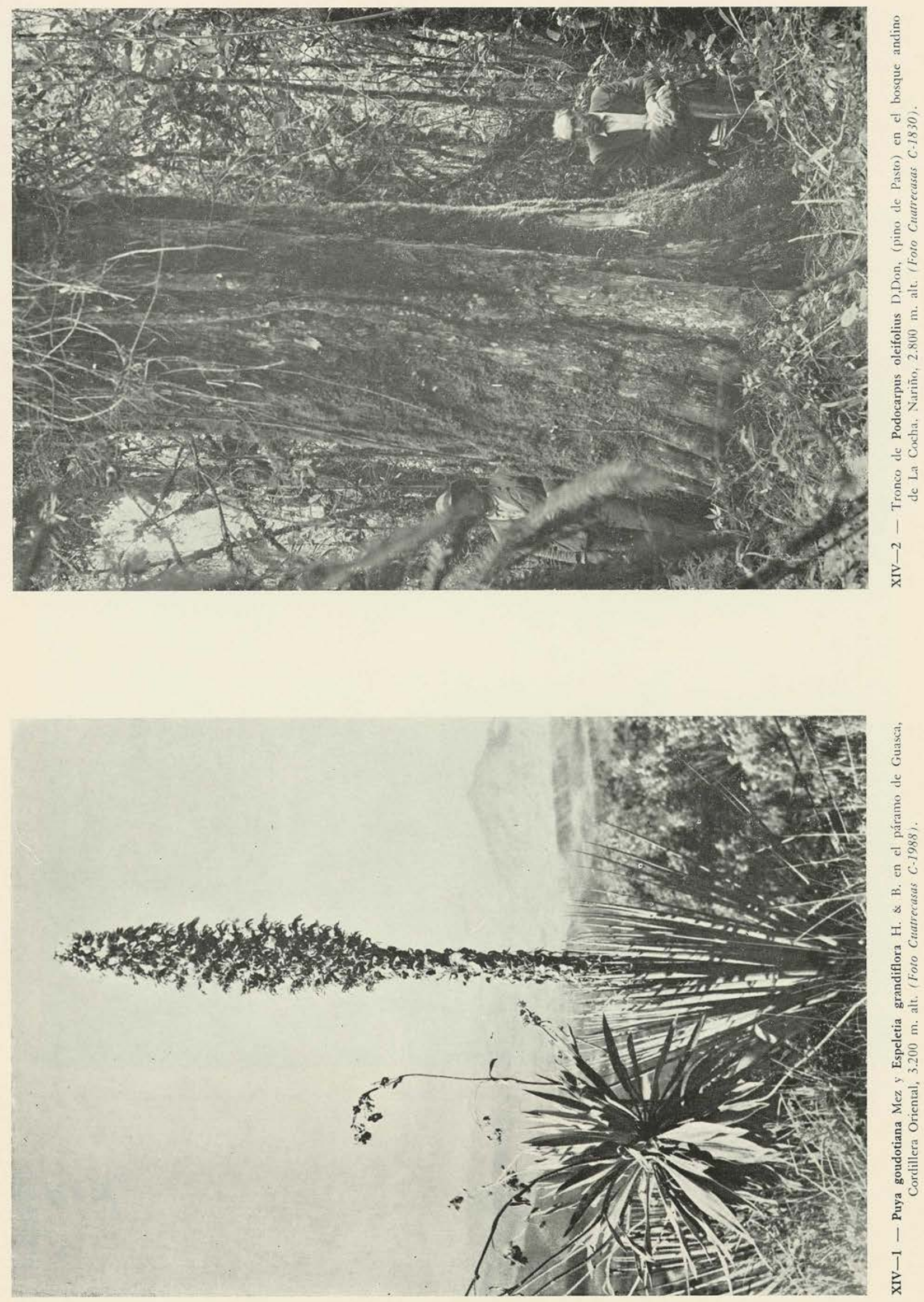


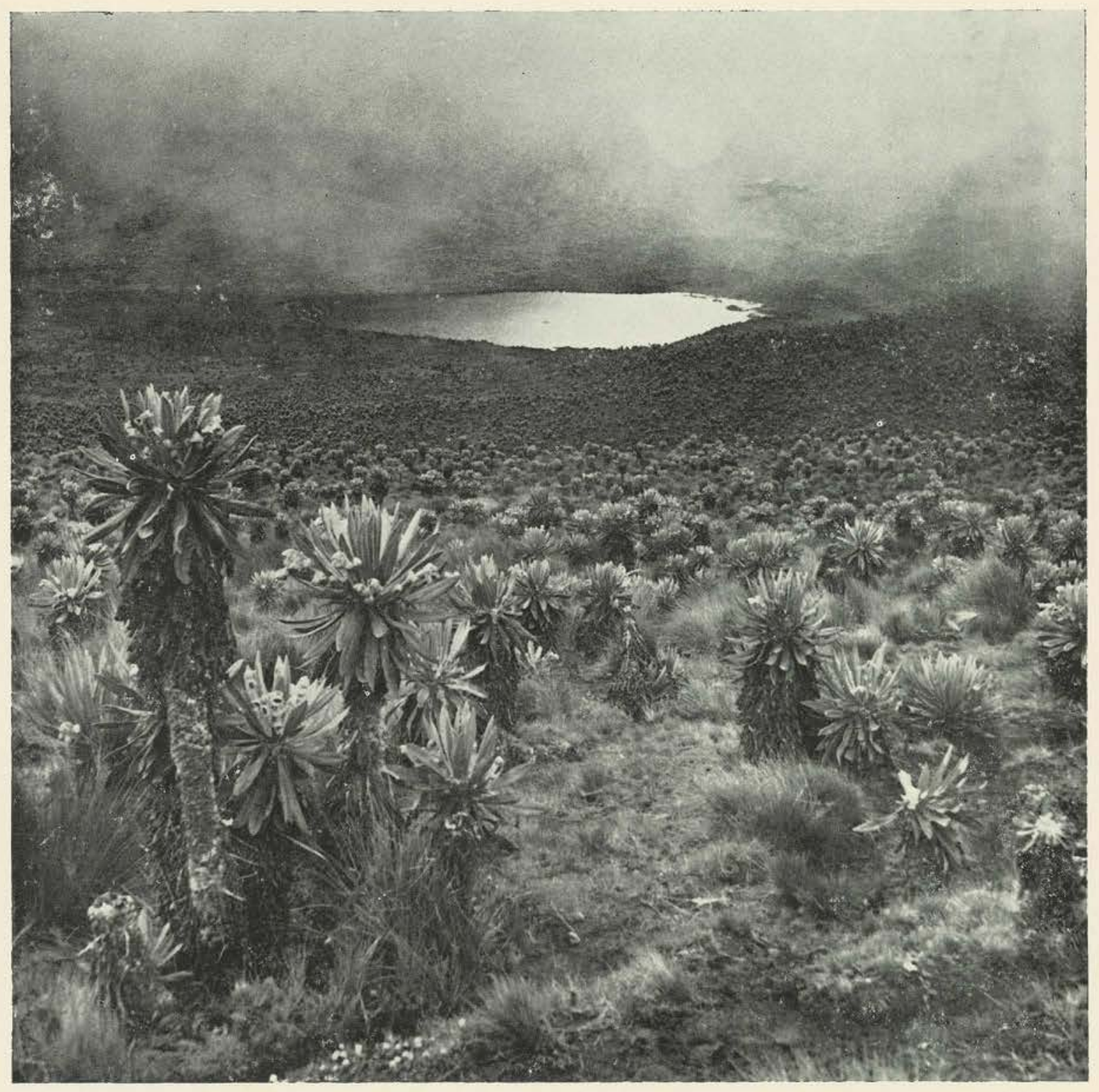

XV-Cordillera Central, Laguna del Ruíz, páramo $3.700 \mathrm{~m}$. alt. Formación de caulirrosuletum de Espeletia hartwegiana con graminetum de Calamagrostis ioarctata. (Foto Cuatrecasas 1-247). 


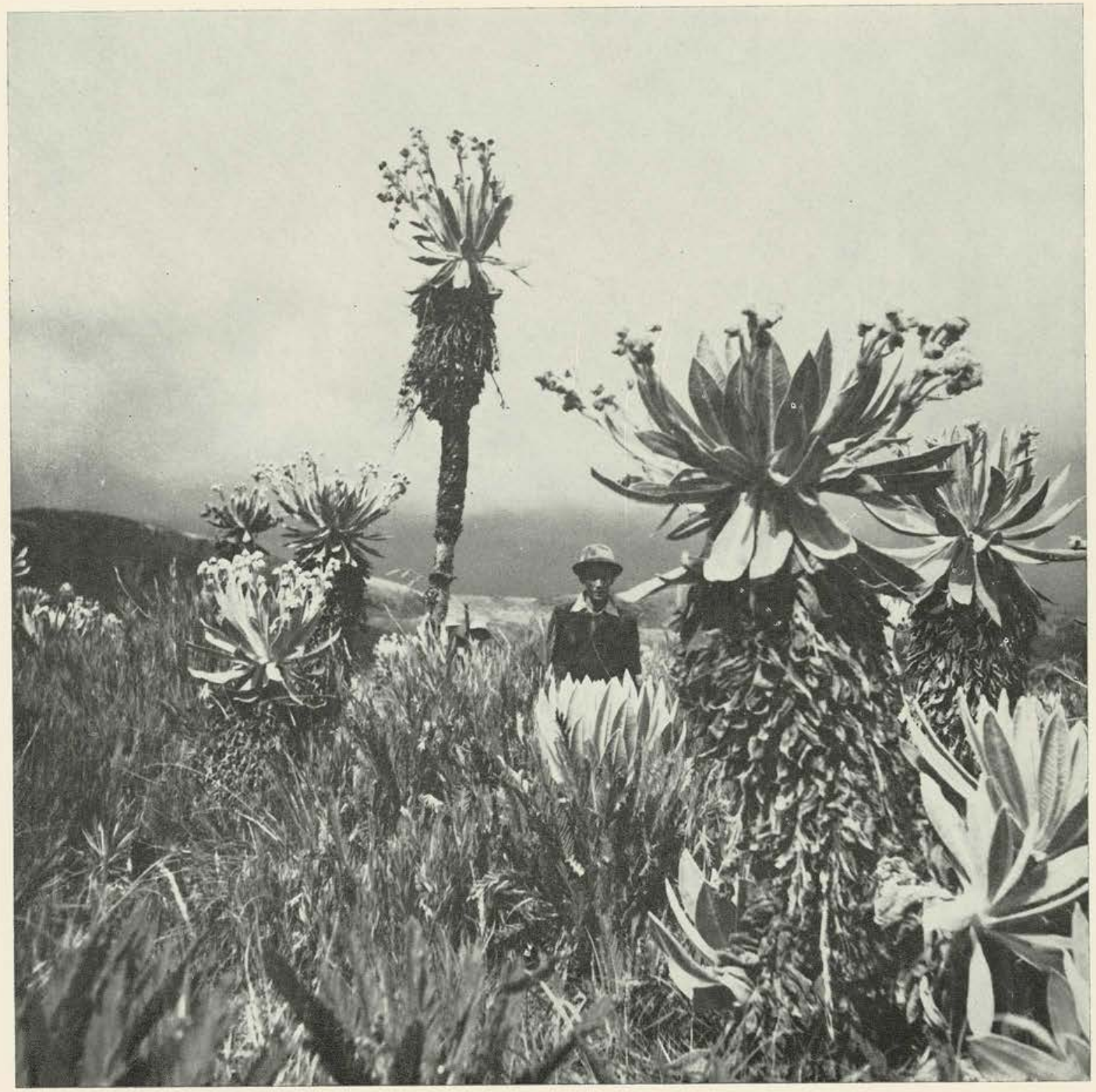

XVI-Cordillera Central, Cauca, Páramo de San Rafael, $3.360 \mathrm{~m}$. alt., grupo de Espeletia hartwegiana Cuadr. con Blechnum schomburgkii (K1.) Chr. (Foto Cuatrecasas 1-1909). 


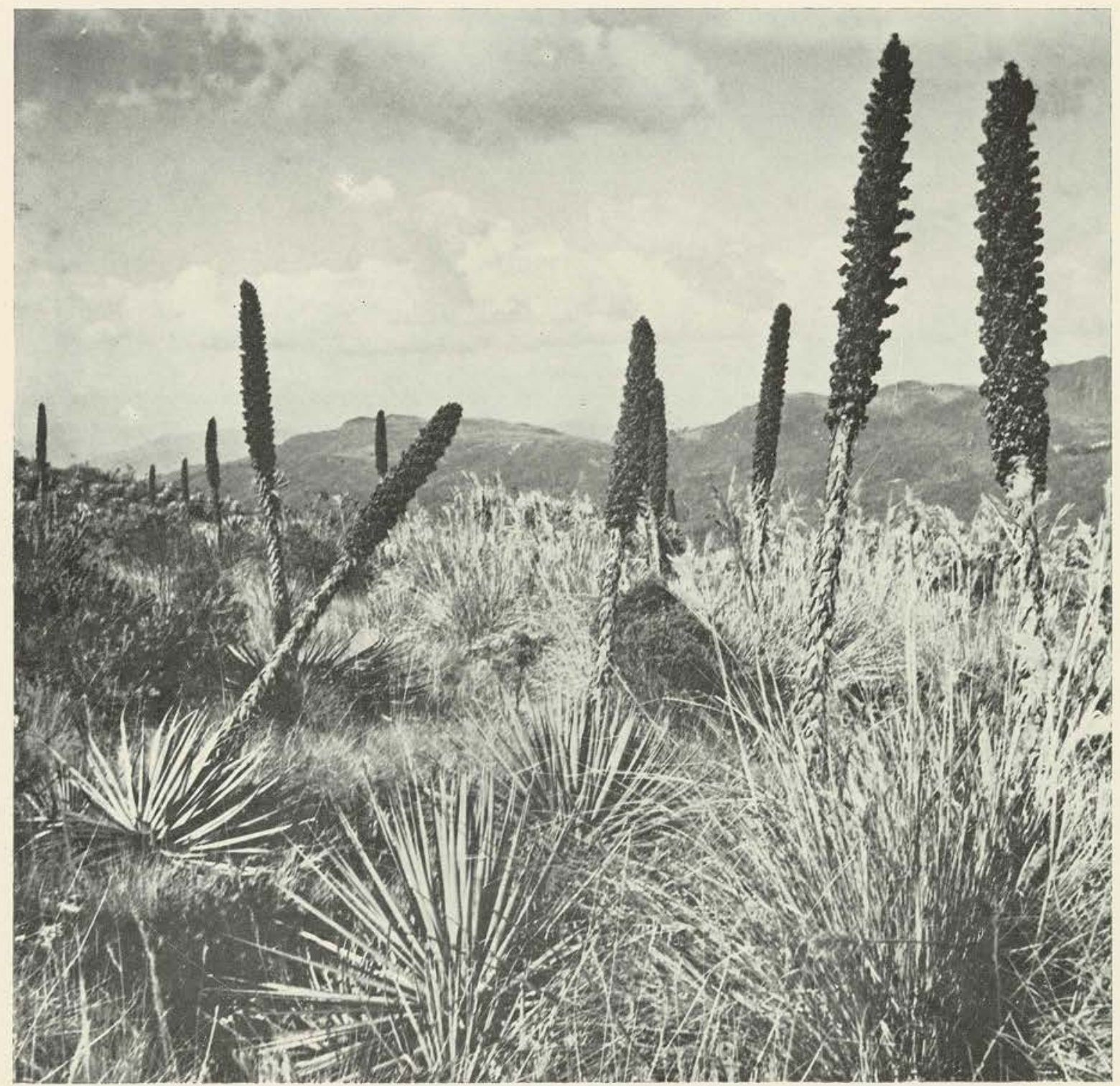

XVII-Cordillera Oriental, macizo de Bugotá, páramo $3.250 \mathrm{~m}$ alt formación de Puya goudotiana, grandes haces de Cortaderia nitida matas de Aragoa cupresina al fondo rosetones de Espeletia grandiflora, etc. (Foto Cuatrecasas l-129). 


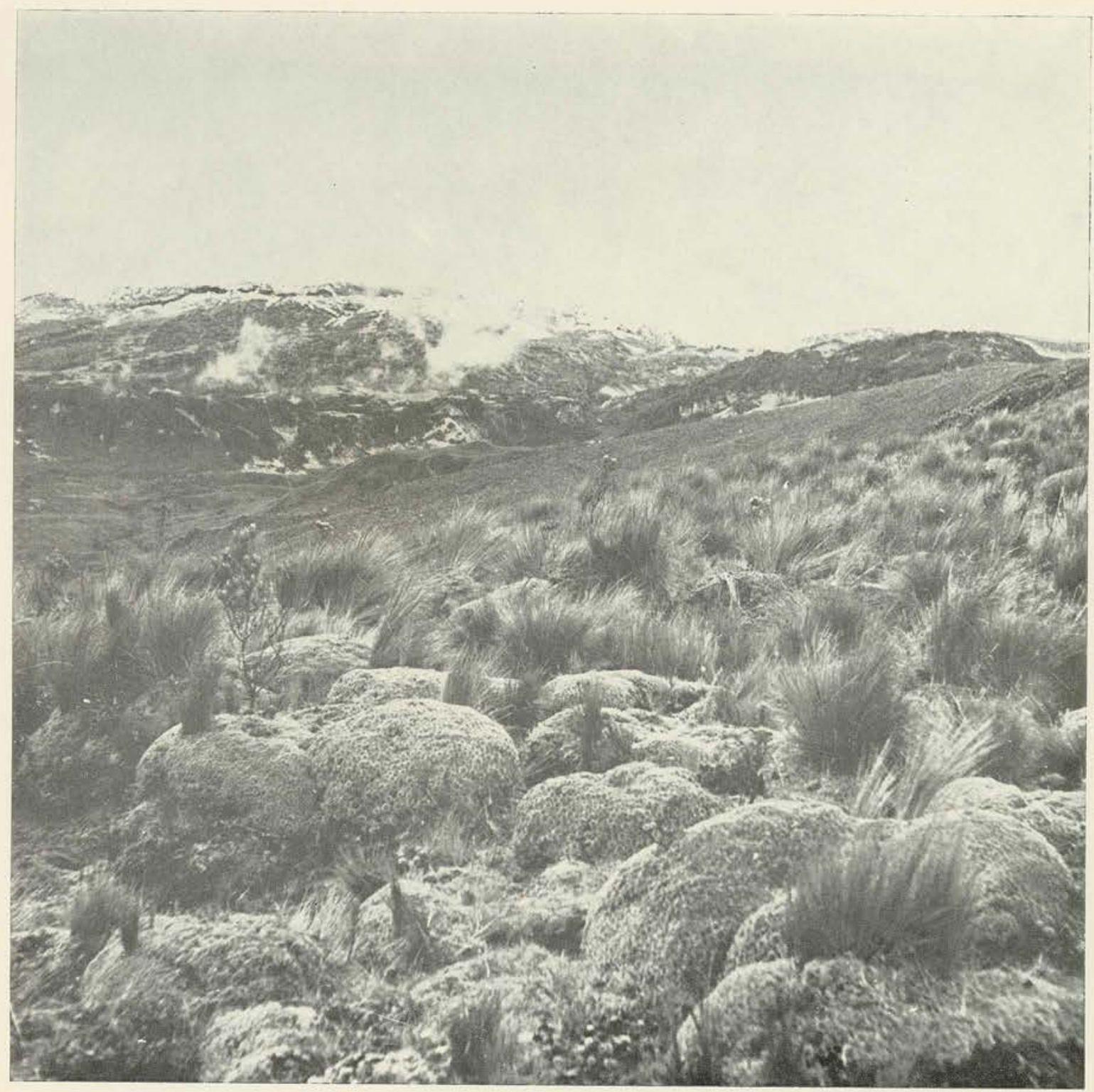

XVIII-Nevado del Ruiz (Cordillera Central); páramo $4.300 \mathrm{~m}$. alt. con almohadillas de Plantago rigida HBK con pajonal de Calamagrostis effusa Steud. y C. recta Tr. (Foto Cuatrecasas 1-235). 


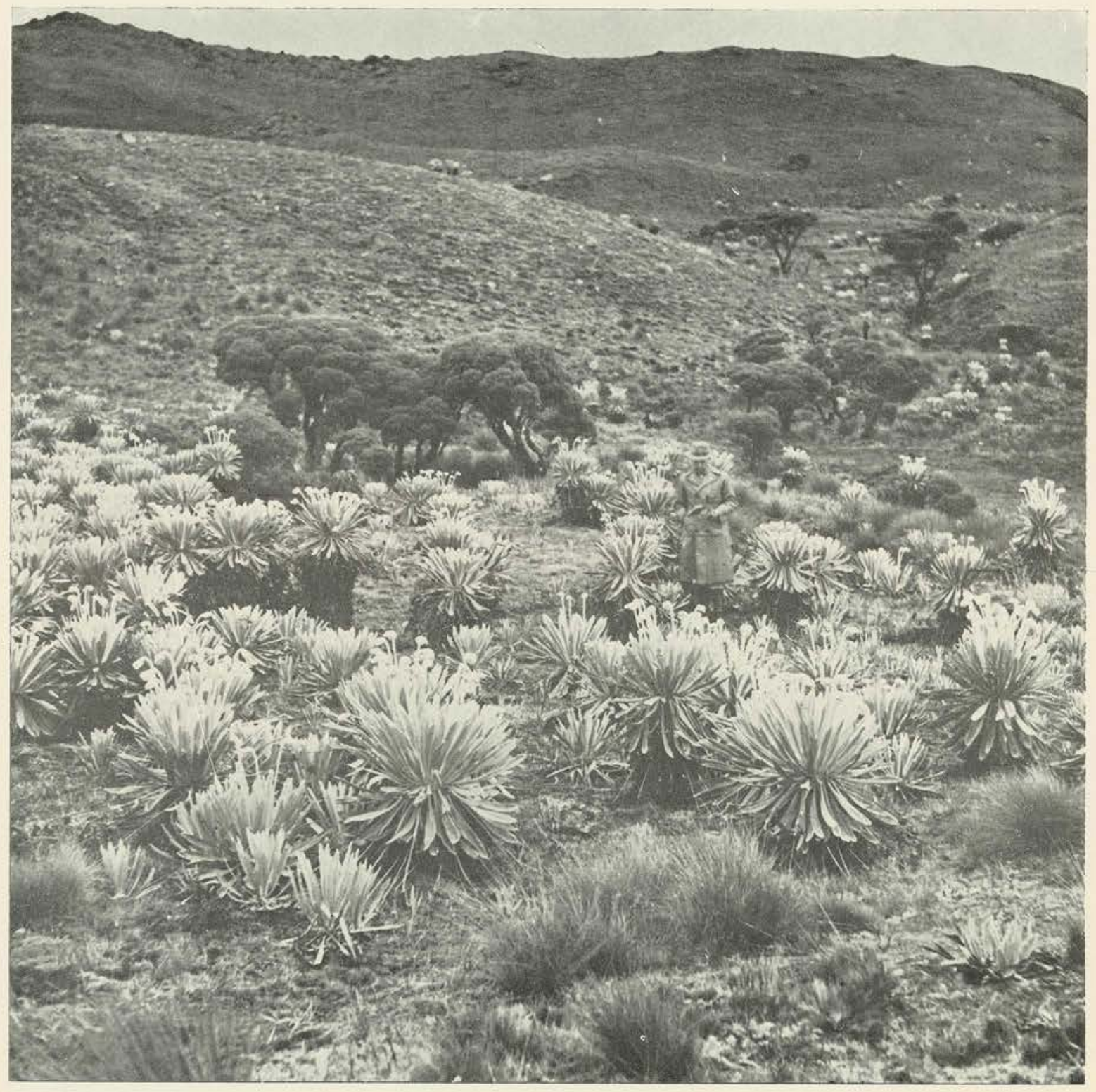

XIX-Cordillera Oriental, páramo del Almorzadero, en una quebrada $3.800-3.900 \mathrm{~m}$. alt. Formación de Espeletia conglomerata Sm. con arbolitos de Diplostephium revolutum BI., fascigraminetum de Calamagrostis effusa y demás especies de páramo. (Foto Cuatrecasas 1-388). 


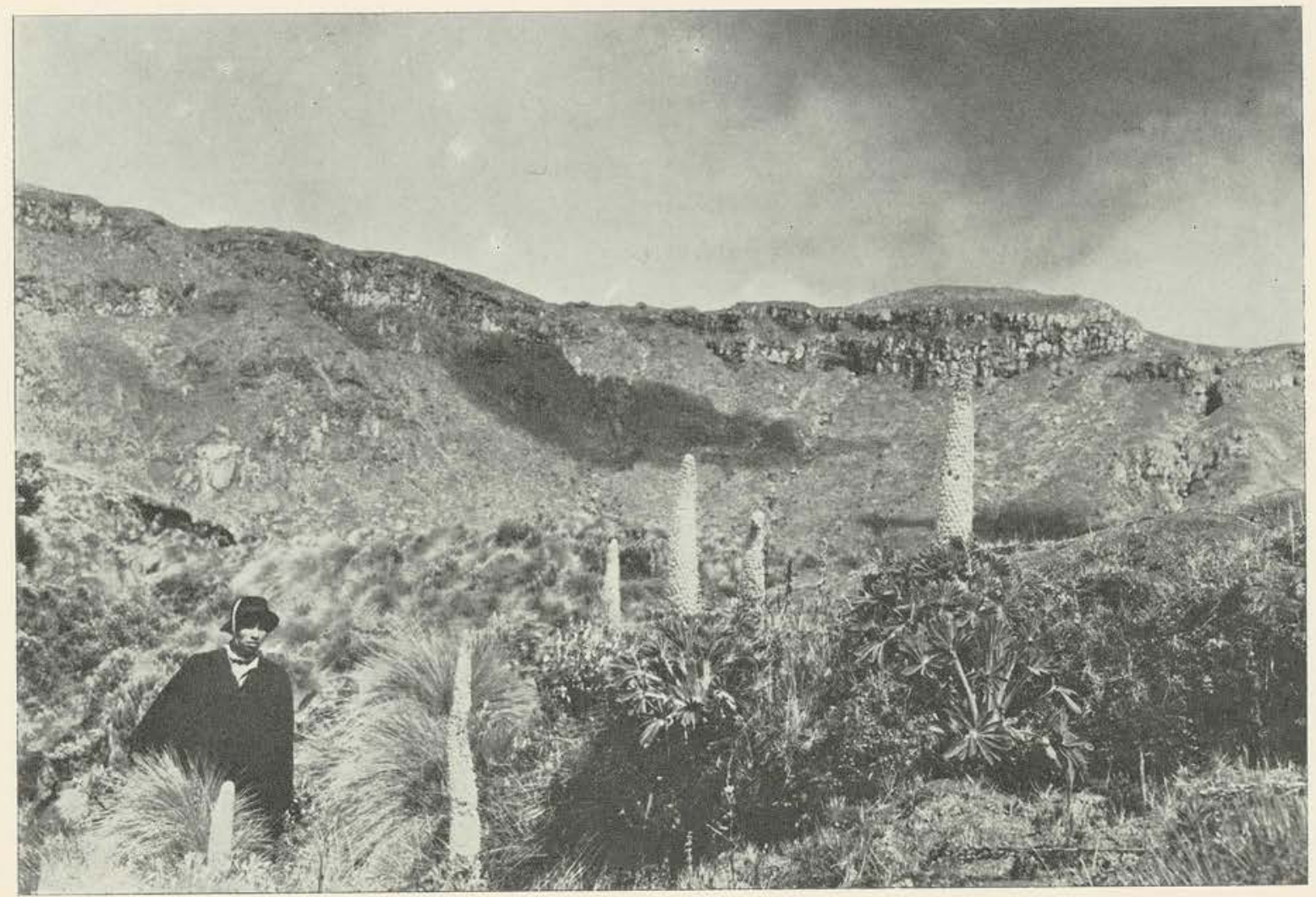

XX-1 - Cordillera Central, páramo de Puracé, $3.900 \mathrm{~m}$. alt. Lupinus alopecuroides Desr. (Foto Cuatrecasas C-2016).

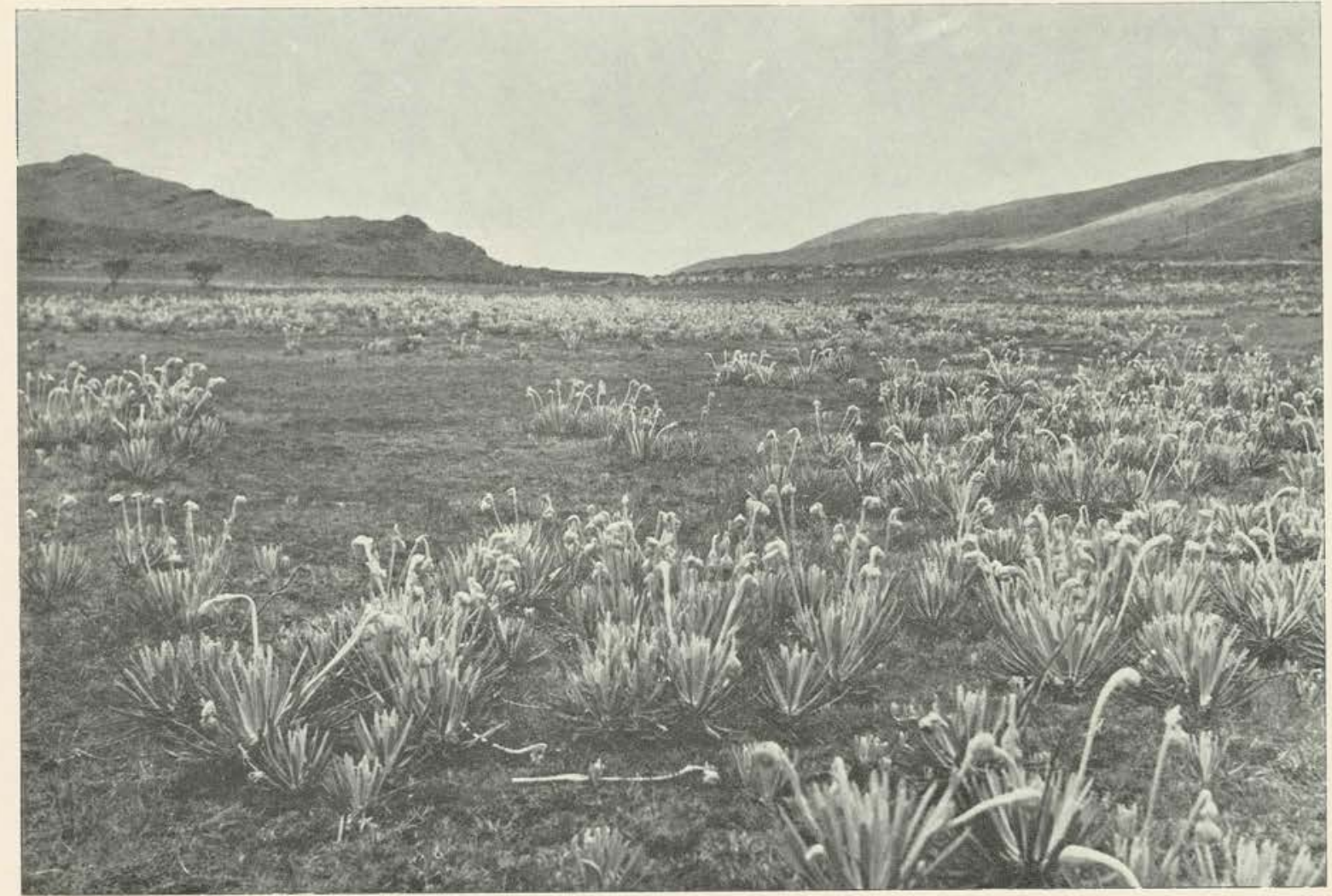

XX - 2 - Cordillera Oriental, páramo del Almorzadero, $3.800 \mathrm{~m}$. alt., prado turboso-pantanoso con Espeletia estanislana. (Foto Cuatrecasas $(-1705)$. 


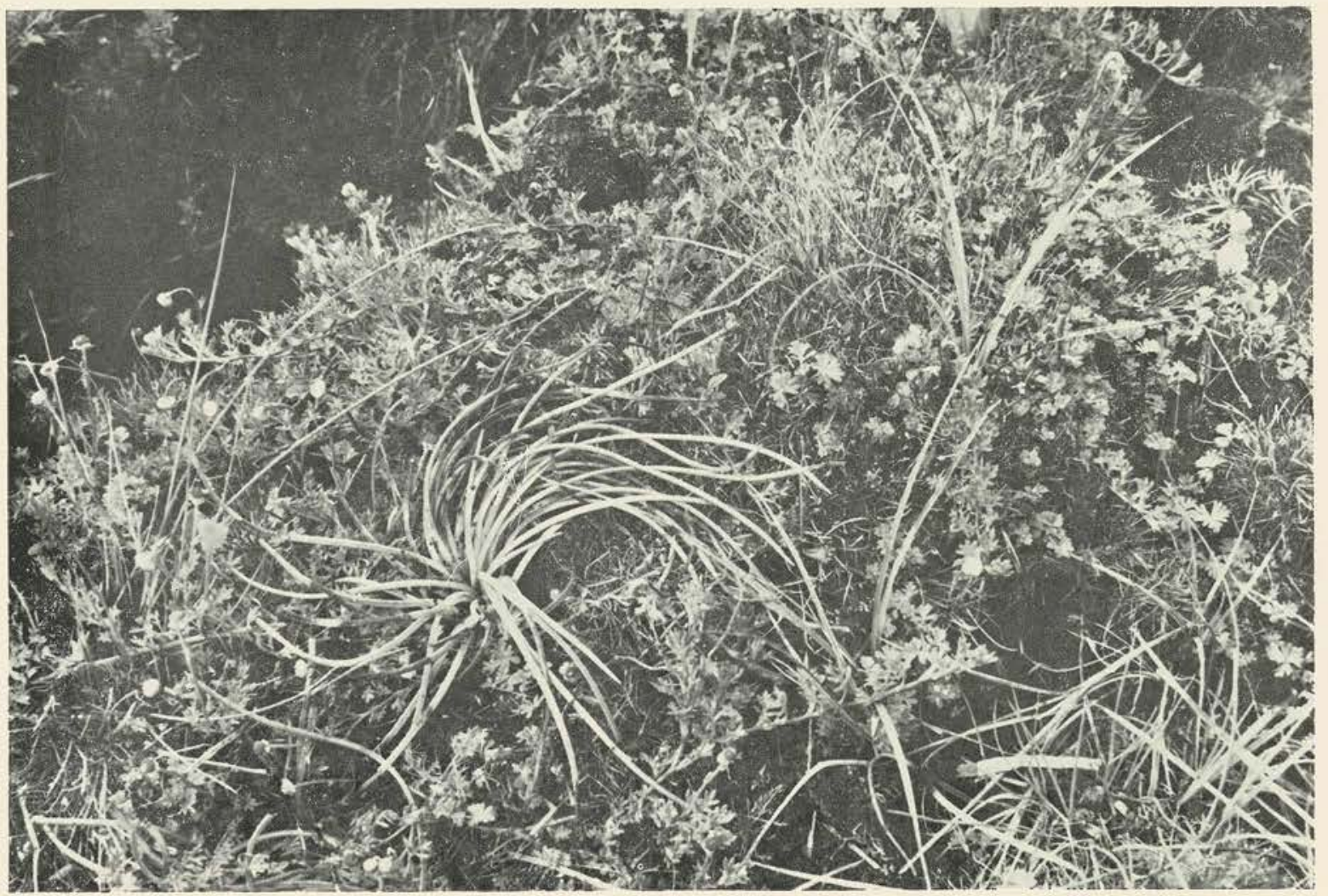

XXI-1 - Cordillera Central, cabeceras del río Tuluá, páramo $3.500 \mathrm{~m}$. alt., prado embebido, con Isoetes killipii, Plagiocheilus solivaeformis, Oreobulus obtusangulus como principales elementos visibles. (Foto Cuatrecasas C-2398).

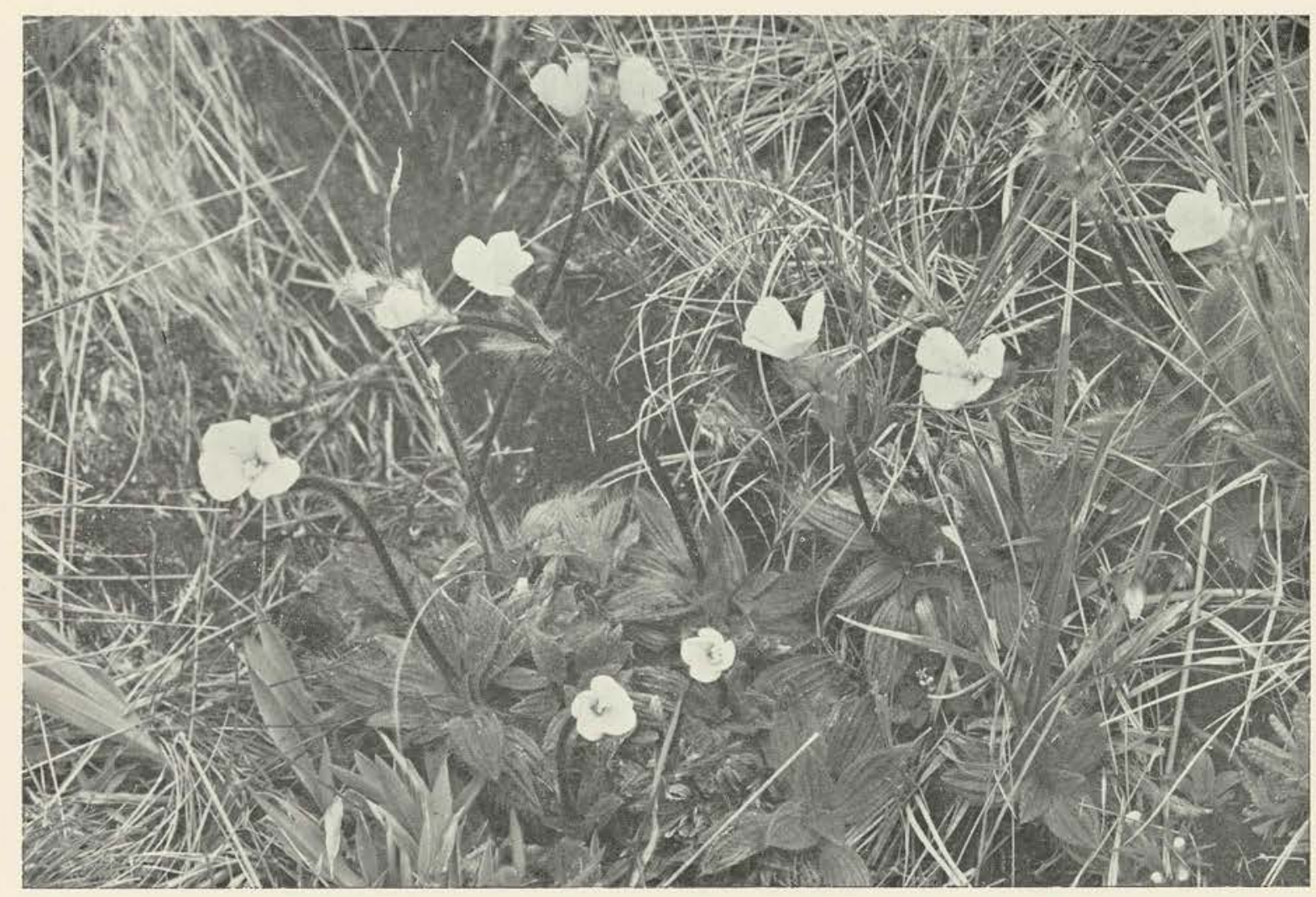

XXI-2 - Cordillera Oriental, macizo de Bogotá, páramo $3.380 \mathrm{~m}$. alt., típica melastomatácea arrosetada del prado paramuno, con flores amarillas: Castratella pilloseloides. (Bonpl.) Naud. (Foto Cuatrecasas C-1405). 


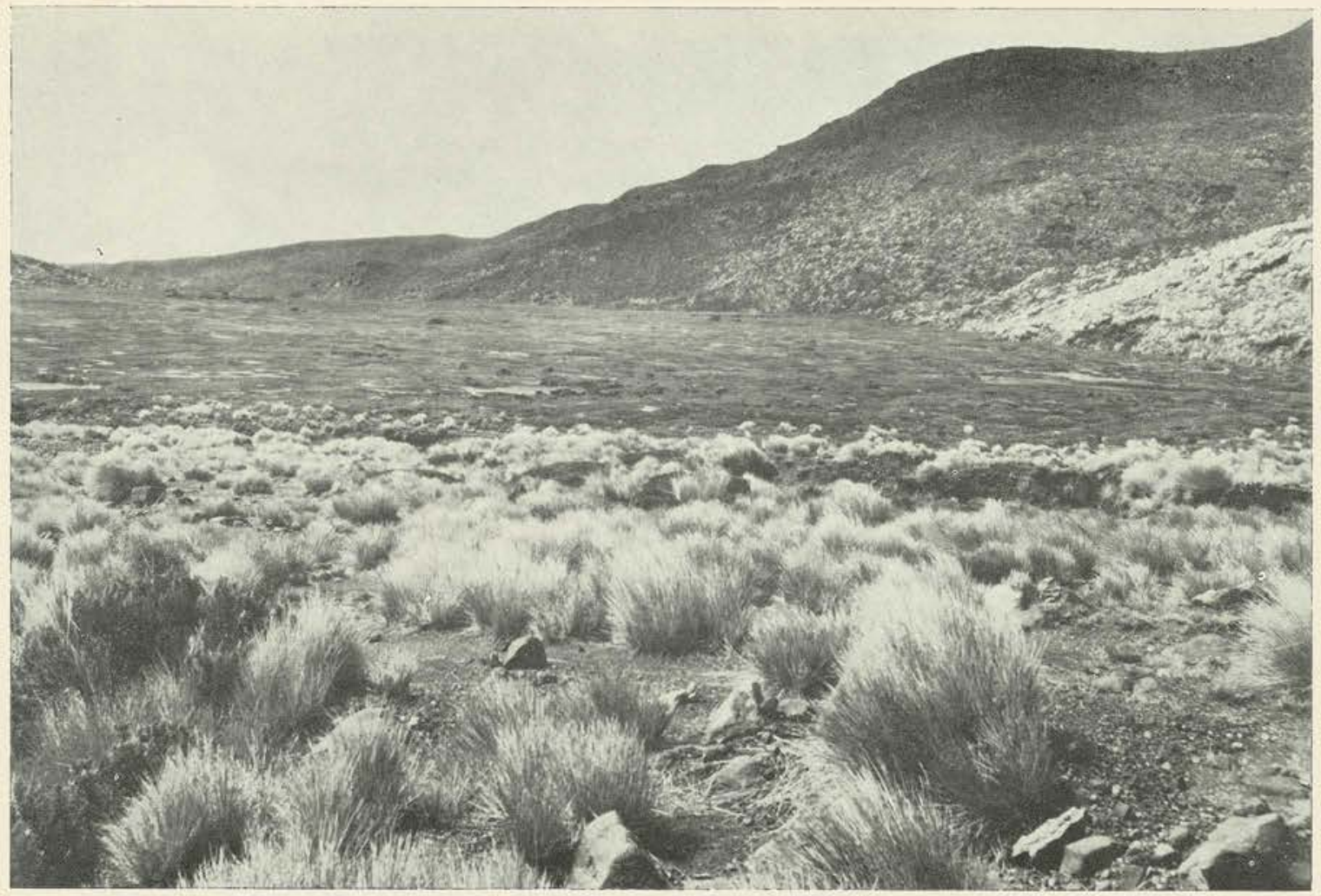

XXII-1 - Cardillera Central, prado pantanoso en un viejo cráter del Puracé llamado El Alfombrado, $4.100 \mathrm{~m}$. alt. Compacta alfombra flotante de Distichia tolimensis con esporádicos ejemplares entremezclados de Cotula minuta, Plagiocheilus solivaeformis, Werneria, Gunera magellanica, Cyperaceae; lomas con pajonal de Festuca tolucensis, fruticeto de Senecio vaccinioides, Loricaria, almohadlillas de Azorella crenata y grupos de Senecio puracensis. Primer término Agrostis foliata y Loricaria thujoides v, microphyila. (Foto Cuatre casas C-2105),

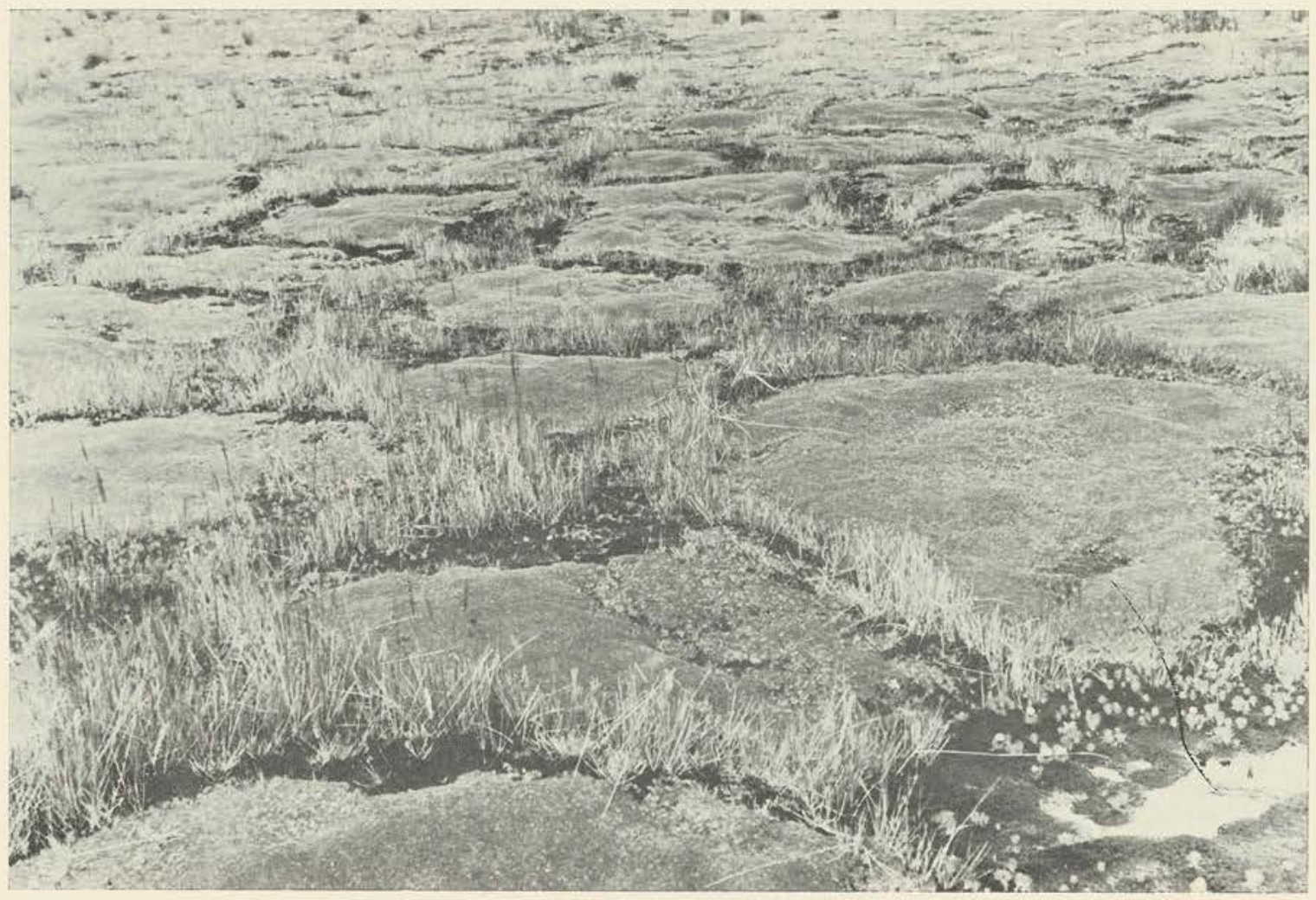

XXII-2 - Cordillera Oriental; Nevado del Gucuy, $4.200 \mathrm{~m}$. alt. pantano con alfombras compactas flotantes de Distichia tolimensis. Entre las placas se ve Calamagrostis sp., Werneria crassa v. minor, Plagiocheilus solivaeformis subsp. multiflorus y escasas ramillas em. potradas de Pernettya prostrata. (Foto Cuatrecasas C-1231). 


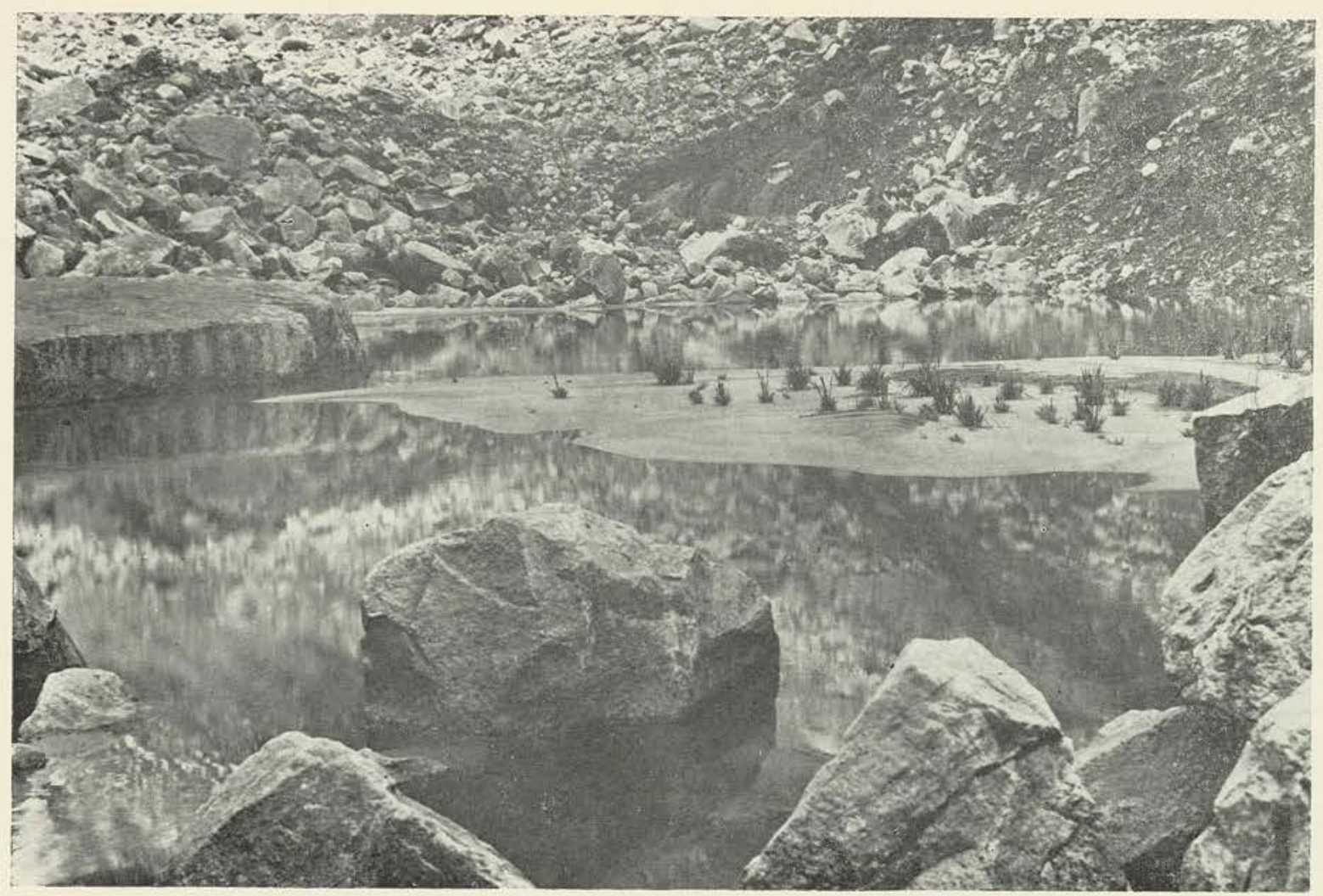

XXIII-1 - Superpáramo del Nevado del Cocuy, inmediatamente debajo del glaciar, $4.500 \mathrm{~m}$. alt. Agrostis nigritella Pilger como especie única entre las finas arenas bañadas en el agua de funclición. (Foto Cuatrecasas C-1229).

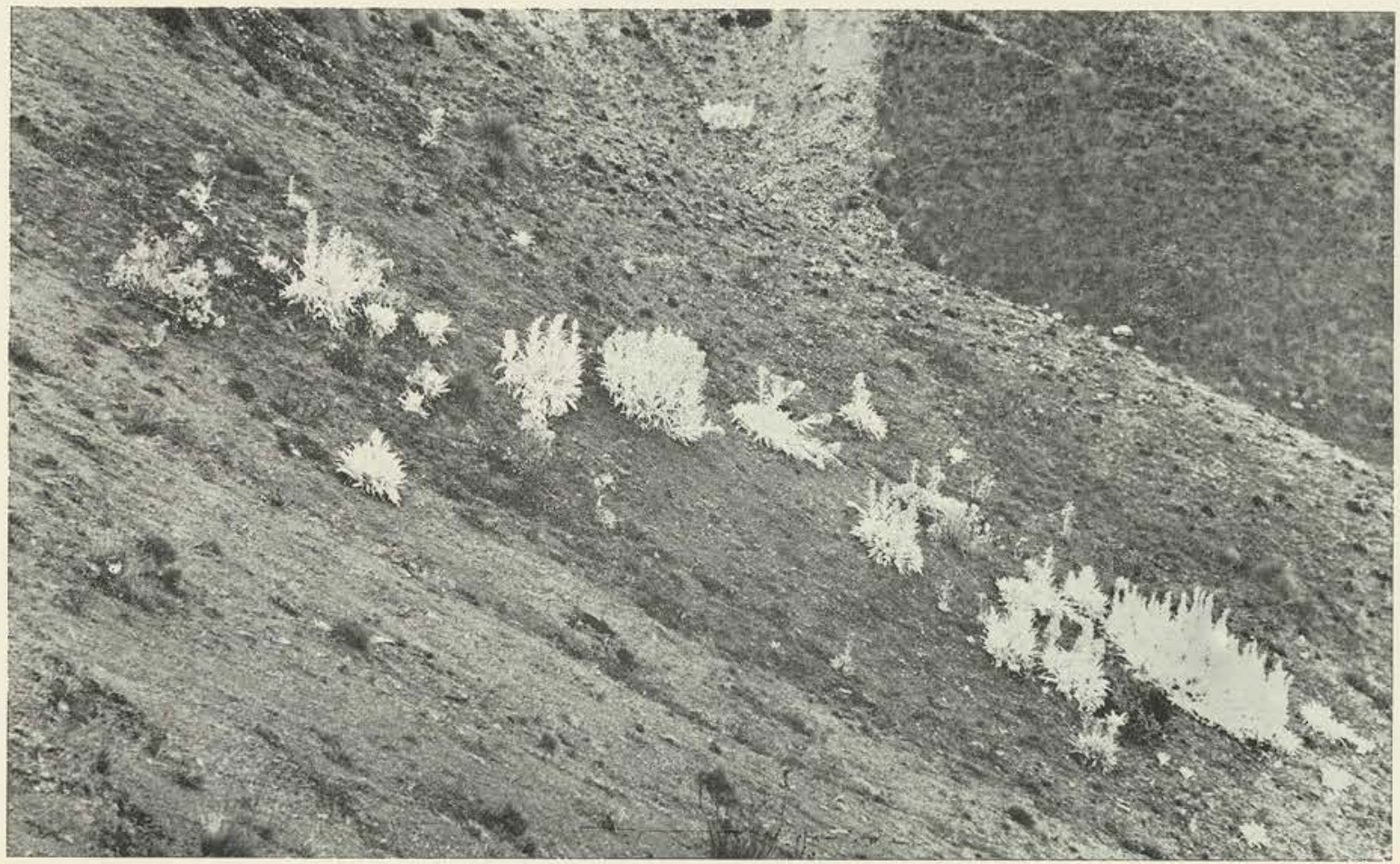

XXII-2 - Superpáramo en la Cordillera Oriental, en el Páramo del Almorzadero, 3.800 m. alt., formación en arenales de Senecio niveo-aureus, S. almorzaderonis, S. canescens fma. boyacensis y S. foliiserratus. (Foto Cuatrecasas C-1974). 


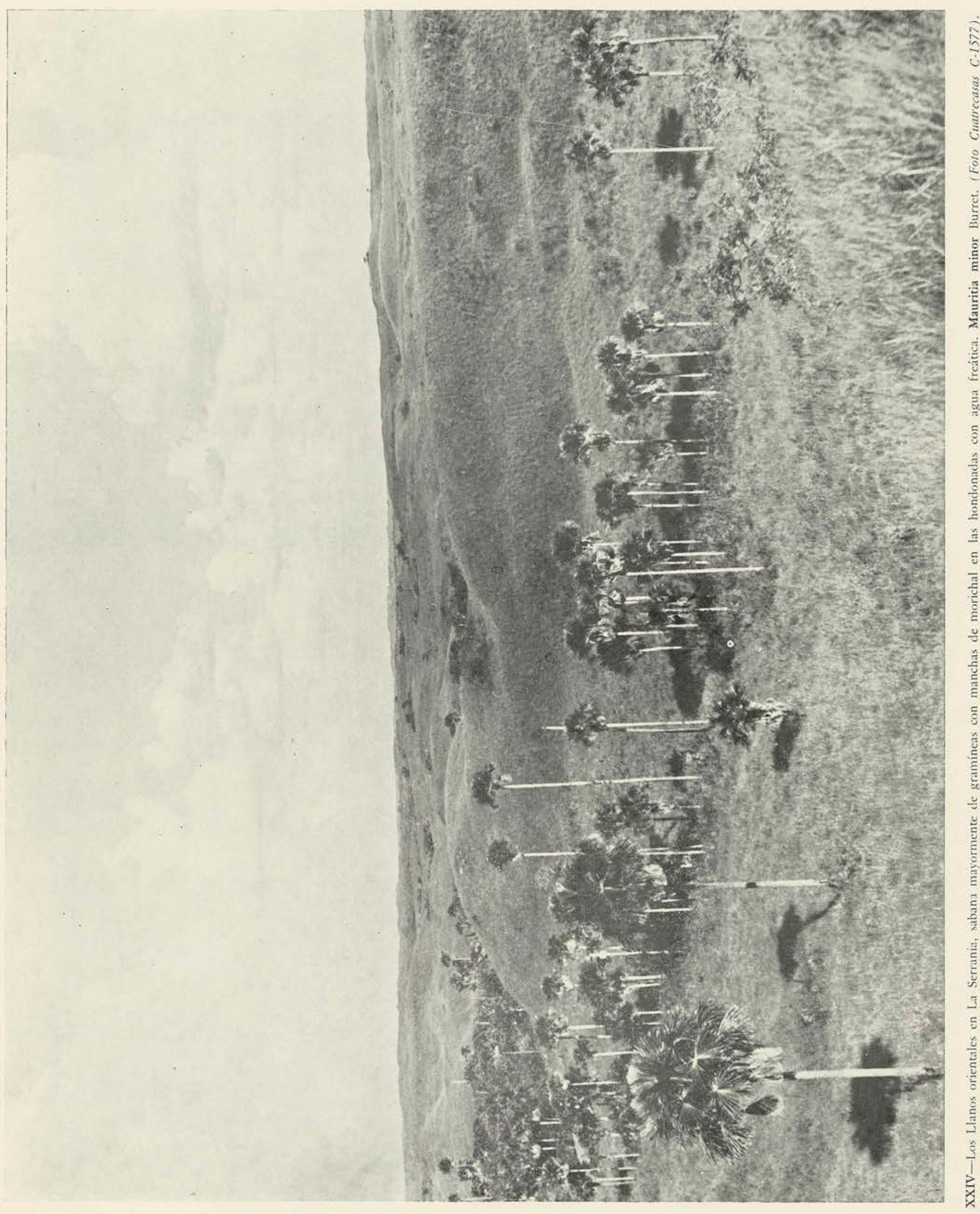




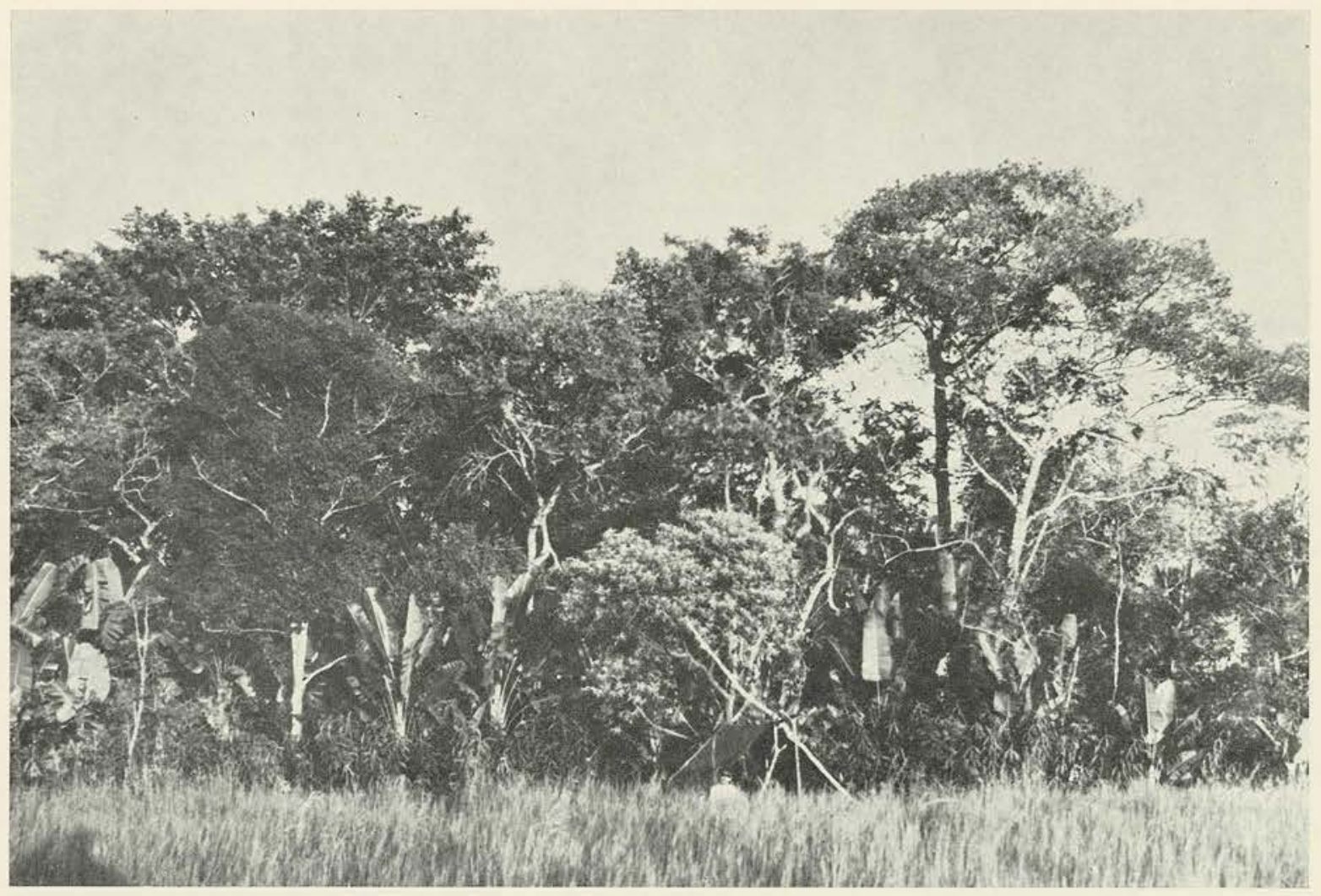

XXV-1 - Los Llanos orientales. Frente de una mata de monte con matas de la musácea Phenakospermum guianense (terriago) muy destacadas, Capironia decorticans y otros árboles de los citados en la pág. 254. Sabana con pajonal de Andropogon leucostachyus. (Foto Cuatrecasas C-1572).

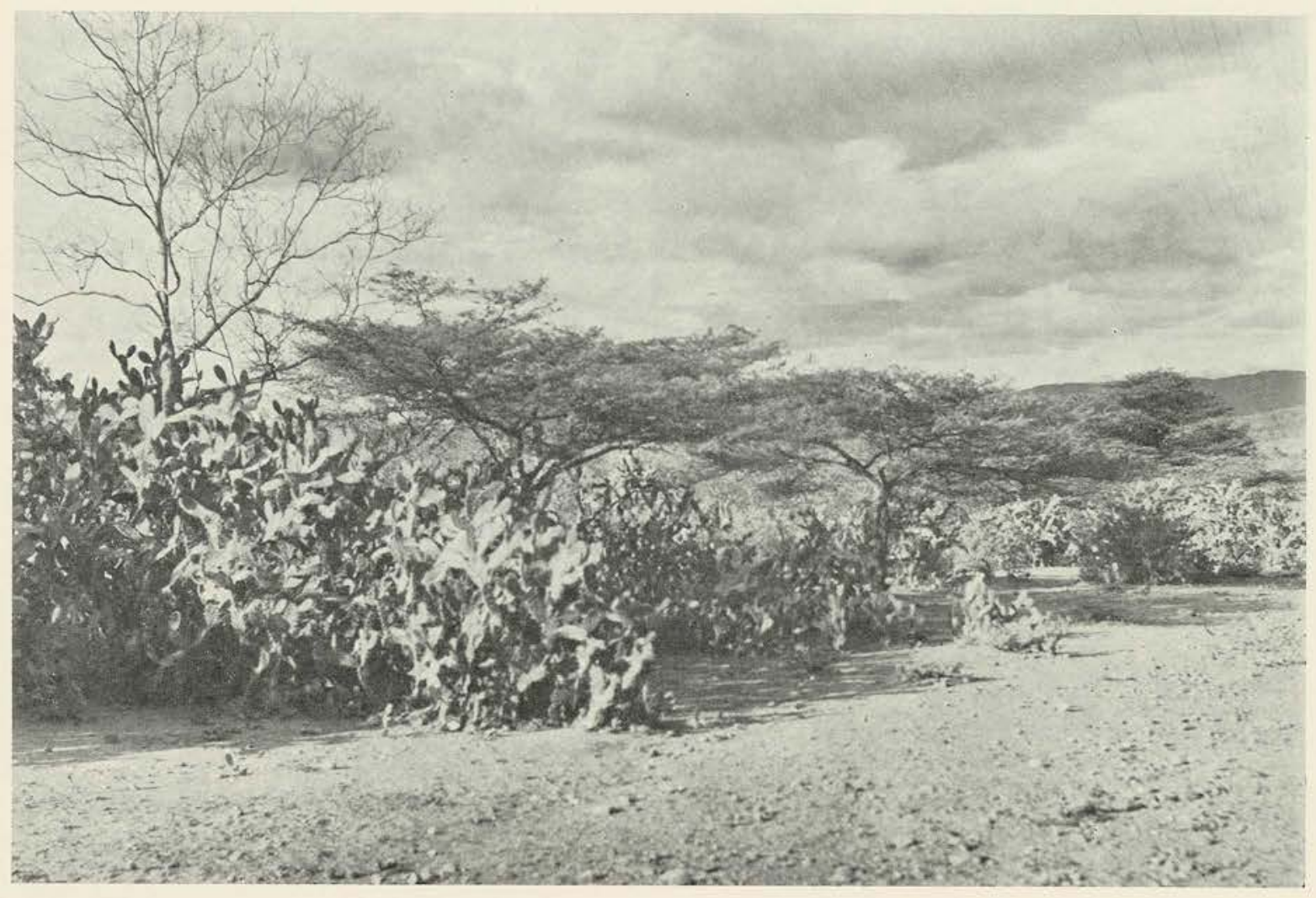

XXV-2 - Formación xerófita cerca de Cúcuta (N. de Santander); arbolitos aparasolados de "cuji" (Ncltuma juliflora) y Opuntia sp. (Foto Cuatrecasas C-1572). 


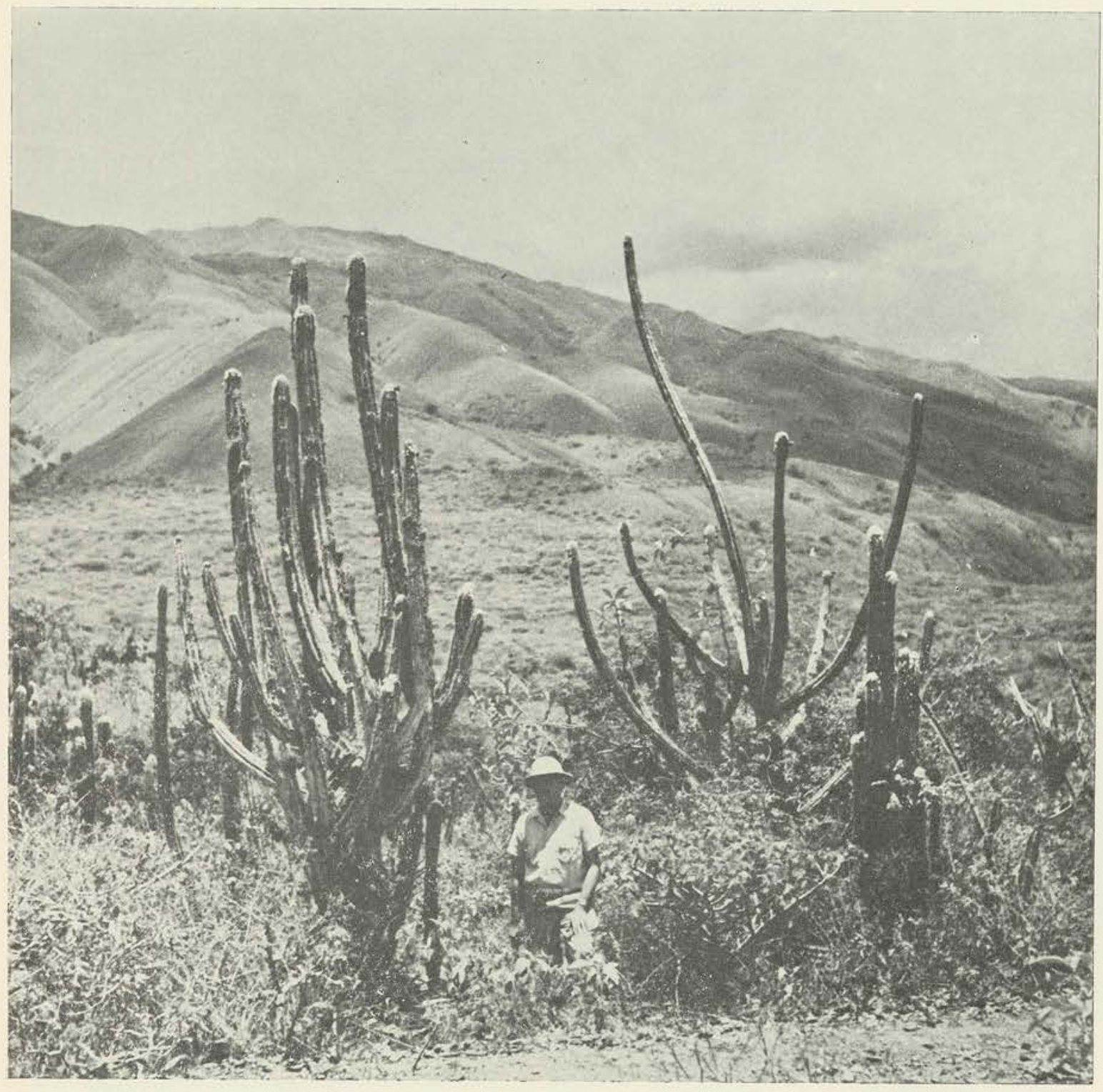

XXVI-Enclave xerófito de Dagua, $650 \mathrm{~m}$. alt. Cephalocerues colombianus B.\&R. (Foto Cuatrecasas 1-1140). 


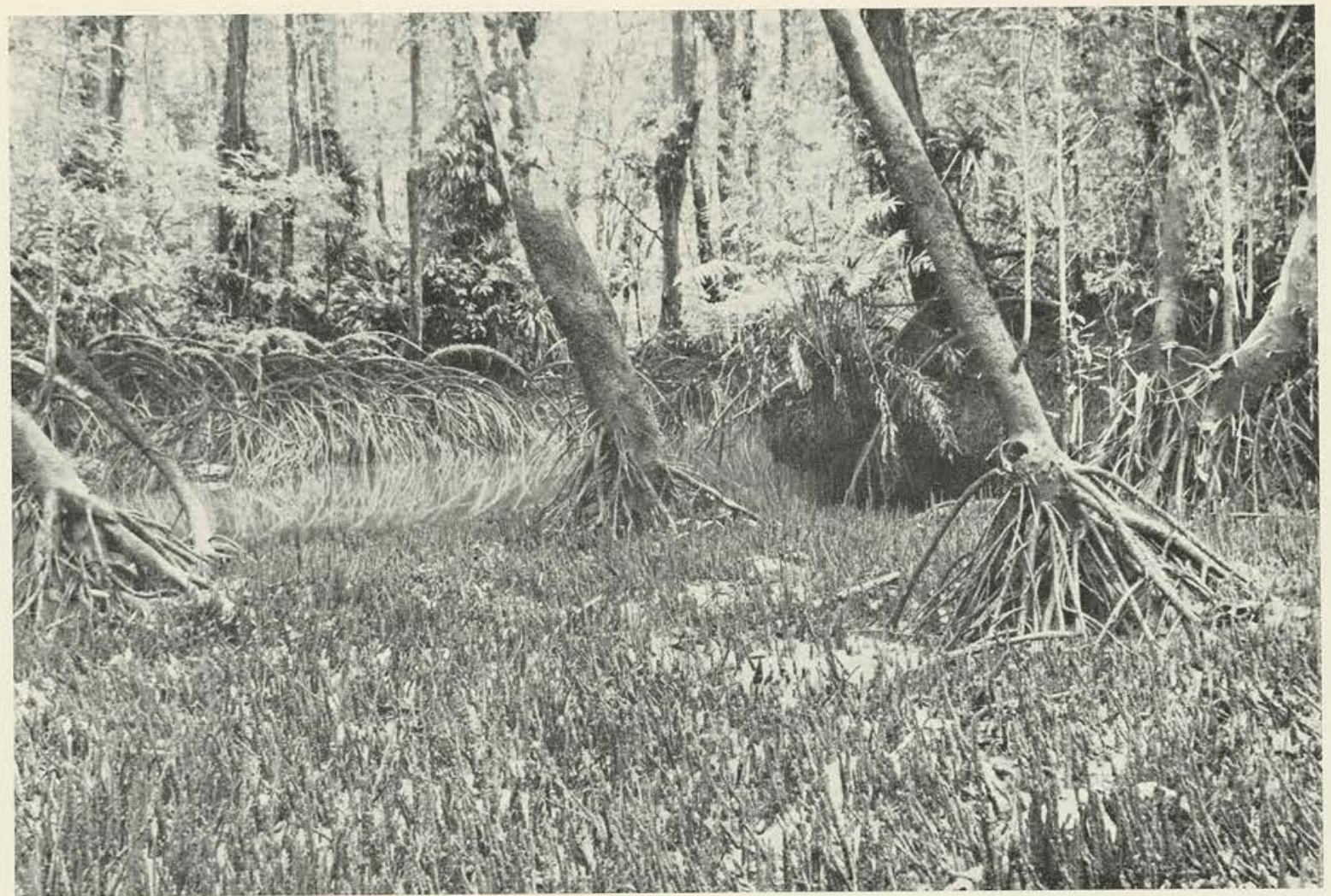

XXVII-1 - Manglar en la costa del Pacífico. Tres troncos de Avicenia nitida (iguanero) con sus cortos fúlcreos basilares y una gran producción de raíces terrífugas en bujía. Fondo con Rhizophora brevistyla y Acrostichum aureum. (Foto Cuatrecasas C-2189).

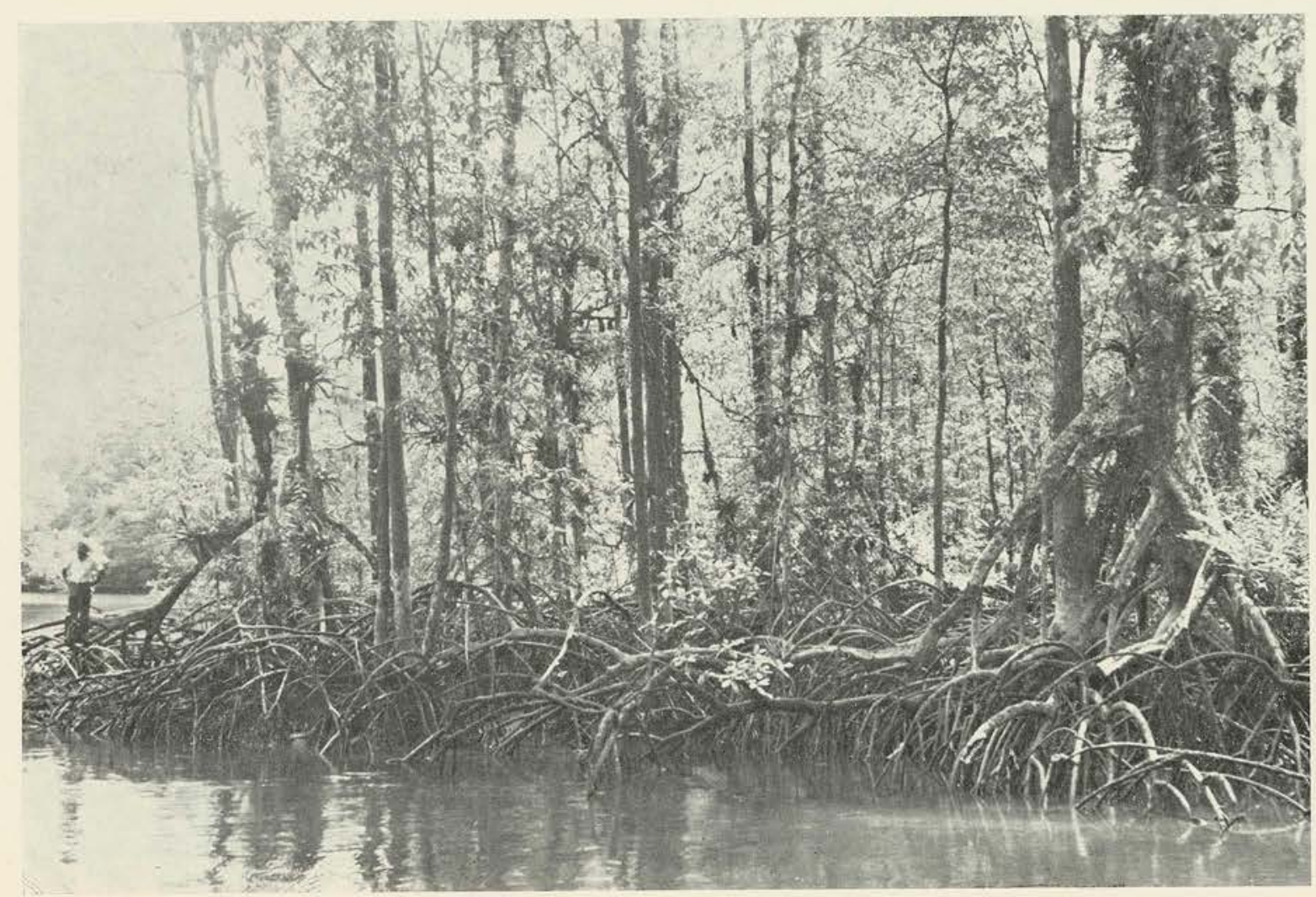




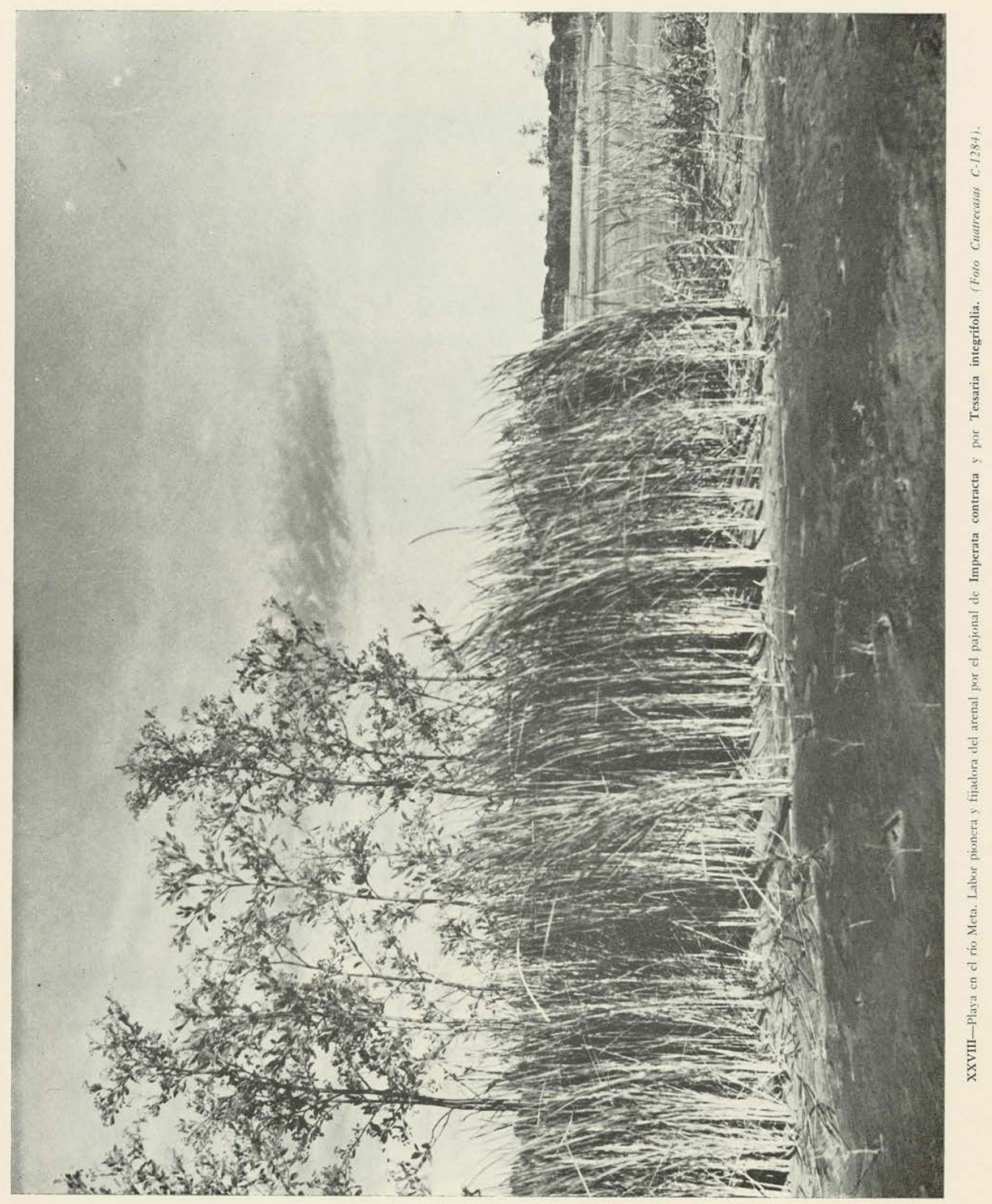




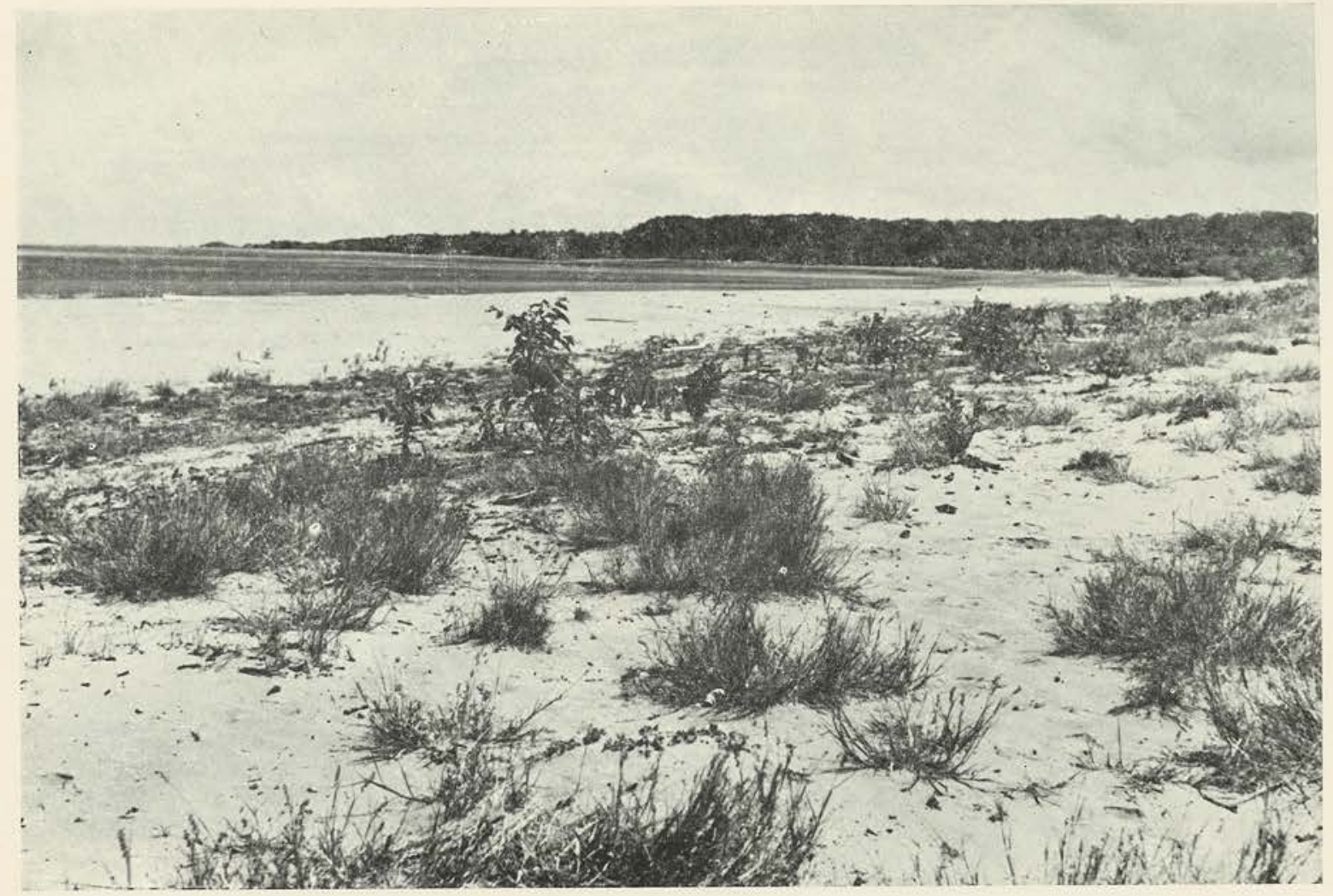

XXIX - 1 - Playa en la isla del Guayabal (costa del Pacífico). Gramíneas fijadoras de la playa: Cenchrus pauciflorus y Homolepis aturensis. Pequeños pimpollos de guanabanillo (Anona glabra). Además esparcidos, Carex sp., Borreria ocymoides, Desmodium triflorum y Phyla nodiflora. (Foto Cuatrecasas C-2207).

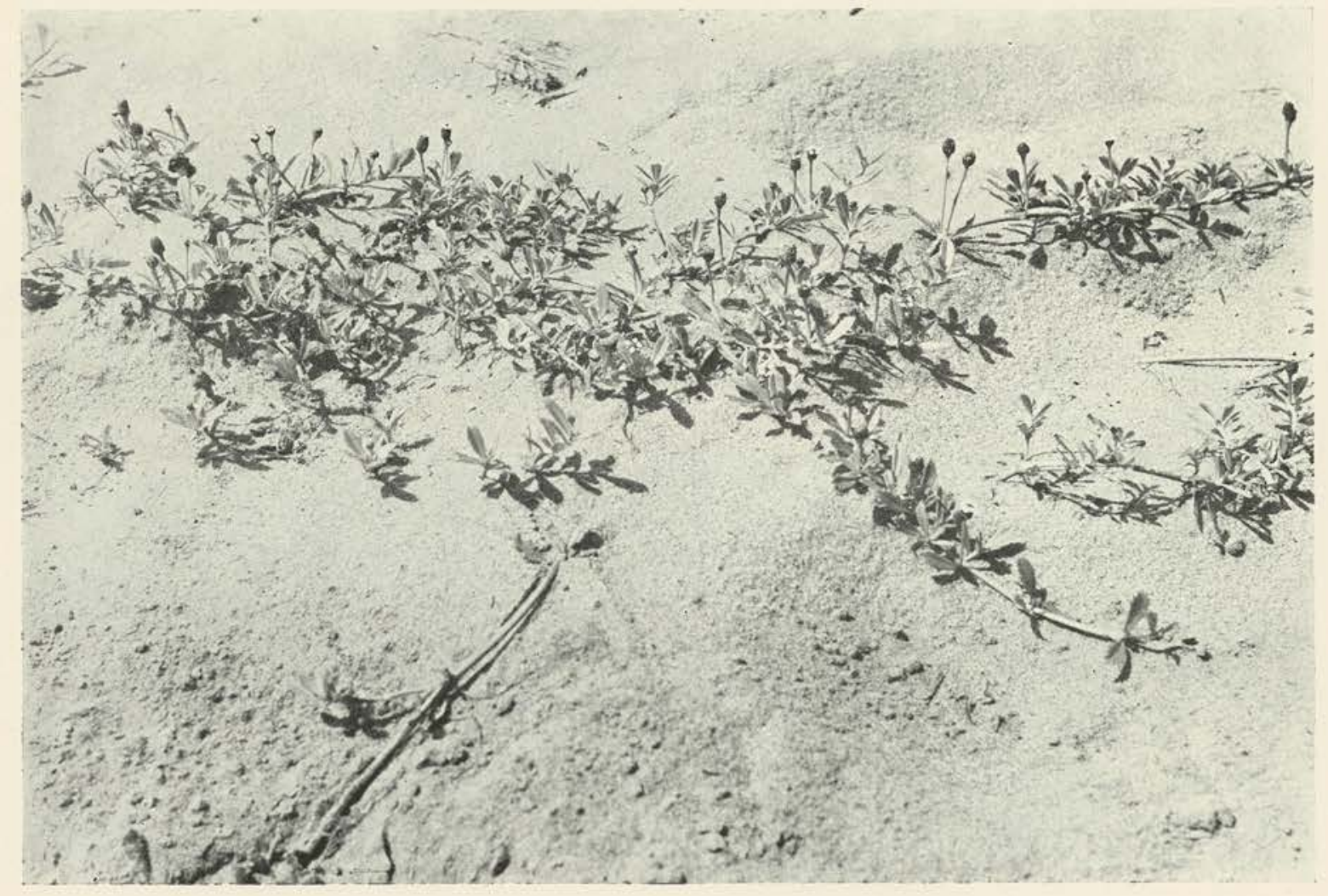

XXIX-2 - Playa en la isla del Guayabal (costa del Pacífico), Phyla nodiflora, fijadora de arenales. (Foto Cuatrecasas C-2206). 


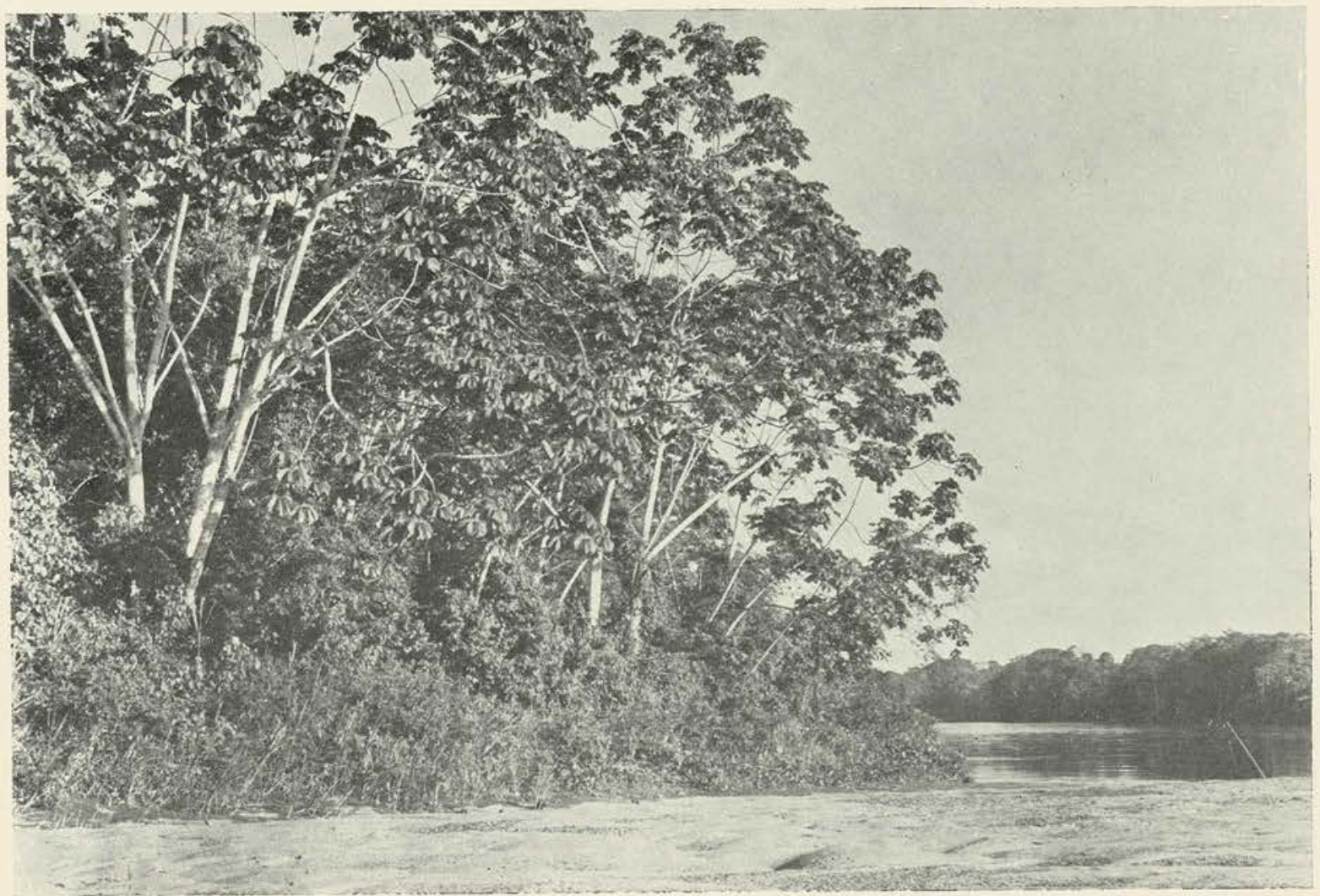

XXX-1-Orillas del río Sucumbíos (Putumayo). Formación de Cecropia pacis (guarumo) precedida por matorral de Zygia sp. y por Gynerium sagittatum. (Foto Cuatrecasas C-1763).

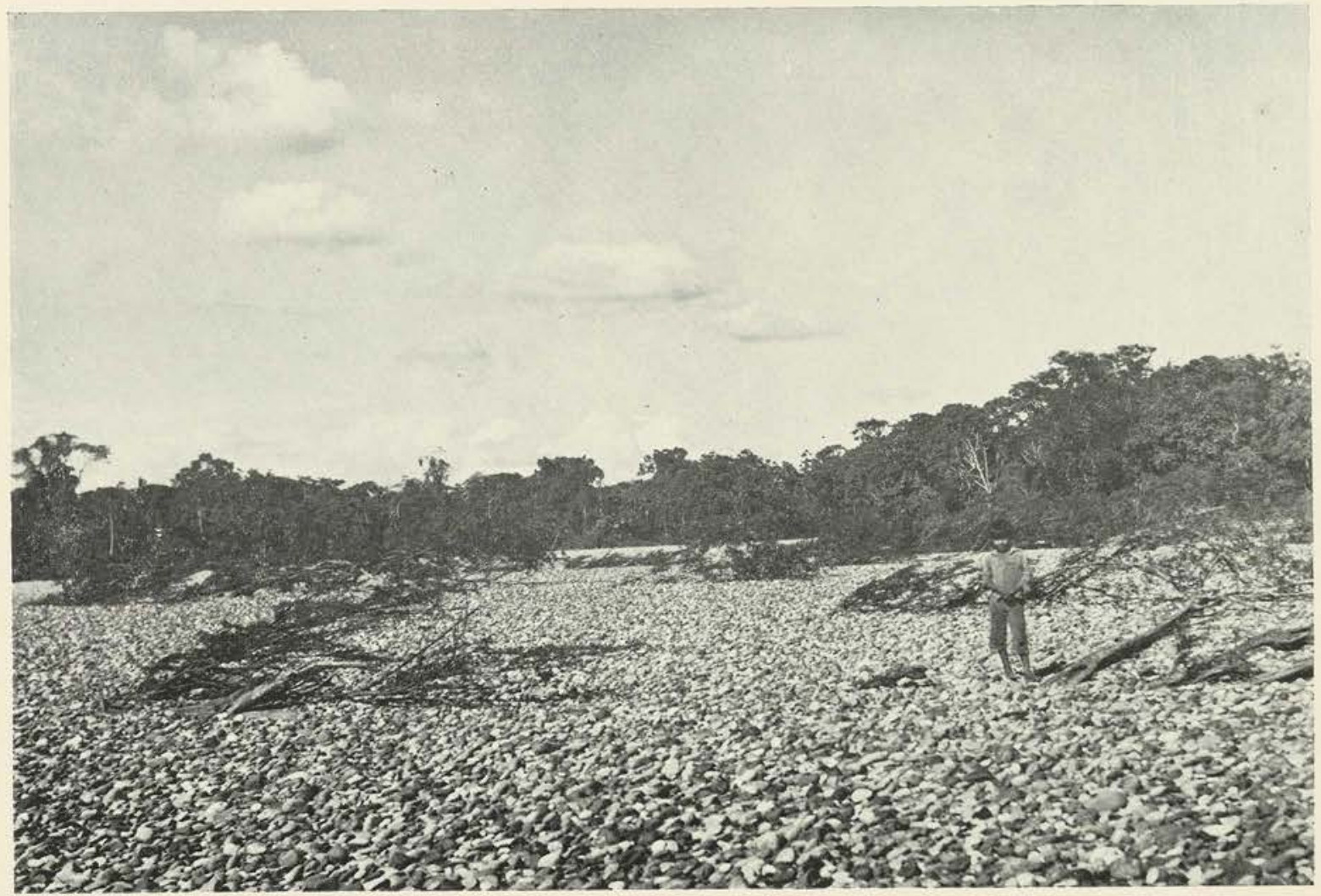

XXX-2 - Isla de arena y cantos rodados del río Sucumbíos, desnuda y con solo arbolitos aplanados, e inclinados por la corriente, de Calliandra angustifolia ("chíparo"). (Foto Cuatrecasas C-1766). 


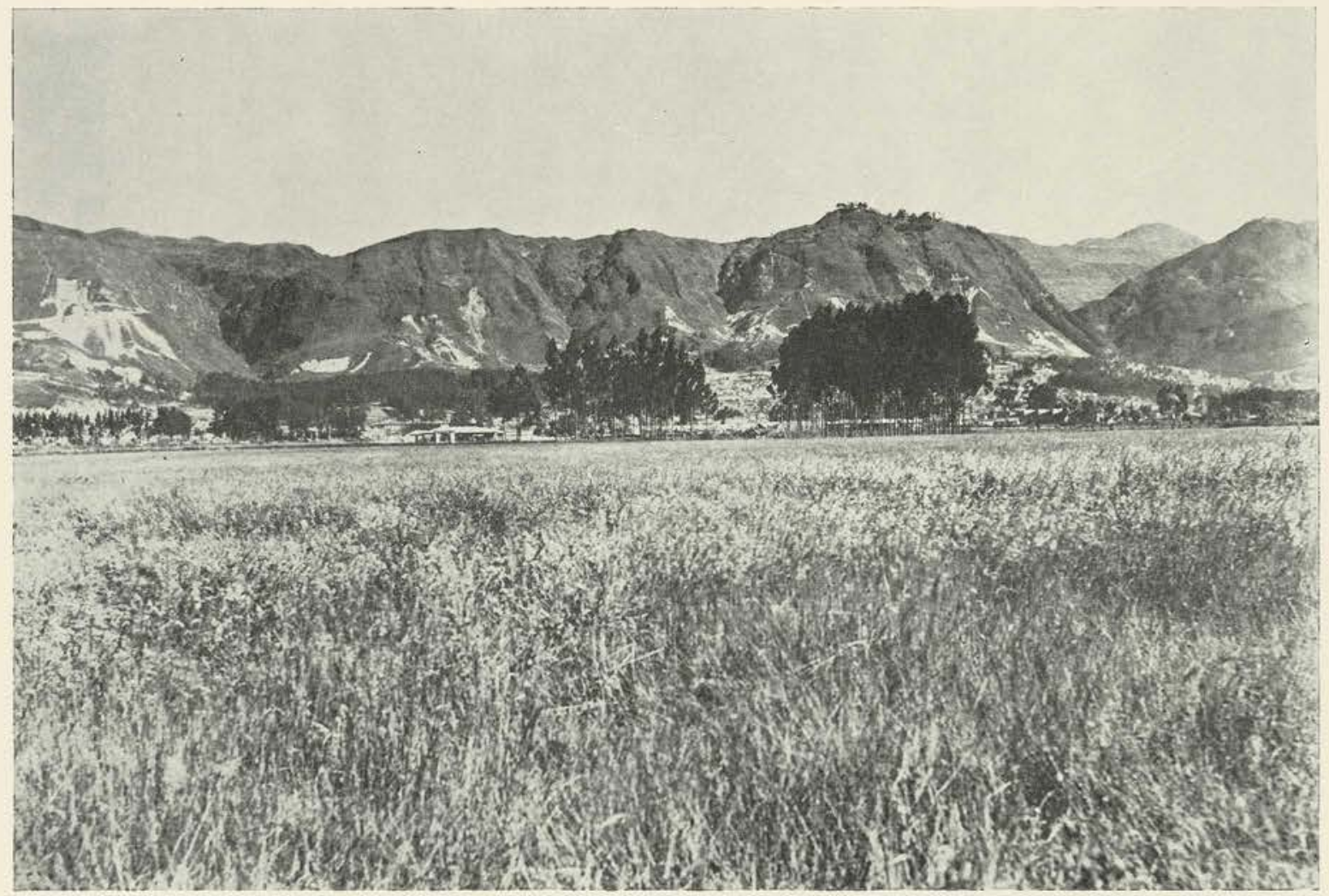

XXXI-1 - Sabana de Bogotá, prados en los terrenos actualmente ocupados por la Ciudad Universitaria, dominados por Holcus lanatus, Anthoxantum odoratum y Agrostispalustris. (Foto Cuatrecasas C-1373).

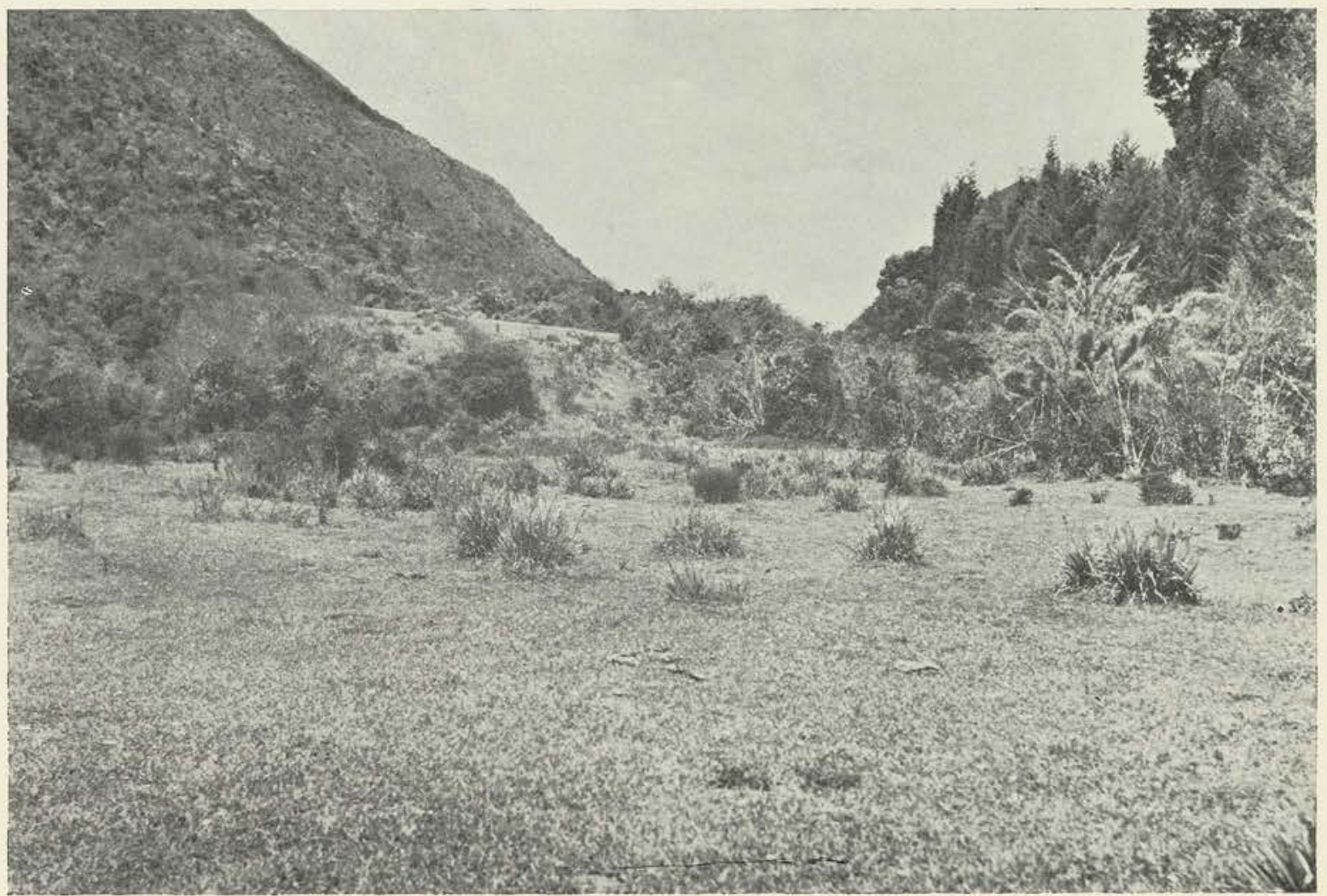

XXXI-2 - Quebrała de San Cristóbal, arriba de Bogotá, $2.950 \mathrm{~m}$. ait., Prado de Lachemilletum entre matorrales subparameros resultantes de la destrucción del bosque andino. Véase págs. 259-260. (Foto Cuatrecasas C-1599). 


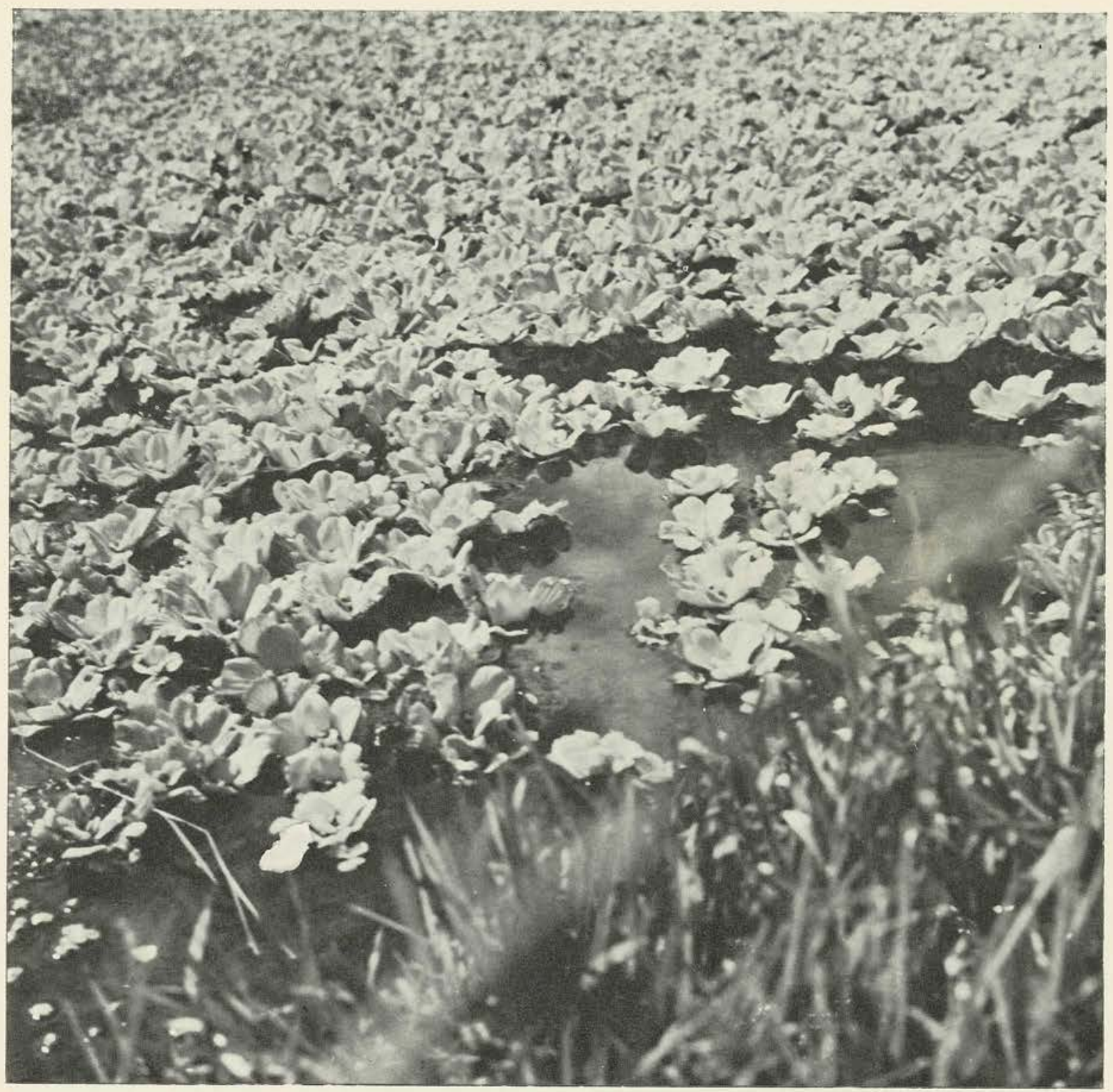

XXXII-Asociación hidrófila flotante de Pistia stratiotes, cerca de Guadalupe (Huila), $1.000 \mathrm{~m}$. alt. (Foto Cuatrecasas l-154). 


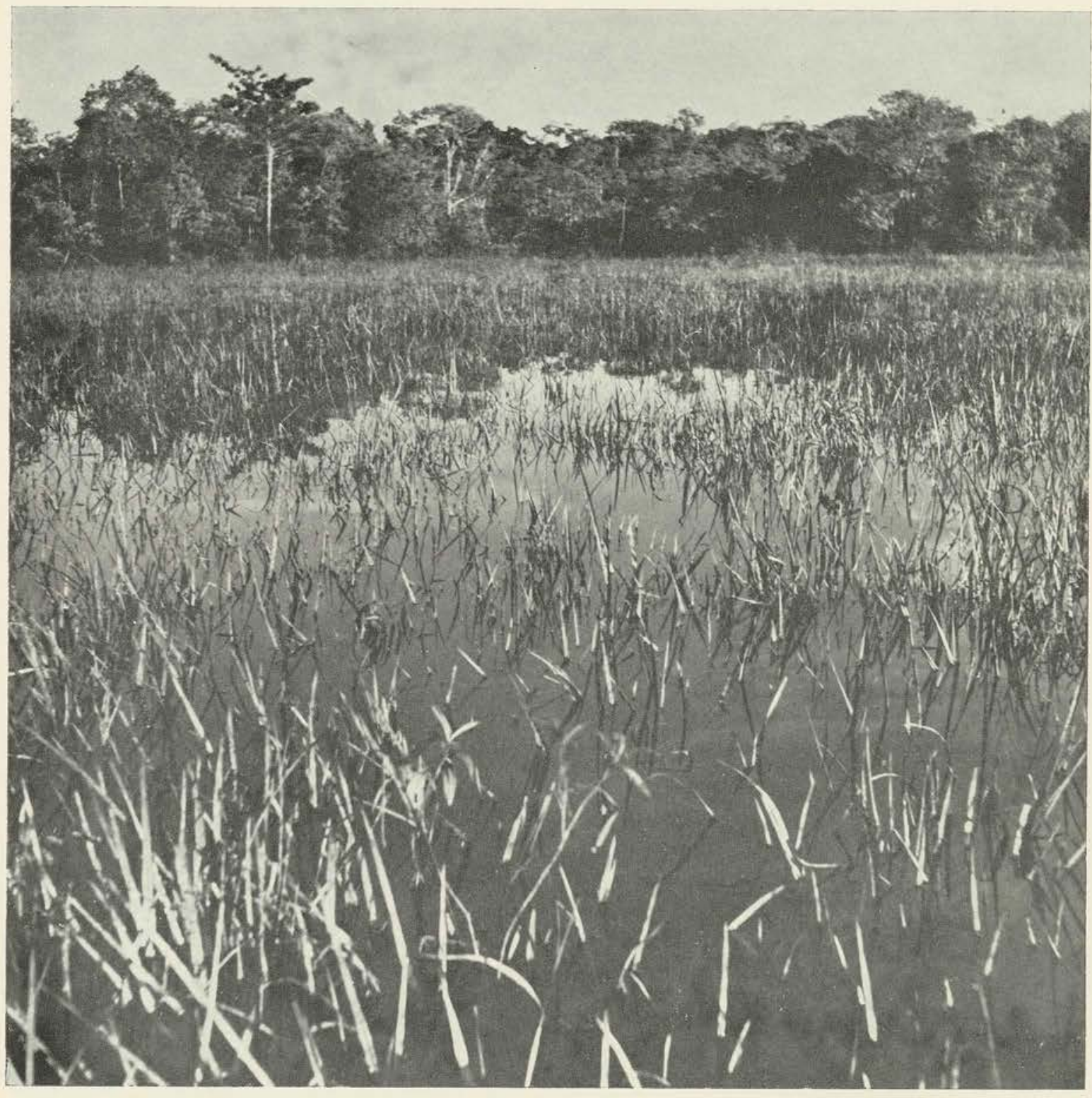

XXXIII-Vaupés: Latguna de Urania hacia Mitú, con pajonal inundado de la "cortadera" Lagenocarpus guianensis. (Foto Cuatrecasas I-66). 


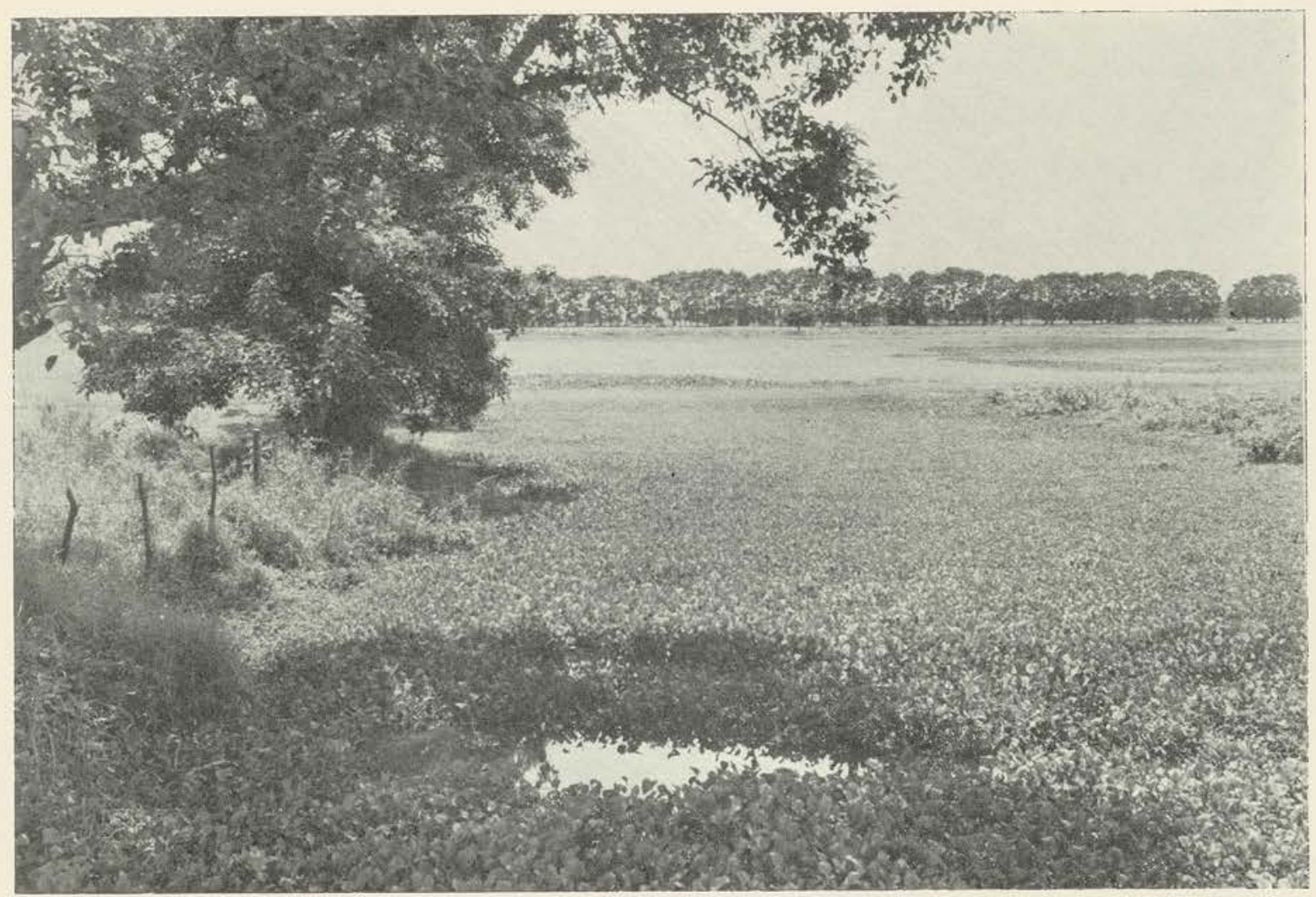

XXXIV-1 - Valle del Cauca. Pantanos con densa vegetación flotante de Eichornia crassipes. Márgenes con hileras de cachimbos, Erythrina poeppigiana. (Foto Cuatrecasas C-1437).

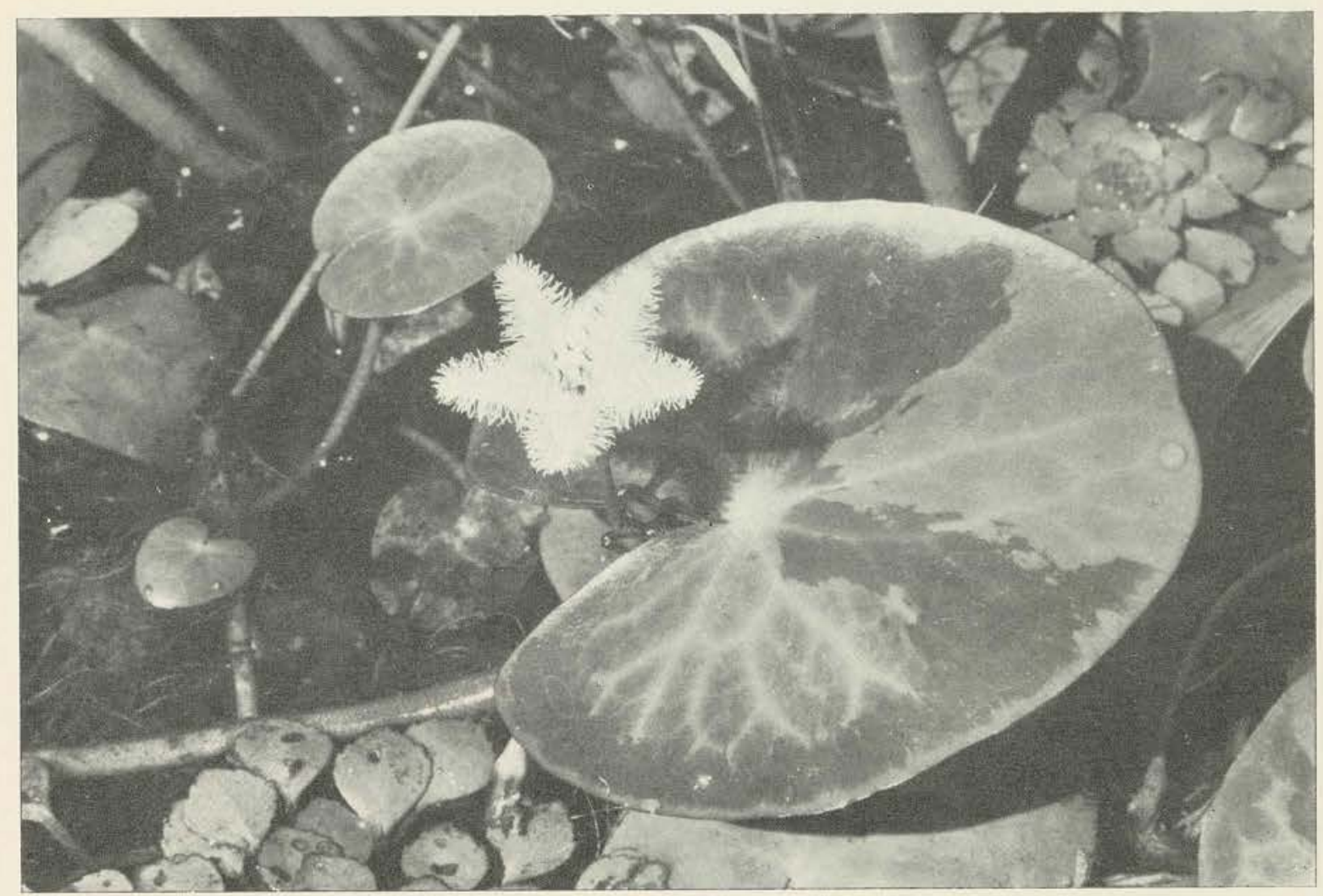

XXXIV-2 - Valle del Cauca. Nymphaea goudotiana, flor de Limnanthemum humboldtianum, Trapa natans, Cabomba aquatica, Eleocharis interstincta. (Foto Cuatrecasas C-2375). 


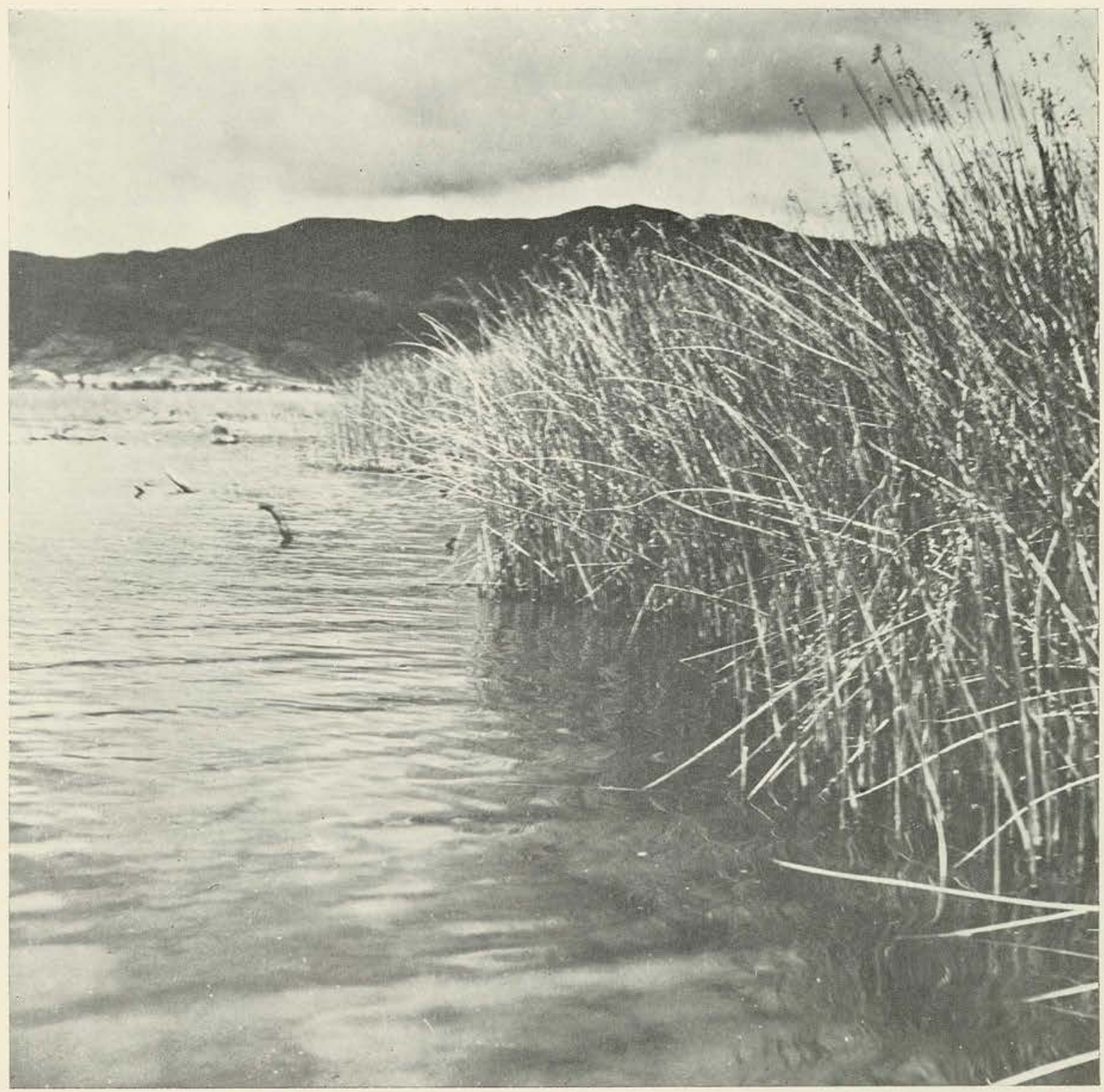

XXXV-Extremo norte de la laguna La Cocha (Nariño) vegetación anfibia de Juncus bogotensis (totoral), $\pm 2.710 \mathrm{~m}$. alt. (Foto Cuatrecasas $1-731)$. 